

\section{NOTICE}

This report was prepared as an account of work sponsored by an agency of the United States government. Neither the United States government nor any agency thereof, nor any of their employees, makes any warranty, express or implied, or assumes any legal liability or responsibility for the accuracy, completeness, or usefulness of any information, apparatus, product, or process disclosed, or represents that its use would not infringe privately owned rights. Reference herein to any specific commercial product, process, or service by trade name, trademark, manufacturer, or otherwise does not necessarily constitute or imply its endorsement, recommendation, or favoring by the United States government or any agency thereof. The views and opinions of authors expressed herein do not necessarily state or reflect those of the United States government or any agency thereof.

Available electronically at http://www.osti.gov/bridge

Available for a processing fee to U.S. Department of Energy and its contractors, in paper, from:

U.S. Department of Energy

Office of Scientific and Technical Information

P.O. Box 62

Oak Ridge, TN 37831-0062

phone: 865.576 .8401

fax: 865.576 .5728

email: mailto:reports@adonis.osti.gov

Available for sale to the public, in paper, from:

U.S. Department of Commerce

National Technical Information Service

5285 Port Royal Road

Springfield, VA 22161

phone: 800.553 .6847

fax: 703.605.6900

email: orders@ntis.fedworld.gov

online ordering: http://www.ntis.gov/ordering.htm

This publication received minimal editorial review at NREL 


\title{
2010 Wind Technologies Market Report
}

\author{
Primary authors \\ Ryan Wiser, Lawrence Berkeley National Laboratory \\ Mark Bolinger, Lawrence Berkeley National Laboratory \\ With contributions from \\ Galen Barbose, Naïm Darghouth, Ben Hoen, Andrew Mills, Joachim Seel (Berkeley Lab) \\ Kevin Porter, Michael Buckley, Sari Fink (Exeter Associates) \\ Frank Oteri (National Renewable Energy Laboratory) \\ Russell Raymond (Energetics Incorporated)
}

\section{Table of Contents}

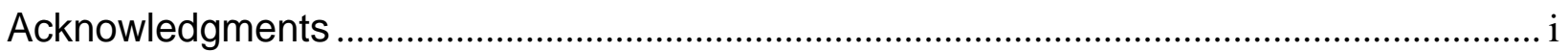

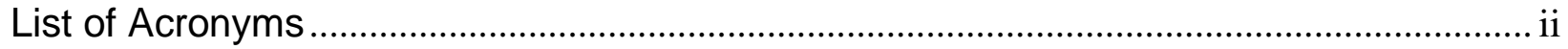

Executive Summary ..................................................................................................

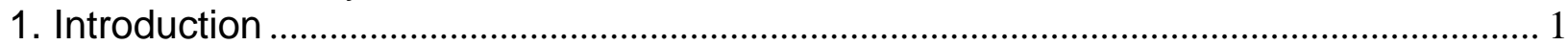

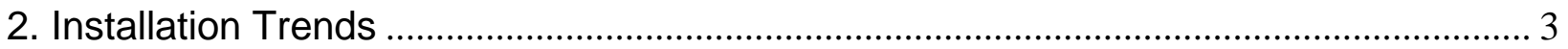

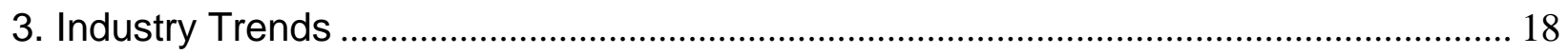

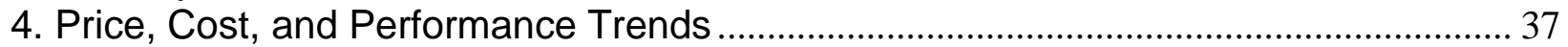

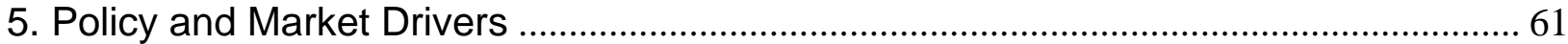

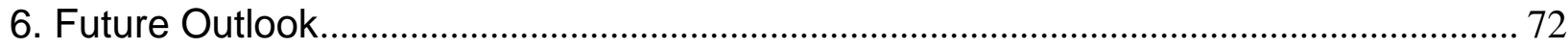

Appendix: Sources of Data Presented in this Report...................................................... 76

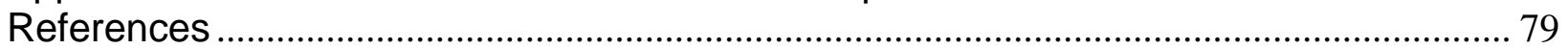

\section{Acknowledgments}

For their support of this ongoing report series, the authors thank Mark Higgins, Megan McCluer, Jim Ahlgrimm, Brian Connor, Patrick Gilman, Michele Desautels and Gary Norton of the U.S. Department of Energy's (DOE) Wind \& Water Power Program. For reviewing elements of this report or providing key input, we also acknowledge: Brendan Kirby (consultant); J. Charles Smith (Utility Wind Integration Group); Erik Ela, Eric Lantz, Walt Musial, Aaron Smith and Suzanne Tegen (National Renewable Energy Laboratory, NREL); Charlton Clark, Michele Desautels, Cash Fitzpatrick and Patrick Gilman (DOE); Michael Goggin and Jessica Isaacs (American Wind Energy Association); Aaron Zubaty (MAP); Emily Pennel (Southwest Power Pool); Doug Johnson (Bonneville Power Administration); Matt Schuerger (Wind on the Wires); Doug Larson and Thomas Carr (Western Governors' Association), Jim Walker (enXco), Chris Namovicz (Energy Information Administration), Ed DeMeo (Renewable Energy Consulting Services, Inc.), Alice Orrell (Pacific Northwest National Laboratory), John Eber (JPMorgan Capital Corporation), Mike O'Sullivan (NextEra Energy Resources), Steve Clemmer (Union of Concerned Scientists), and Andrew David (U.S. International Trade Commission). Thanks to the American Wind Energy Association (Elizabeth Salerno) for the use of their database of wind power projects. We also thank Tyler Tringas and Amy Grace (Bloomberg New Energy Finance) for the use of Bloomberg NEF's graphic on domestic wind turbine nacelle assembly capacity; Donna Heimiller and Billy Roberts (NREL) for assistance with the wind project and wind manufacturing maps. Berkeley Lab's contributions to this report were funded by the Wind \& Water Power Program, Office of Energy Efficiency and Renewable Energy of the U.S. Department of Energy under Contract No. DE-AC02$05 \mathrm{CH} 11231$. The authors are solely responsible for any omissions or errors contained herein. 


\section{List of Acronyms}

AWEA American Wind Energy Association

BOEMRE Bureau of Ocean Energy Management, Regulation, and Enforcement

BPA Bonneville Power Administration

CAISO California Independent System Operator

CCGT combined cycle gas turbine

COD commercial operation date

CREZ competitive renewable energy zone

DOE U.S. Department of Energy

EIA Energy Information Administration

ERCOT Electric Reliability Council of Texas

FERC Federal Energy Regulatory Commission

GE General Electric Corporation

GW gigawatt

IOU investor-owned utility

IPP independent power producer

ISO independent system operator

ISO-NE New England Independent System Operator

ITC investment tax credit

$\mathrm{kW} \quad$ kilowatt

kWh kilowatt-hour

MISO Midwest Independent System Operator

MW megawatt

MWh megawatt-hour

NERC North American Electric Reliability Corporation

NREL National Renewable Energy Laboratory

NYISO New York Independent System Operator

OEM original equipment manufacturer

O\&M operations and maintenance

PJM PJM Interconnection

POU publicly owned utility

PPA power purchase agreement

PTC Production Tax Credit

PUC public utility commission

REC renewable energy certificate

RFI request for information

RPS renewables portfolio standard

RTO regional transmission organization

SPP Southwest Power Pool 


\section{Executive Summary}

The U.S. wind power industry experienced a trying year in 2010, with a significant reduction in new builds compared to both 2008 and 2009. The delayed impact of the global financial crisis, relatively low natural gas and wholesale electricity prices, and slumping overall demand for energy countered the ongoing availability of existing federal and state incentives for wind energy deployment. The fact that these same drivers did not impact capacity additions in 2009 can be explained, in part, by the "inertia" in capital-intensive infrastructure investments: 2009 capacity additions were largely determined by decisions made prior to the economy-wide financial crisis that was at its peak in late 2008 and early 2009, whereas decisions on 2010 capacity additions were often made at the height of the financial crisis. Cumulative wind power capacity still grew by a healthy $15 \%$ in 2010 , however, and most expectations are for moderately higher wind power capacity additions in 2011 than witnessed in 2010, though those additions are also expected to remain below the 2009 high.

Key findings from this year's "Wind Technologies Market Report” include:

- Wind Power Additions Slowed in 2010, with Roughly 5 GW of New Capacity Added in the United States and \$11 Billion Invested. Wind power installations in 2010 were similar in magnitude to those recorded in 2007, but were just half those seen in 2009 and were $40 \%$ lower than in 2008. Nonetheless, cumulative wind power capacity still grew by $15 \%$ in 2010, bringing the total to more than 40,000 MW.

- Wind Power Comprised 25\% of U.S. Electric Generating Capacity Additions in 2010. This is down from $42 \%$ in $2009,43 \%$ in 2008 , and $34 \%$ in 2007 , but exceeds wind power's contributions in earlier years. In 2010, wind power was the third-largest new resource (behind natural gas and coal power plants) added to the U.S. electrical grid in terms of aggregate gross capacity, breaking a five-year streak in which wind power was second only to natural gas plants.

- The United States Was Overtaken by China in Cumulative Wind Power Capacity, Remained the Second Largest Market in Annual Additions, and Was Well Behind the Market Leaders in Wind Energy Penetration. After leading the world in annual wind power capacity additions from 2005 through 2008, the U.S. has now - for two years - been second to China, capturing roughly $13 \%$ of the global market in 2010, down substantially from $26 \%$ in $2009,29 \%$ in 2008 , and $27 \%$ in 2007 . In terms of cumulative capacity, the United States ended the year with $20 \%$ of total global wind power capacity, dropping to the second largest market by this metric, also after China. A number of countries are beginning to achieve relatively high levels of wind energy penetration in their electricity grids: end-of2010 wind power capacity is estimated to be capable of supplying the equivalent of roughly $26 \%$ of Denmark's electricity demand, $17 \%$ of Portugal's, $15 \%$ of Spain's, $14 \%$ of Ireland's, and $9 \%$ of Germany's. In the United States, the cumulative wind power capacity installed at the end of 2010 is estimated, in an average year, to equate to roughly $2.9 \%$ of the nation's electricity consumption.

- Texas Once Again Added More New Wind Power Capacity than Any Other State, While Four States Exceed 10\% Wind Energy Penetration. With 680 MW added, Texas once-again led the 28 other states in which new large-scale wind turbines were installed in 2010, though by a much narrower margin than in years past (the next highest were Illinois 
with $498 \mathrm{MW}$ and California with $455 \mathrm{MW}$ ). Texas also became the first state to surpass the $10 \mathrm{GW}$ milestone in terms of cumulative wind power. South Dakota had enough wind power capacity installed by the end of 2010 to generate an estimated $23 \%$ of all in-state generation in an average year. Three other states are also estimated to exceed $10 \%$ penetration by this metric: Iowa (17\%), North Dakota (14\%), and Minnesota (12\%).

- Offshore Wind Power Project and Policy Developments Continued in 2010. To date no offshore projects have been installed in the United States and the emergence of an offshore wind power market still faces many challenges. Nonetheless, interest exists in developing offshore wind energy in several parts of the country, with nine projects totaling 2,322 MW that have advanced significantly in the permitting and development process. Of these projects, three have signed power purchase agreements with terms and details that have been made public. Notably, the Cape Wind project was granted approval by the Department of Interior in 2010; several significant strides relating to offshore wind energy have been made recently in the federal arena; and a variety of other recent project and state policy announcements demonstrate continued activity in the offshore wind energy sector.

- Data from Interconnection Queues Demonstrate that an Enormous Amount of Wind Power Capacity Is Under Consideration. At the end of 2010, there were $258 \mathrm{GW}$ of wind power capacity - more than six times current installed wind power capacity - within the transmission interconnection queues administered by independent system operators, regional transmission organizations, and utilities reviewed for this report. This wind power capacity represented more than $50 \%$ of all generating capacity within these queues at that time, and was more than twice as much capacity as the next-largest resource (natural gas). Most (91\%) of this wind power capacity is planned for the Midwest, Mountain, Texas, PJM Interconnection, Northwest, and Southwest Power Pool regions. Projects currently in interconnection queues are often very early in the development process, so much of this capacity is unlikely to be built as planned. Nonetheless, these data demonstrate the high level of developer interest in wind power.

- GE Remained the Top Turbine Manufacturer in the U.S. Market. GE secured 50\% of U.S. market share (by capacity installed) in 2010, followed by Siemens (16\%), Gamesa (11\%), Mitsubishi (7\%), Suzlon (6\%), Vestas (4\%), Acciona (2\%), Clipper (1\%), REpower $(1 \%)$, and Nordex and DeWind (both at $0.4 \%$ ). There has been a notable increase in the number of wind turbine manufacturers serving the U.S. market since 2005, with the number of manufacturers installing more than $1 \mathrm{MW}$ increasing from just 6 in 2005 to 16 manufacturers in 2010. Recently, however, there is evidence of gains in market share by some of the leading manufacturers. Globally, perhaps the most significant continuing story in 2010 was the growing market share of Chinese turbine manufactures: four of the top ten leading global suppliers of wind turbines now hail from China. To date, that growth has been based almost entirely on sales to the Chinese market, though both Chinese (and South Korean) manufacturers continue to take steps to enter the international wind turbine market, including limited early installations in the United States.

- Domestic Wind Turbine and Component Manufacturing Activity Has Increased, but Has Also Been Challenged by the Economic Downturn. Nine of the eleven wind turbine manufacturers with the largest share of the U.S. market in 2010 already have one or more manufacturing facilities in the United States. These figures compare to just one utility-scale wind turbine manufacturer (GE) assembling nacelles in the United States in 2004. In addition, a considerable number of new wind turbine and component manufacturing facilities 
were either announced or opened in 2010, by both foreign and domestic firms. Though domestic manufacturing capabilities have grown, the wind turbine and component manufacturing industry continues to face economic headwinds. The growth in U.S. wind turbine manufacturing capability and the drop in wind power plant installations, for example, led to an estimated over-capacity of U.S. nacelle assembly capability of roughly $2.5 \mathrm{GW}$ in 2010, in comparison to $4 \mathrm{GW}$ of under-capacity in 2009. The year 2010 also saw downward revisions to revenue and profit forecasts throughout the wind turbine and component manufacturing supply chain. The American Wind Energy Association, meanwhile, estimates that the entire wind energy sector directly and indirectly employed 75,000 full-time workers in the United States at the end of 2010 - about 10,000 fewer full-time-equivalent jobs than in 2009, mostly due to the decrease in new wind power plant construction.

- A Growing Percentage of the Equipment Used in U.S. Wind Power Projects Has Been Sourced Domestically in Recent Years. U.S. trade data show that the United States remained a large importer of wind power equipment in 2010, but that wind power capacity growth has outpaced the growth in imports in recent years. As a result, a growing percentage of the equipment used in wind power projects is being sourced domestically. Imports of wind turbines and select components in 2010 are estimated at $\$ 2.5$ billion, down from $\$ 4.2$ billion in 2009 and $\$ 5.5$ billion in 2008 , but up from $\$ 1.3$ billion in 2005 . When presented as a fraction of total equipment-related wind turbine costs, the overall import fraction is estimated to have declined significantly from $65 \%$ in $2005-2006$ to roughly $40 \%$ in 20092010 as domestic manufacturing investments outpaced import growth. Exports of windpowered generating sets from the United States have also increased, rising from \$15 million in 2007 to $\$ 119$ million in 2009, and again increasing to \$142 million in 2010.

- The Average Nameplate Capacity, Hub Height, and Rotor Diameter of Installed Wind Turbines Increased. The average nameplate capacity of wind turbines installed in the United States in 2010 increased to 1.79 MW, up from 1.74 MW in 2009 and 1.66 MW in 2008. Since 1998-99, average turbine nameplate capacity has increased by $151 \%$, but growth in this metric has slowed in recent years due to the dominance of GE's 1.5 MW turbine and as a result of the logistical challenges associated with transporting larger turbines to project sites. Average hub heights and rotor diameters have also scaled with time, to 79.8 and 84.3 meters, respectively, in 2010. Since 1998-99, the average turbine hub height has increased by $43 \%$, while the average rotor diameter has increased by $76 \%$. Industry expectations as well new turbine announcements (especially to serve lower-wind-speed sites) suggest that significant further scaling, especially in rotor diameter, is anticipated in the near term.

- Consolidation among Wind Project Developers Continued, Albeit at a Slower Pace. Consolidation on the development end of the wind power business has slowed since 2007. At least three significant acquisition or investment transactions involving more than $10 \mathrm{GW}$ of in-development wind power projects were announced in 2010, compared to six transactions and $18 \mathrm{GW}$ in 2009.

- The Project Finance Environment Improved Throughout 2010. After a rather dismal project-finance environment in 2009 (which contributed to the slowdown in 2010 wind power capacity additions), the environment for wind power project finance improved steadily throughout 2010. By the end of the year, there were reportedly 16 third-party tax equity providers back in the market - up from just a handful in 2009 - and the amount of tax equity committed to wind power projects was somewhere on the order of $\$ 4$ billion, more than twice as much as was invested in 2009 and exceeding levels invested in 2007 and 2008. 
Activity in the debt market was also brisk, with as many as 30 banks and a number of institutional lenders back in the market, offering longer tenors in combination with lower spreads and up-front fees. Meanwhile, the Section 1705 U.S. Department of Energy (DOE) loan guarantee program closed on two wind project loan guarantees in 2010 and issued conditional commitments for two more in early 2011. Looking ahead to 2011, the one-year extension of the Section 1603 grant program should help the tax equity market to continue to recover.

- IPP Project Ownership Remained Dominant, while Utility and Community Ownership Held Steady. Independent power producers (IPPs) own $83 \%$ of all new wind power capacity installed in the United States in 2010, and also $83 \%$ of cumulative capacity. Meanwhile, $15 \%$ of all new 2010 and cumulative wind power capacity is owned by electric utilities, with investor-owned utilities claiming $12 \%$ and publicly owned utilities the other $3 \%$. Community wind power projects account for the remaining 2\% of both new 2010 and cumulative capacity.

- Long-Term Contracted Sales to Utilities Remained the Most Common Off-Take Arrangement, but Scarcity of Power Purchase Agreements Drove Continued Merchant Development. Electric utilities continued to be the dominant off-takers of wind power in 2010, either owning (15\%) or buying (58\%) power from $72 \%$ of the new capacity installed last year. Merchant/quasi-merchant projects were less-prevalent in 2010 than they have been in recent years, accounting for $23 \%$ of all new capacity. With wholesale power prices remaining low in 2010 and power purchase agreements (PPAs) in relatively short supply, it is likely that most of the merchant/quasi-merchant projects built in 2010 are merchant by necessity rather than by choice - i.e., many of these projects may have had to deploy turbines ordered prior to the financial crisis or may have been built in part to take advantage of the Treasury Grant Program (which, only later, was extended for an additional year), and are presumably actively seeking long-term PPAs to provide greater revenue stability. On a cumulative basis, utilities own $(15 \%)$ or buy $(49 \%)$ power from $64 \%$ of all wind power capacity in the United States, with merchant/quasi-merchant projects accounting for another $25 \%$ and power marketers another $10 \%$.

- Wind Power Prices from Projects Installed in 2010 Were Higher, but Relief Is on the Way. Although some of the upward cost pressures facing the industry in recent years have eased considerably since 2008, such relief has thus far been slow to work its way through the project development pipeline to impact average historical wind power prices. As such, 2010 was another year of higher wind power prices. The capacity-weighted average 2010 sales price for bundled power and renewable energy certificates, based on projects in the sample built in 2010, was roughly $\$ 73 / \mathrm{MWh}$. This value is up from an average of $\$ 62 / \mathrm{MWh}$ for the sample of projects built in 2009, and is more than twice the average of \$32/MWh (all in 2010 dollars) among projects built during the low point in 2002 and 2003. Texas, the Heartland, and the Mountain regions appear to be among the lowest price areas, on average, while California is, by far, the highest price region. One reason for the continued increase in historical prices is that many projects built in 2010 may have entered into turbine supply agreements in 2008 (i.e., at the height of the market), and likely established the price terms of PPAs at a similar point in time. Other drivers include the relative prevalence of projects built in California (if all California projects are removed from the 2010 sample, the capacityweighted average price drops from $\$ 73 / \mathrm{MWh}$ to $\$ 64 / \mathrm{MWh}$ ) as well as a general trend towards building out lower wind speed sites. Indications from projects that came online in 
late 2010 and early 2011 suggest a price thaw, however, as a number of PPAs that start in the low-to-mid \$40/MWh range (or even lower) have been witnessed. Though lower average prices for projects installed in 2011 are therefore anticipated, the recent decline in turbine prices may not be fully reflected in average wind power pricing until 2012 and later.

- Low Wholesale Electricity Prices Continued to Challenge the Relative Economics of Wind Power Plants Installed in Recent Years. A simple comparison of historical wind power prices to wholesale electricity prices throughout the United States demonstrates that while wind power had consistently been priced (on average) at the low end of the range of wholesale electricity prices going back through 2003, the drop in wholesale electricity prices in 2009 pushed wind energy to the top of that range, where it remained in 2010 across all regions of the country. Although low wholesale electricity prices are, in part, attributable to the recession-induced drop in energy demand, the discovery and early development of significant shale gas deposits has also resulted in reduced expectations for price increases going forward. Comparing wind and wholesale electricity prices in this manner is not appropriate if one's goal is to fully account for the costs and benefits of wind energy relative to its competition, but these developments may nonetheless put the near-term comparative economic position of wind energy at some risk absent reductions in the price of wind power that counteract the decline in wholesale electricity prices (and absent policy drivers that support wind energy expansion without regard to its comparative economics).

- The Average Installed Cost of Wind Power Projects Held Steady in 2010, but Is Expected to Decline in the Near Term. Among a large sample of wind power projects installed in 2010 , the capacity-weighted average installed cost of $\$ 2,155 / \mathrm{kW}$ was similar to that seen in 2009. The estimated average cost among a preliminary sample of projects that either have been or will be built in 2011 suggests that average installed costs will decline in the near term, consistent with recent trends in wind turbine prices. Installed project costs are found to exhibit some economies of scale, at least at the low end of the project size range. Texas is found to be the lowest-cost region, while California and New England were the highest-cost regions.

- Wind Turbine Prices Have Declined Since 2008 and Will Yield Lower Project-Level Installed Costs and Power Sales Prices in the Years Ahead. Wind turbine prices have dropped substantially since their peak in late 2008, despite continued technological advancements that have yielded increases in hub heights and especially rotor diameters. After hitting a low of roughly $\$ 700 / \mathrm{kW}$ from 2000 to 2002, average wind turbine prices increased by approximately $\$ 800 / \mathrm{kW}(>100 \%)$ through 2008 , rising to an average of roughly $\$ 1,500 / \mathrm{kW}$. Wind turbine prices have since declined substantially, with price quotes for recent transactions in the range of $\$ 900-\$ 1,400 / \mathrm{kW}$, suggesting price declines of as much as $33 \%$ or more since late 2008 , with an average decline closer to $20 \%$ for orders announced in 2010. These price reductions, coupled with improved turbine technology and more-favorable terms for turbine purchasers, are expected, over time, to exert downward pressure on total project costs and wind power prices.

- Wind Power Project Performance Has Generally Improved Over Time, but Has Leveled Off in Recent Years. Boosted primarily by higher hub heights and larger rotor diameters, cumulative sample-wide average capacity factors have, in general, gradually increased over time, from $25 \%$ in 1999 to a high of nearly $34 \%$ in 2008, before dropping to roughly $30 \%$ in 2009 and 2010. The drop in 2009 and 2010 is, in part, attributable to wind power curtailment, which has been particularly significant in Texas: nearly $8 \%$ of all 
potential wind energy generation within the Electric Reliability Council of Texas (ERCOT) was curtailed in 2010, down from 17\% curtailment in 2009. If not for the curtailment experienced in ERCOT, the Midwest, and a few other regions, the sample-wide average U.S. capacity factor would have been 1-2 percentage points higher nationwide in 2008 through 2010 (e.g., increasing from $30.5 \%$ to $31.6 \%$ in 2010). Other factors that may have slowed the rate of capacity factor increase for projects installed in more recent years include an emphasis on lower-quality wind resource sites (due to transmission and siting constraints, and perhaps also policy influence), moderation of the historical increase in average hub heights and rotor diameters at least from 2006 through 2009, and some challenges with turbine reliability.

- Operations and Maintenance (O\&M) Costs Are Affected by the Age and Commercial Operation Date of the Project. Despite limited data availability, it appears that projects installed more recently have, on average, incurred lower O\&M costs than older projects in their first several years of operation, and that O\&M costs increase as projects age.

- Extension of the Treasury Grant Program and Bonus Depreciation Provides Some Measure of Federal Policy Certainty Through 2012. In mid-December 2010, legislation extended the deadline to qualify for the Section $160330 \%$ cash grant by one year (projects must now start construction by the end of 2011 and be online by the end of 2012) and also doubled first-year bonus depreciation to $100 \%$ for those projects placed in service between September 8, 2010 and the end of 2011. Two other Recovery Act programs that had generated excitement among the industry in 2009 and 2010, however, were either not extended (the Section 48C advanced energy manufacturing tax credit program) or will sunset in 2011 (the Section 1705 loan guarantee program for commercially viable projects). Even so, with the production tax credit, $30 \%$ investment tax credit, $30 \%$ cash grant, and various levels of bonus depreciation all firmly in place through 2012, the wind industry currently enjoys two years of relative (and relatively favorable) federal policy certainty in 2011 and 2012. Beyond 2012, however, federal policy towards wind energy remains uncertain.

- State Policies Play a Role in Directing the Location and Amount of Wind Power Development. From 1999 through 2010, 63\% of the wind power capacity built in the United States was located in states with renewables portfolio standard (RPS) policies; in 2010, this proportion was 58\%. As of June 2011, mandatory RPS programs existed in 29 states and Washington D.C., and a number of states strengthened their RPS programs in 2010. Existing RPS programs are projected to drive annual average renewable energy additions of 4-6 GW/year between 2011 and 2020, roughly equivalent to the amount of renewable capacity added in 2010 but well below the pace of capacity additions in 2008 and 2009 (growth in 2008 and 2009 was based in part on the market's willingness to construct merchant wind power projects). Utility resource planning requirements, voluntary customer demand for "green" power, state clean energy funds, and state and regional carbon reduction policies also play a role in supporting wind energy deployment.

- Despite Progress on Overcoming Transmission Barriers, Constraints Remain.

Transmission development has continued to gain some traction, with 8,800 circuit miles of new transmission added in 2010, another 3,100 miles under construction, and an additional 39,000 circuit miles projected by 2020 . Nonetheless, siting, planning, and cost allocation issues remain key barriers to transmission investment. In June 2010, the Federal Energy Regulatory Commission (FERC) issued a proposed transmission cost allocation rule aimed at easing planning and cost allocation barriers. States, grid operators, utilities, regional 
organizations, and the DOE also continue to take proactive steps to encourage transmission investment to improve access to renewable resources. Finally, construction and development progress was made in 2010 on a number of transmission projects that are designed, in part, to support wind power.

- Integrating Wind Energy into Power Systems Is Manageable, but Not Free of Costs, and System Operators Are Implementing Methods to Accommodate Increased Penetration. Recent studies show that wind energy integration costs are below $\$ 10 / \mathrm{MWh}-$ and often below $\$ 5 / \mathrm{MWh}$ - for wind power capacity penetrations up to about $40 \%$ of the peak load of the system in which the wind power is delivered. The increase in balancing reserves with increased wind power penetration is projected to be a maximum of $18 \%$ of the nameplate capacity of wind power, and typically considerably less than this figure, particularly in studies that use intra-hour scheduling. Moreover, a number of strategies that can help to ease the integration of increasing amounts of wind energy - including the use of larger balancing areas, the use of wind forecasts, and intra-hour scheduling - are being implemented by grid operators across the United States.

With federal incentives for wind energy in place through 2012, an improved project finance environment, and lower wind turbine and wind power pricing, modest growth in annual wind power capacity additions appears likely for 2011 relative to 2010. Additions are expected to remain well below the 2009 high, however, due in part to relatively low wholesale electricity prices and limited need for new electric capacity additions, and in part to existing state-level RPS programs that, in aggregate, are not sizable enough to support continued wind power capacity additions at 2008 and 2009 levels. Most projections show further growth in 2012, as the cost of wind energy continues to decline as a result of lower wind turbine pricing, and as wind project developers rush to capture federal incentives currently slated to expire at the end of that year. Forecasts for 2013, meanwhile, span a particularly wide range, depending in part on assumptions about the possible extension of federal incentives beyond 2012, but in general are weighed down by current policy uncertainty as well as the expected limited need for new electric capacity additions. 


\section{Introduction}

The U.S. wind power industry experienced a trying year in 2010, with a significant reduction in new builds compared to both 2008 and 2009. The delayed impact of the global financial crisis, relatively low natural gas and wholesale electricity prices, and slumping overall demand for energy countered the ongoing availability of existing federal and state incentives for wind energy deployment. Nonetheless, cumulative wind power capacity still grew by a healthy $15 \%$ in 2010 , and most expectations are for moderately higher wind power capacity additions in 2011 than witnessed in 2010, though 2011 additions are also expected to remain below the 2009 high.

Notwithstanding the slowed growth in 2010, the wind power sector is dynamic, making it difficult to keep up with evolving trends in the marketplace. This annual report - now in its fifth year - meets the need for timely, objective information on the industry and its progress by providing a detailed overview of developments and trends in the United States wind power market, with a particular focus on 2010.

As with previous editions, this report begins with an overview of key installation-related trends: trends in wind power capacity growth; how that growth compares to other countries and generation sources; the amount and percentage of wind energy in individual states; the status of offshore wind power development; and the quantity of proposed wind power capacity in various interconnection queues in the United States. Next, the report covers an array of wind power industry trends, including: developments in turbine manufacturer market share; manufacturing and supply-chain investments; wind turbine and component imports into and exports from the United States; wind turbine size, hub height, and rotor diameter; project financing developments; and trends among wind power project owners and power purchasers. The report then turns to a discussion of price, cost, and performance trends. In so doing, it reviews the prices paid for wind power in the United States, and how those prices compare to short-term wholesale electricity prices. The report also describes trends in installed wind power project costs, wind turbine transaction prices, project performance, and operations and maintenance expenses. Next, the report examines other policy and market factors impacting the domestic wind power market, including federal and state policy drivers, transmission issues, and grid integration. Finally, the report concludes with a preview of possible near-term market developments.

This fifth edition of the annual report updates data presented in previous editions, while highlighting key trends and important new developments from 2010. New to this edition is a more in-depth summary of developments in offshore wind energy; an expanded discussion of curtailment, with more (but still incomplete) data from several regions of the country; and further information on domestic nacelle assembly capacity. The report concentrates on larger-scale wind turbines, defined here as individual turbines that exceed $100 \mathrm{~kW}$ in size. ${ }^{1}$ The U.S. wind power sector is multifaceted, however, and also includes smaller, customer-sited wind turbines used to power residences, farms, and businesses. Data on these latter applications are not the focus of this report, though a brief discussion on Small Wind Turbines is provided on page 4.

\footnotetext{
${ }^{1}$ The $100 \mathrm{~kW}$ cut-off between 'small' and 'large' wind turbines is strictly used for 2009 and 2010 projects, in part justified by the fact that the U.S. tax code makes a similar distinction; in years prior to 2009, however, different cutoffs are used to ensure that older utility-scale wind power projects in California are not excluded from the sample.
} 
Much of the data included in this report were compiled by Berkeley Lab, and come from a variety of sources, including the American Wind Energy Association (AWEA), the Energy Information Administration (EIA), and the Federal Energy Regulatory Commission (FERC). The Appendix provides a summary of the many data sources used in the report, and a list of specific references follows the Appendix. Data on 2010 wind power capacity additions in the United States are based largely on information provided by AWEA; methodological differences exist in the processing of those and other data, however, and the data presented here therefore vary somewhat relative to AWEA (2011a). ${ }^{2}$ In other cases, the data shown here represent only a sample of actual wind power projects installed in the United States; furthermore, the data vary in quality. As such, emphasis should be placed on overall trends, rather than on individual data points. Finally, each section of this document primarily focuses on historical market information, with an emphasis on 2010; with some limited exceptions (including the final section of the report), the report does not seek to forecast future trends.

\footnotetext{
${ }^{2}$ For example, large wind turbines are defined in this report as exceeding $100 \mathrm{~kW}$, and by AWEA (2011a) as equal to and exceeding $100 \mathrm{~kW}$. The accounting of older wind power plants also differs to a certain degree, yielding modestly different estimates for installed capacity. Other methodological differences between AWEA (2011a) and this report are noted as appropriate in the pages that follow.
} 


\section{Installation Trends}

\section{Wind Power Additions Slowed in 2010, with Roughly 5 GW of New Capacity Added in the United States and \$11 Billion Invested}

The U.S. wind power market slowed in 2010, with 5,113 MW of new capacity added, bringing the cumulative total to more than 40,000 MW (Figure 1). ${ }^{3}$ This growth translates into $\$ 11$ billion (real 2010 dollars) invested in wind power project installation in 2010, for a cumulative investment total of $\$ 78$ billion since the beginning of the $1980 \mathrm{~s}^{4}$

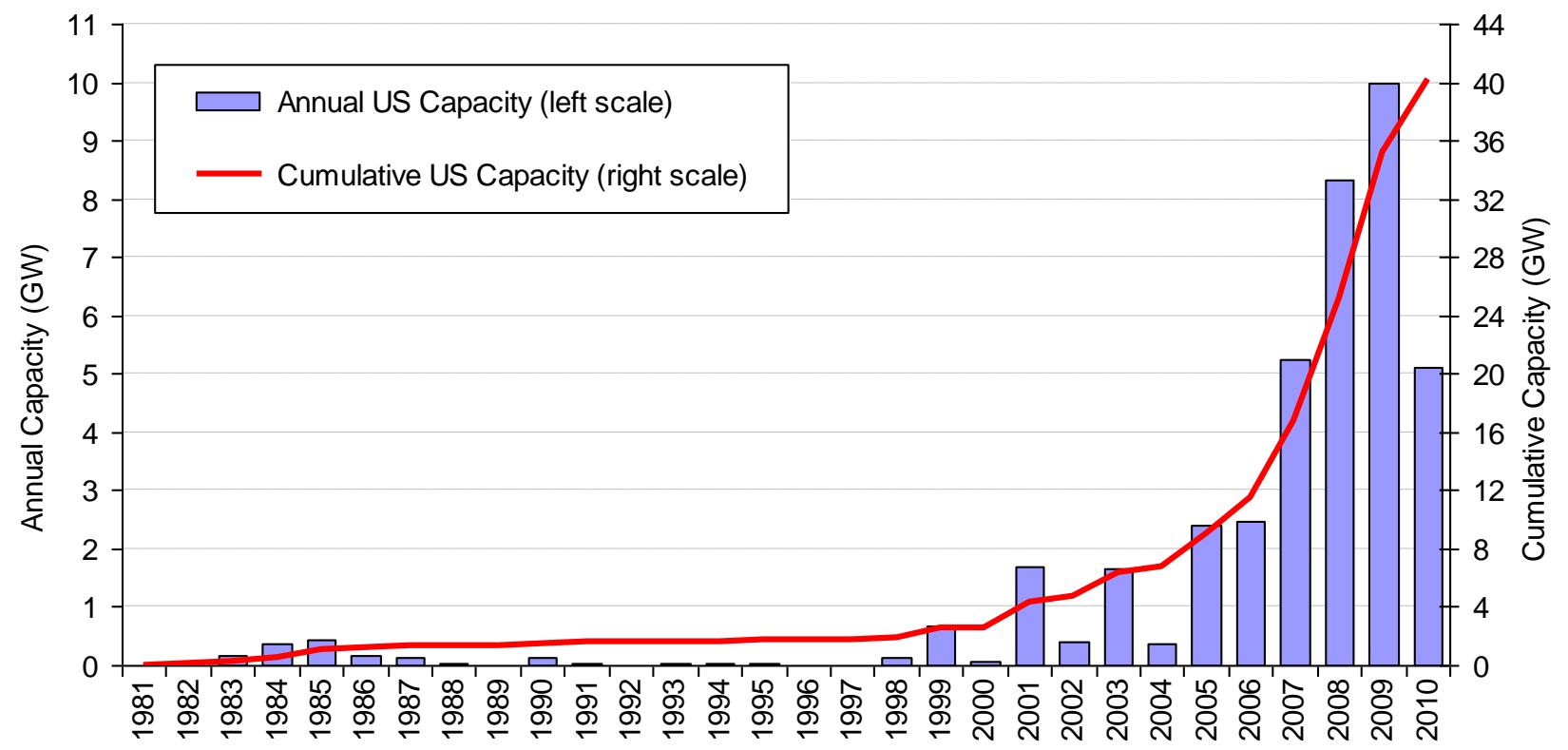

Source: AWEA project database

Figure 1. Annual and Cumulative Growth in U.S. Wind Power Capacity

Wind power installations in 2010 were similar in magnitude to those recorded in 2007, but were just half those seen in 2009 and were 40\% lower than in 2008. Cumulative wind power capacity grew by $15 \%$ in 2010. Factors retarding growth in 2010 included: the delayed impact of the global financial crisis (which impacted the apparent availability of capital for 2010 projects that were being planned in 2009); relatively low natural gas and wholesale electricity prices (which, in part, inhibited the development of merchant projects that were more-common in previous years); and slumping overall demand for energy (which reduced utility demand for wind energy power purchase agreements). The fact that these same drivers did not impact capacity additions in 2009 can be explained, in part, by the "inertia" in capital-intensive infrastructure investments:

\footnotetext{
${ }^{3}$ When reporting annual wind power capacity additions, this report focuses on gross capacity additions of large wind turbines. The net increase in capacity each year can be somewhat lower, reflecting turbine decommissioning. Some of the reasons for the modest differences between the figures presented here and by AWEA (2011a) are summarized in footnote 2. These differences lead AWEA (2011a) to report 5,116 MW of wind power capacity additions in 2010, for a cumulative total of 40,181 MW, in comparison to 5,113 MW and 40,267 MW in this report. ${ }^{4}$ These investment figures are based on an extrapolation of the average project-level capital costs reported later in this report, and do not include investments in manufacturing facilities, research \& development expenditures, or operations and maintenance (O\&M) costs.
} 
2009 capacity additions were largely determined by decisions made prior to the economy-wide financial crisis that was at its peak in late 2008 and early 2009, whereas decisions on 2010 capacity additions were often made at the height of the financial crisis.

These drivers overwhelmed the countervailing trends of continued and expanded federal and state incentives for wind energy deployment in 2010 (including elements of the Recovery Act, most prominently the Section 1603 Treasury Grant Program, and state renewables portfolio standards (RPS)), demonstrating that growth is not solely determined by the availability of incentives. Nevertheless, with federal incentives for wind energy in place through 2012, an improved project finance environment, and lower wind turbine and wind power pricing, growth in annual wind power capacity additions appears likely in 2011 relative to 2010. Additions in 2011 are expected to remain well below the 2009 high, however, due in part to relatively low wholesale electricity prices and limited need for new electric capacity additions, and in part to existing state-level RPS programs that, in aggregate, are not sizable enough to support continued wind power capacity additions at 2008 and 2009 levels.

\section{Small Wind Turbines}

Small wind turbines can provide power directly to homes, farms, schools, businesses, and industrial facilities, offsetting the need to purchase some portion of the host's electricity from the grid; such wind turbines can also provide power to off-grid sites. Wind turbines used in these applications are often much smaller - generally ranging in size from a few hundred watts to $100 \mathrm{~kW}$ - than the larger-scale turbines that are the primary focus of this report.

The table below summarizes sales of small wind turbines, $100 \mathrm{~kW}$ and less in size, into the U.S. market from 2005 through 2009; data on 2010 sales are not yet available but will be released by AWEA later in 2011. More than $20 \mathrm{MW}$ of small wind turbines were sold in the U.S. in 2009; most of this new capacity came from turbines manufactured by U.S. companies. These installation figures represent a $15 \%$ growth in annual sales - in capacity terms - relative to 2008 , yielding a cumulative installed capacity of small wind turbines in the United States of roughly $100 \mathrm{MW}$ by the end of 2009 (AWEA 2010).

Within this market segment, there has been a trend towards larger, grid-tied systems. Sales of turbines $<1 \mathrm{~kW}$ in size (often used off-grid) were flat from 2006-09 at roughly 3 MW. Sales of 1-10 kW turbines (often used in the grid-tied residential market), on the other hand, grew from less than $2 \mathrm{MW}$ in 2006 to $8 \mathrm{MW}$ in 2009, while sales of 11-100 kW turbines (often used in the grid-tied commercial / light industrial / government market) grew from around $3 \mathrm{MW}$ in 2006 to almost $10 \mathrm{MW}$ in 2009 (AWEA 2010).

\begin{tabular}{|c|c|c|c|}
\hline \multirow{2}{*}{ Year } & \multicolumn{3}{|c|}{ Annual Sales of Small Wind Turbines $(\leq 100 \mathrm{~kW})$ into the United States } \\
\hline & Number of Turbines & Capacity Additions & Sales Revenue \\
\hline 2005 & 4,324 & $3.3 \mathrm{MW}$ & $\$ 10$ million \\
\hline 2006 & 8,329 & $8.6 \mathrm{MW}$ & $\$ 33$ million \\
\hline 2007 & 9,092 & 9.7 MW & $\$ 42$ million \\
\hline 2008 & 10,386 & 17.4 MW & $\$ 73$ million \\
\hline 2009 & 9,800 & $20.3 \mathrm{MW}$ & $\$ 82$ million \\
\hline 2010 & available later in 2011 & available later in 2011 & available later in 2011 \\
\hline
\end{tabular}

Source: AWEA (2010)

Growth in this sector has been driven - at least in part - by a variety of state incentive programs. In addition, wind turbines equal to or under $100 \mathrm{~kW}$ in size are eligible for an uncapped $30 \%$ federal investment tax credit. 


\section{Wind Power Comprised 25\% of U.S. Electric Generating Capacity Additions in 2010}

Wind power has recently represented one of the largest new sources of electric capacity additions in the United States, though a considerable drop in wind energy's contribution occurred in 2010. Breaking a streak of five years in which wind power was the second-largest new resource added to the U.S. electrical grid in terms of aggregate gross capacity, in 2010 wind power placed third, behind the 7,200 MW of new natural gas and 6,000 MW of new coal-fired generation capacity. ${ }^{5}$ New wind power projects contributed roughly $25 \%$ of the new nameplate capacity added to the U.S. electrical grid in 2010, compared to $42 \%$ in $2009,43 \%$ in $2008,34 \%$ in $2007,18 \%$ in 2006 , $12 \%$ in 2005, and less than 4\% from 2000 through 2004 (Figure 2).

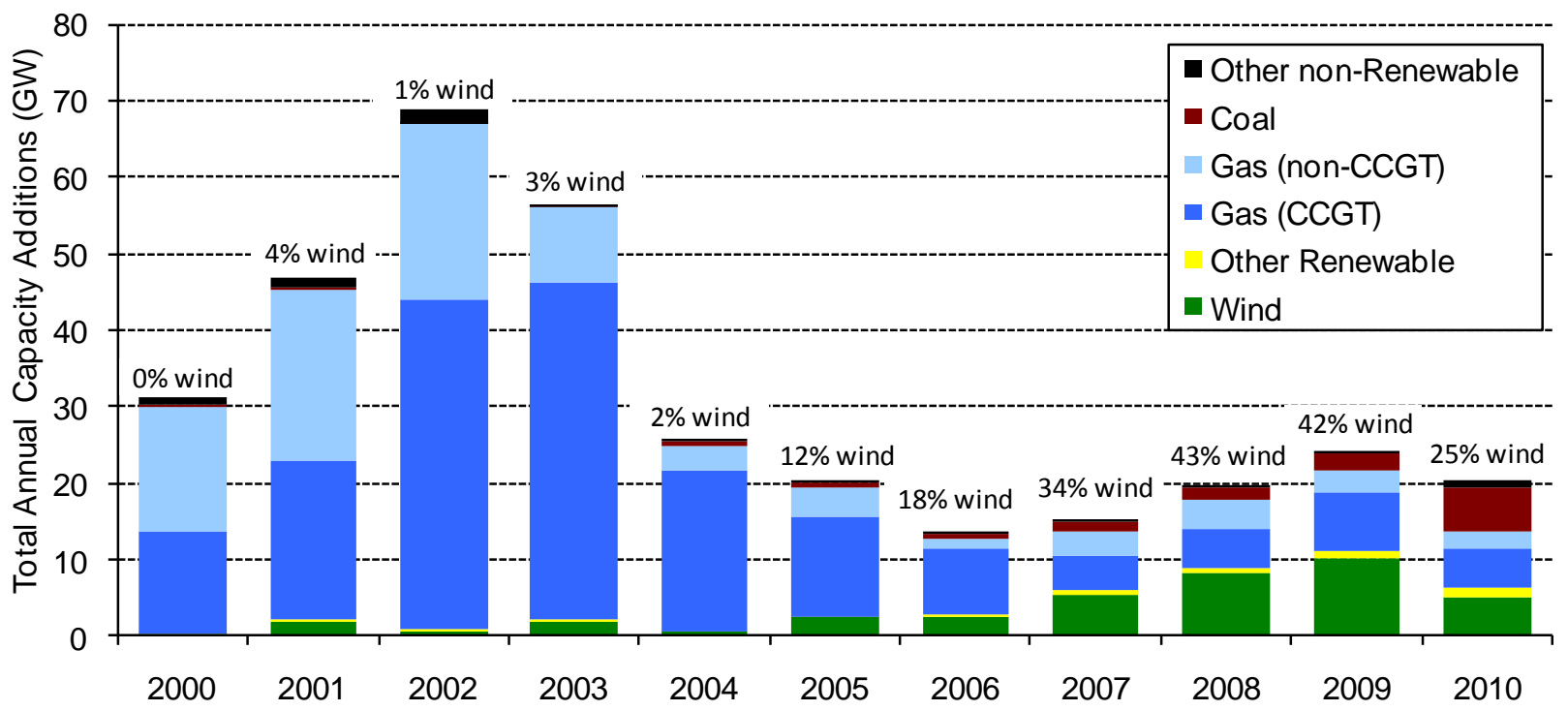

Source: EIA, Ventyx, AWEA, IREC, SEIA/GTM, Berkeley Lab

Figure 2. Relative Contribution of Generation Types in Annual Capacity Additions

EIA's (2011) reference-case forecast projects that total U.S. electricity supply will need to increase at an average pace of roughly 41TWh (0.9\%) per year from 2010 to 2035 in order to meet demand growth. On an energy basis, the annual amount of electricity expected to be generated by the new wind power capacity added in 2010 represents roughly $35 \%$ of this average annual projected growth in supply. By extension, if net wind power additions continued through 2035 at even the relatively slow pace as set in 2010 , then roughly $35 \%$ of the nation's projected increase in electricity generation from 2010 through 2035 would be met with wind electricity. Although future growth trends are hard to predict, it is clear that a significant portion of the country's new generation needs is already being met by wind.

\footnotetext{
${ }^{5}$ Data presented here are based on gross capacity additions, not considering retirements. The results presented in Figure 2 differ somewhat from AWEA (2011a), which reports that wind maintained its second-place showing in 2011, due to differing data sources for coal-fired generation capacity additions.
} 


\section{The United States Was Overtaken by China in Cumulative Wind Power Capacity, Remained the Second Largest Market in Annual Additions, and Was Well Behind the Market Leaders in Wind Energy Penetration}

Global wind power capacity additions in 2010 were similar to 2009, buoyed largely by China and dragged down by the relatively poor performance of the U.S. market. On a worldwide basis, roughly 39,000 MW of wind power capacity was added in 2010, similar to the 2009 figure and bringing the cumulative total to nearly 200,000 MW (BTM 2011; Table 1). ${ }^{6}$ In terms of cumulative capacity, the United States ended the year with $20 \%$ of total global wind power capacity, but dropped to the second largest market in the world by this metric, after China (Table $1) .^{7}$ Over the past 10 years, cumulative wind power capacity has grown an average of $32 \%$ per year in the United States, somewhat higher than the $27 \%$ growth rate globally. Annual growth in cumulative capacity was down in 2010 , however, at $15 \%$ for the U.S. and $25 \%$ globally.

After leading the world in annual wind power capacity additions from 2005 through 2008, the U.S. has now - for two years - been second to China (Table 1), capturing roughly $13 \%$ of the global market in 2010, down substantially from 26\% in 2009, 29\% in 2008, and 27\% in 2007. China now dominates global wind power rankings, with an approximate $50 \%$ share of the global market for new wind power additions in 2010; without growth in China, global wind capacity additions in 2010 would have shrunk considerably relative to 2009. India, Germany, and the U.K. rounded out the top five countries in 2010 for annual capacity additions.

\section{Table 1. International Rankings of Wind Power Capacity}

\begin{tabular}{|lrl|r|}
\multicolumn{2}{c}{$\begin{array}{c}\text { Annual Capacity } \\
\text { (2010, MW) }\end{array}$} & & \multicolumn{2}{c}{$\begin{array}{c}\text { Cumulative Capacity } \\
\text { (end of 2010, MW) }\end{array}$} \\
\hline China & 18,928 & China & 44,781 \\
U.S. & $\mathbf{5 , 1 1 3}$ & U.S. & $\mathbf{4 0 , 2 6 7}$ \\
India & 2,139 & Germany & 27,364 \\
Germany & 1,551 & Spain & 20,300 \\
U.K. & 1,522 & India & 12,966 \\
Spain & 1,516 & France & 5,961 \\
France & 1,186 & U.K. & 5,862 \\
Italy & 948 & Italy & 5,793 \\
Canada & 690 & Canada & 4,011 \\
Sweden & 604 & Portugal & 3,837 \\
Rest of World & 5,205 & Rest of World & 28,371 \\
\hline TOTAL & $\mathbf{3 9 , 4 0 2}$ & TOTAL & $\mathbf{1 9 9 , 5 1 3}$
\end{tabular}

Source: BTM Consult; AWEA project database for U.S. capacity

\footnotetext{
${ }^{6}$ Yearly and cumulative installed wind power capacity in the United States are from the present report, while global wind power capacity comes from BTM (2011), but updated with the U.S. data presented here. Some disagreement exists among these data sources and others, e.g., Windpower Monthly, the Global Wind Energy Council, and AWEA. BTM (2011), for example, reports 3\% more global wind power capacity additions in 2010 than in 2009 , whereas other sources report a modest drop in capacity additions.

${ }^{7}$ Wind power additions and cumulative capacity in China are from BTM (2011), and include a considerable amount of capacity that was installed but that had not yet begun to deliver electricity by the end of 2010. All of the U.S. capacity reported here, on the other hand, was capable of electricity delivery. If only considering the cumulative wind power capacity that was delivering electricity as of the end of 2010, the United States would have again led the world in cumulative capacity at the end of 2010.
} 
A number of countries are beginning to achieve relatively high levels of wind energy penetration in their electricity grids. Figure 3 presents data on end-of-2010 (and end-of-2006/07/08/09) installed wind power capacity, translated into projected annual electricity supply based on assumed country-specific capacity factors, and divided by projected 2011 (and 2007/08/09/10) electricity consumption. Using this approximation for the contribution of wind power to electricity consumption, and focusing only on the 20 countries with the greatest cumulative installed wind power capacity, end-of-2010 installed wind power is estimated to be capable of supplying the equivalent of roughly $26 \%$ of Denmark's electricity demand, $17 \%$ of Portugal's, $15 \%$ of Spain's, $14 \%$ of Ireland's, and 9\% of Germany's. In the United States, the cumulative wind power capacity installed at the end of 2010 is estimated, in an average year, to equate to roughly $2.9 \%$ of the nation's electricity consumption (up from $2.6 \%$ at the end of $2009,1.8 \%$ at the end of $2008,1.2 \%$ at the end of 2007 , and $0.8 \%$ at the end of 2006). ${ }^{8}$ On a global basis, wind energy's contribution at the end of 2010 is estimated to be $2.2 \%$.

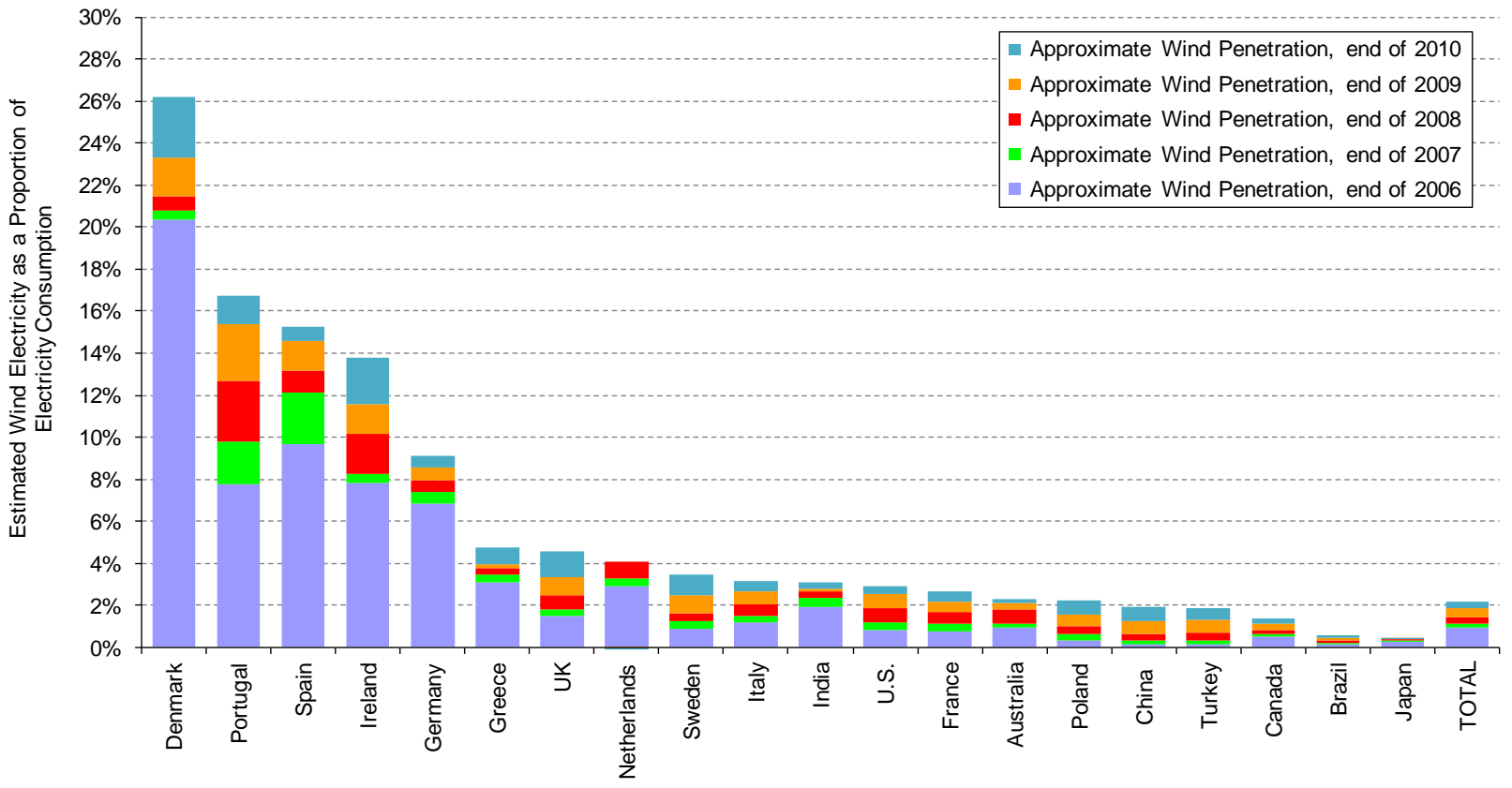

Source: Berkeley Lab estimates based on data from BTM Consult, EIA, and elsewhere

Figure 3. Approximate Wind Energy Penetration in the Twenty Countries with the Greatest Installed Wind Power Capacity

\section{Texas Once Again Added More New Wind Power Capacity than Any Other State, While Four States Exceed 10\% Wind Energy Penetration}

New large-scale ${ }^{9}$ wind turbines were installed in 29 states in 2010. Texas again led all states in terms of new wind power capacity, with $680 \mathrm{MW}$ installed in 2010, but this figure is down sharply from 2,292 MW installed in 2009 and 2,671 MW installed in 2008. As shown in Figure

\footnotetext{
${ }^{8}$ In terms of actual 2010 deliveries, EIA reports that wind energy represented $2.3 \%$ of net electricity generation and $2.5 \%$ of national electricity consumption in the United States. These figures are below the $2.9 \%$ figure provided above in part because $2.9 \%$ is a projection based on end-of-year 2010 wind power capacity.

9 "Large-scale" turbines are defined consistently with the rest of this report - i.e., turbines over $100 \mathrm{~kW}$.
} 
4 and Table 2, other leading states in terms of new capacity (each with more than $300 \mathrm{MW}$ ) included Illinois, California, South Dakota, Minnesota, Oklahoma, Wyoming, and Indiana. Fifteen states added more than $100 \mathrm{MW}$ each in 2010.

On a cumulative basis, Texas exceeded the $10 \mathrm{GW}$ milestone in 2010 . In fact, Texas has more installed wind power capacity than all but five countries worldwide. U.S. states following Texas in cumulative installed capacity are Iowa, California, Minnesota, Washington, Oregon, and Illinois. Seventeen states had more than $500 \mathrm{MW}$ of wind power capacity as of the end of 2010, with seven of these topping 2,000 MW. Although all wind power projects in the United States to date have been installed on land, offshore development activities continued in 2010, as discussed in the next section.

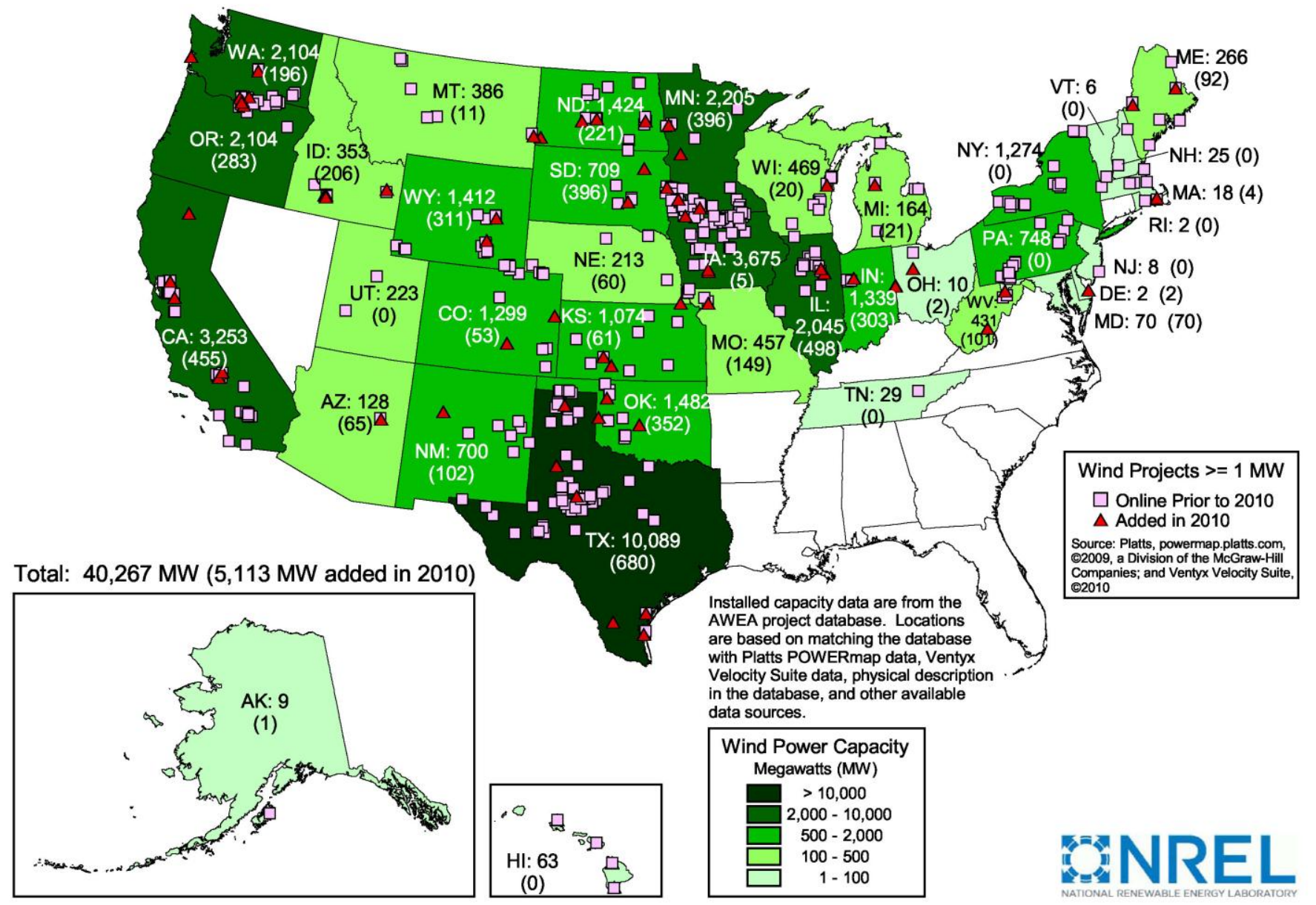

Note: Numbers within states represent cumulative installed wind capacity and, in parentheses, annual additions in 2010.

Figure 4. Location of Wind Power Development in the United States

Some states are beginning to realize relatively high levels of wind energy penetration. The right half of Table 2 lists the top 20 states based on both actual wind electricity generation in 2010 as well as estimated wind electricity generation from end-of-2010 wind power capacity, both 
divided by total in-state electricity generation in $2010 .{ }^{10}$ Using either method, the same four upper Midwest states - North and South Dakota, Minnesota, and Iowa - lead the list (though in a different order). Most notably, the wind power capacity installed in South Dakota as of the end of 2010 is estimated, in an average year, to be capable of generating approximately $23 \%$ of all in-state electricity generation. This estimated penetration is up sharply from the actual 2010 penetration of $8 \%$, and reflects the growth in wind power capacity in South Dakota in 2010, much of which was commissioned towards the end of the year (i.e., too late to contribute much to actual 2010 penetration). Three other states are also estimated to exceed $10 \%$ penetration by this metric: Iowa (17\%), North Dakota (14\%), and Minnesota (12\%).

Table 2. United States Wind Power Rankings: The Top 20 States

\begin{tabular}{|c|c|c|c|c|c|c|c|}
\hline \multicolumn{4}{|c|}{ Capacity (MW) } & \multicolumn{4}{|c|}{ Percentage of In-State Generation } \\
\hline \multicolumn{2}{|c|}{ Annual (2010) } & \multicolumn{2}{|c|}{ Cumulative (end of 2010) } & \multicolumn{2}{|c|}{ Actual (2010)* } & \multicolumn{2}{|c|}{ Estimated (end of 2010)** } \\
\hline Texas & 680 & Texas & 10,089 & Iowa & $15.4 \%$ & South Dakota & $23.2 \%$ \\
\hline Illinois & 498 & Iowa & 3,675 & North Dakota & $12.0 \%$ & Iowa & $16.9 \%$ \\
\hline California & 455 & California & 3,253 & Minnesota & $9.7 \%$ & North Dakota & $13.5 \%$ \\
\hline South Dakota & 396 & Minnesota & 2,205 & South Dakota & $8.3 \%$ & Minnesota & $12.3 \%$ \\
\hline Minnesota & 396 & Washington & 2,104 & Kansas & $7.1 \%$ & Oregon & $9.8 \%$ \\
\hline Oklahoma & 352 & Oregon & 2,104 & Oregon & $7.1 \%$ & Wyoming & $8.2 \%$ \\
\hline Wyoming & 311 & Illinois & 2,045 & Wyoming & $6.7 \%$ & Colorado & $7.8 \%$ \\
\hline Indiana & 303 & Oklahoma & 1,482 & Colorado & $6.6 \%$ & Kansas & $7.6 \%$ \\
\hline Oregon & 283 & North Dakota & 1,424 & Texas & $6.4 \%$ & Idaho & $7.3 \%$ \\
\hline North Dakota & 221 & Wyoming & 1,412 & Oklahoma & $5.1 \%$ & Oklahoma & $6.9 \%$ \\
\hline Idaho & 206 & Indiana & 1,339 & New Mexico & $5.0 \%$ & Texas & $6.7 \%$ \\
\hline Washington & 196 & Colorado & 1,299 & Washington & $4.6 \%$ & New Mexico & $6.0 \%$ \\
\hline Missouri & 149 & New York & 1,274 & Idaho & $4.0 \%$ & Washington & $5.2 \%$ \\
\hline New Mexico & 102 & Kansas & 1,074 & California & $3.3 \%$ & Maine & $4.4 \%$ \\
\hline West Virginia & 101 & Pennsylvania & 748 & Montana & $3.1 \%$ & Montana & $3.9 \%$ \\
\hline Maine & 92 & South Dakota & 709 & Maine & $2.9 \%$ & California & $3.9 \%$ \\
\hline Maryland & 70 & New Mexico & 700 & Indiana & $2.4 \%$ & Indiana & $3.0 \%$ \\
\hline Arizona & 65 & Wisconsin & 469 & Hawaii & $2.3 \%$ & Illinois & $2.8 \%$ \\
\hline Kansas & 61 & Missouri & 457 & Illinois & $2.2 \%$ & Hawaii & $2.3 \%$ \\
\hline Nebraska & 60 & West Virginia & 431 & New York & $2.0 \%$ & New York & $2.0 \%$ \\
\hline Rest of U.S. & 118 & Rest of U.S. & 1,974 & Rest of U.S. & $0.3 \%$ & Rest of U.S. & $0.3 \%$ \\
\hline TOTAL & 5,113 & TOTAL & 40,267 & TOTAL & $2.3 \%$ & TOTAL & $2.6 \%$ \\
\hline
\end{tabular}

\footnotetext{
${ }^{10}$ Wind energy penetration can either be expressed as a percentage of in-state load or in-state generation. In-state generation is used here, primarily because wind energy (like other energy resources) is often sold across state lines, which tends to distort penetration levels expressed as a percentage of in-state load. The actual penetration of wind electricity generation in 2010 is based exclusively on preliminary EIA data for 2010, and matches what AWEA provides in its U.S. Wind Industry Annual Market Report (AWEA 2011a). For the estimated penetration, end-of2010 wind power capacity is translated into estimated annual wind electricity production based on estimated statespecific capacity factors that derive from the project performance data reported later in this report. The resulting state-specific wind electricity generation estimates are then divided by preliminary EIA data on total in-state electricity generation in 2010 .
} 


\section{Offshore Wind Power Project and Policy Developments Continued in 2010}

At the end of 2010, global offshore wind power capacity stood at over 3,000 MW (BTM 2011), with the vast majority ( $>95 \%$ ) of 2010 offshore wind power additions and cumulative capacity located in Europe. To date, no offshore projects have been installed in the United States, and the emergence of a U.S. offshore wind power market still faces many challenges. Perhaps most importantly, the projected near-term costs of offshore wind energy remain high. Additionally, though political support exists for offshore wind energy in some quarters, planning, siting, and permitting can be challenging, as demonstrated in the long history of the Cape Wind project. Competing uses of offshore waters and public concerns can complicate the process and, despite recent progress in clarifying the permitting procedures in federal waters, uncertainties in federal and state permitting processes remain.

Nonetheless, interest in developing offshore wind energy exists in several parts of the country. Driving this interest is the proximity of offshore wind resources to population centers, the potential for local economic development benefits, advances in technology, and superior capacity factors (and, in some instances, peak load coincidence) compared to the finite set of developable land-based wind power projects available in some regions.

\section{Federal Activities}

Several significant strides relating to offshore wind energy have been made recently in the federal arena. The U.S. Department of the Interior (DOI) signed a Memorandum of Understanding (MOU) with the governors of 10 coastal states in June 2010 forming the Atlantic Offshore Wind Energy Consortium. ${ }^{11}$ The aim of the Consortium is to facilitate the coordination of offshore development off the Eastern Coast. Additionally, DOI's Bureau of Ocean Energy Management, Regulation, and Enforcement (BOEMRE) formed Renewable Energy Task Forces in several coastal states in late 2009. The mission of these Task Forces is to engage local stakeholders in the development of federal regulations for offshore renewable energy and the commercial leasing process. In 2010, Task Forces in Maryland, Delaware, and Massachusetts published Requests for Information (RFI) to gauge commercial interest and gather comments regarding potential commercial leases in designated areas; other state Task Forces have plans to publish similar RFIs in 2011.

Major news was made in April 2010, when the Cape Wind project in Massachusetts became the first proposed offshore wind plant to receive final federal regulatory approval from BOEMRE, with a final lease issued in October. Following from that first lease, in November 2010, DOI announced its "Smart from the Start" initiative, intended to streamline and shorten the federal offshore permitting process. The first of several targets of the initiative is to proactively identify high-priority Wind Energy Areas for offshore wind energy development and expedite the environmental review process and site assessment activities for leasing within these areas. In February 2011, BOEMRE unveiled four tentative Wind Energy Areas in the Mid-Atlantic for public comment (Figure 5). BOEMRE is expected to announce additional proposed Wind Energy Areas later in 2011. In March 2011, NRG Bluewater Wind's Delaware project became the first project to begin the commercial leasing process under the Smart from the Start program.

\footnotetext{
${ }^{11}$ Signatory states include Maine, New Hampshire, Massachusetts, Rhode Island, New York, New Jersey, Delaware, Maryland, Virginia, and North Carolina.
} 
More generally, the program intends to simplify the approval process for offshore projects by eliminating unnecessary regulatory requirements and by moving aggressively to process applications to build offshore transmission lines.

Finally, in February 2011, Secretary of Interior Ken Salazar and Secretary of Energy Steven Chu unveiled a joint national strategy to accelerate the development of the U.S. offshore wind power industry. This joint strategy is a major product from the MOU signed between the two agencies in June 2010 to coordinate offshore renewable energy deployment activities. To support the strategy, the Department of Energy announced $\$ 50.5$ million in competitive funding opportunities to support offshore wind technology development and address market barriers.

\section{Offshore Project Updates and State Activities}

Figure 6 identifies nine proposed offshore wind power projects in the United States that have advanced significantly in the permitting and development process. These projects have either made

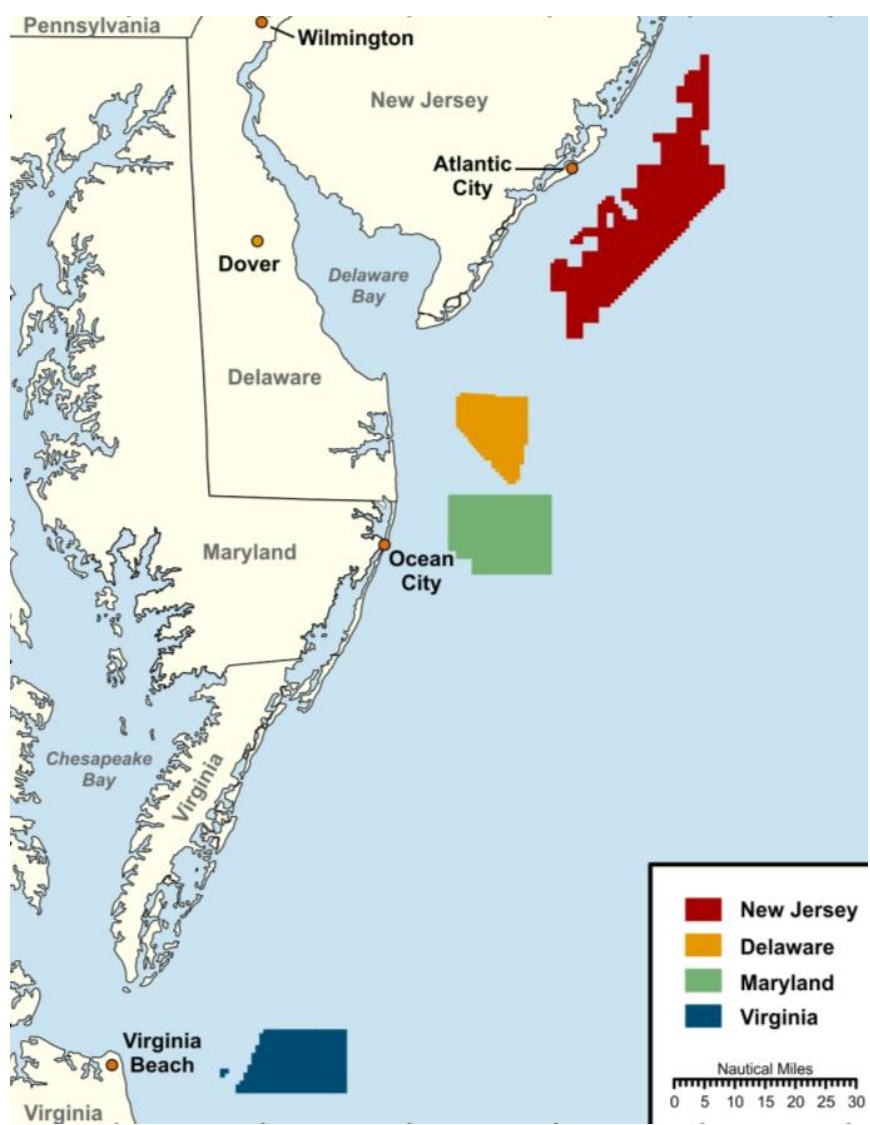

Figure 5: Mid-Atlantic Wind Energy Areas Under Consideration by BOEMRE substantial progress towards receiving state permits or have received a lease or interim limited lease from BOEMRE. ${ }^{12}$ In total, these proposed projects equal 2,322 MW, and are primarily located in the Northeast and Mid-Atlantic, though proposed projects also exist in the Great Lakes and Gulf of Mexico. Since these projects are still in pre-construction stages of development it is not certain which, if any, will come to fruition. Many other proposed offshore wind power projects not listed in Figure 6 exist in the U.S. in earlier planning phases.

\footnotetext{
${ }^{12}$ Interim limited leases were issued in mid-2009 by the then Minerals Management Service under the Interim Policy for regulating renewable energy on the Outer Continental Shelf. The five-year leases authorize data gathering activities, allowing for the construction of meteorological towers to collect site-specific data.
} 


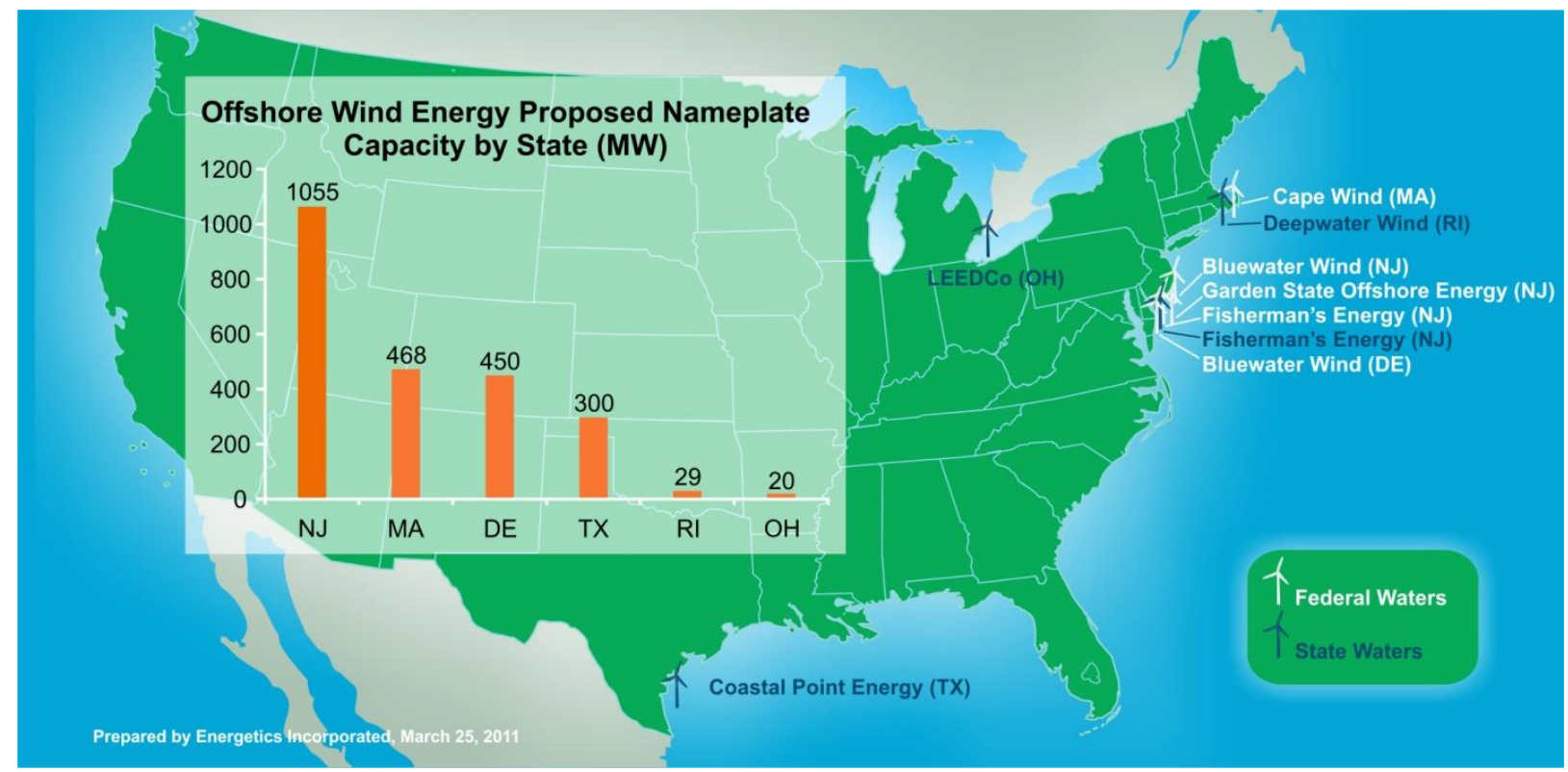

\section{Figure 6. Proposed Offshore Wind Power Projects in a Relatively Advanced State of Development}

Of the projects identified in Figure 6, three have signed power purchase agreements (PPAs) with terms and details that have been made public (Table 3). As shown, offshore wind power prices are substantially greater than those for land-based wind energy (presented later in this report).

\section{Table 3. Power Purchase Agreements for Proposed Offshore Wind Power Projects}

\begin{tabular}{|c|c|c|c|}
\hline $\begin{array}{c}\text { Seller } \\
\text { (Location) }\end{array}$ & Purchaser & Amount & Contract Details (Bundled Price) \\
\hline \multirow{3}{*}{$\begin{array}{l}\text { NRG Bluewater } \\
\text { Wind } \\
\text { (Delaware) }\end{array}$} & Delmarva & $200 \mathrm{MW}$ & $\begin{array}{l}25 \text {-yr contract for electricity, capacity, and a } \\
\text { portion* of the RECs: } \$ 114.25 / \mathrm{MWh} \text { plus } \\
\$ 70.23 / \mathrm{kW} \text {-yr in } 2007 \text { dollars, escalating at } 2.5 \% / \mathrm{yr} \\
\text { since } 2007 \text {; approved by regulatory commission in } \\
\text { July 2008, and amended in August } 2010\end{array}$ \\
\hline & $\begin{array}{l}\text { University } \\
\text { of Maryland }\end{array}$ & $55 \mathrm{MW}$ & Not available \\
\hline & $\begin{array}{l}\text { Delaware } \\
\text { Municipal } \\
\text { Electric }\end{array}$ & $38 \mathrm{MW}$ & $20-y r$ contract \\
\hline $\begin{array}{l}\text { Deepwater } \\
\text { Wind } \\
\text { (Rhode Island) }\end{array}$ & $\begin{array}{c}\text { National } \\
\text { Grid }\end{array}$ & $28.8 \mathrm{MW}$ & $\begin{array}{l}20 \text {-yr contract for electricity and RECs: Not to } \\
\text { exceed } \$ 235.7 / \mathrm{MWh} \text { in } 2012 \text {, escalating at } 3.5 \% / \mathrm{yr} \text {; } \\
\text { approved by regulatory commission in August } 2010\end{array}$ \\
\hline $\begin{array}{c}\text { Cape Wind } \\
\text { (Massachusetts) }\end{array}$ & $\begin{array}{c}\text { National } \\
\text { Grid }\end{array}$ & $\begin{array}{l}\text { Up to } 234 \mathrm{MW} \\
\text { (50\% of } \\
\text { project) }\end{array}$ & $\begin{array}{l}\text { 15-yr contract for electricity and RECs: base price } \\
\text { of } \$ 187 / \mathrm{MWh} \text { in } 2013 \text {, escalating at } 3.5 \% / \mathrm{yr} \text {; option } \\
\text { to extend } 10 \text { yrs; approved by regulatory } \\
\text { commission in November } 2010\end{array}$ \\
\hline
\end{tabular}

* Delmarva would receive $28.6 \%$ of the renewable energy certificates (RECs) generated by this $200 \mathrm{MW}$ portion of the project, while NRG Bluewater would retain the remaining $71.4 \%$ of RECs and could sell those RECs into the market for further revenue support. 
Many announced projects saw continued progress in 2010 and early 2011. Selected project news and policy developments, by state, are summarized below. ${ }^{13}$

- Maine: Legislation was passed in 2010 establishing a goal for at least $300 \mathrm{MW}$ of offshore wind power by 2020 and 5,000 MW by 2030, while also implementing other regulatory changes intended to facilitate offshore wind power development. In September 2010, the Maine Public Utilities Commission issued a Request for Proposals for deepwater offshore wind and tidal energy demonstration projects, most likely employing floating platforms, up to $30 \mathrm{MW}$. The University of Maine-led, DeepCwind Consortium also received Recovery Act funds from the U.S. Department of Energy (DOE) to support deepwater offshore wind energy research, testing, and demonstration projects.

- Massachusetts: Cape Wind received a number of approvals in the past year. Most significantly, the project received the first commercial lease for offshore wind power development in federal waters from BOEMRE. The 28-year federal lease of 46 square miles carries an annual fee of $\$ 88,278$ and a $2-7 \%$ operating fee during production (BOEMRE 2010). Following the BOEMRE announcement, the project received a "no hazard" clearance from the Federal Aviation Administration in August 2010. In November, Cape Wind received approval from the Massachusetts's Department of Public Utilities for a 15-year PPA with National Grid. In January 2011, Cape Wind received a Section 10 permit from the Army Corps of Engineers and a final permit from the Environmental Protection Agency, while in April 2011 BOEMRE approved Cape Wind's Construction and Operations Plan. In 2010, Cape Wind also announced that it had selected Siemens as its turbine supplier (3.6 MW turbines). Despite these significant advances, continuing legal challenges at the state level and a portion of unsold power still confront the project. In May 2011, given a fastapproaching sunset date for the program, it was announced that the project would not immediately receive a loan guarantee from the U.S. Department of Energy.

- Rhode Island: Deepwater Wind's PPA with National Grid for the 28.8 MW Block Island demonstration project was initially rejected by the state's public utilities commission (PUC) in March 2010, but subsequent state legislation led to the approval of a revised PPA in August 2010. The state PUC's decision was appealed to the Rhode Island Supreme Court, however, where it remains under consideration as of June 2011. Meanwhile, Deepwater Wind has replaced its plans for a $385 \mathrm{MW}$ project with a significantly larger 1,000 MW proposal for federal waters between Rhode Island and Massachusetts. ${ }^{14}$

- New Jersey: Governor Christie signed the Offshore Wind Economic Development Act in August 2010. The law creates an offshore renewable energy certificate (OREC) program that calls for a share of the New Jersey RPS to come from offshore wind energy, intended to support at least 1,100 MW of capacity; the New Jersey Board of Public Utilities (BPU) adopted regulations for the program in February 2011. The program also allows for financial assistance and tax credits to qualified offshore projects and associated equipment manufacturers and assembling facilities. In May 2011, the NJ BPU announced it was seeking applications for offshore wind projects under a newly adopted permitting framework. Fisherman's Energy launched an environmental monitoring buoy near Atlantic City in April

\footnotetext{
${ }^{13}$ The information provided here comes from a variety of publically available sources, including press releases, news articles, and federal and state regulatory filings.

${ }^{14}$ Due to its early stage of development, this project is not yet counted among the projects shown in Figure 6.
} 
2010, one of the first steps in their plans for a 25 MW demonstration project in state waters and a larger project in federal waters. In February 2011, Fisherman's Energy filed a petition with the BPU to approve the issuance of ORECs to support financing and construction of their proposed demonstration project, and has since secured key permits for the project from the state. Garden State Offshore Energy, a joint venture of PSEG Global and Deepwater Wind, announced in October 2010 it had received approval from the New Jersey BPU to deploy a floating platform with resource and ecological assessments equipment. In early 2011, Garden State signaled an interest in possibly increasing the size of its proposed 350 MW project. Finally, in June 2011, BOEMRE reported that 11 offshore wind power development companies had expressed interest in federal lease blocks off New Jersey.

- Delaware: NRG Bluewater Wind pushed back plans to install a meteorological tower in 2010 due to a failure to obtain necessary permits. In August 2010, NRG Bluewater Wind and Delmarva amended their $200 \mathrm{MW}$ offshore wind energy PPA, extending by two years the period in which NRG can terminate the agreement (now June 2012) and the deadline by which NRG will start providing power (now December 2016). In March 2011, BOEMRE announced that it was initiating the process to award the first commercial lease under its Smart from the Start program to NRG after determining there was no competitive interest for the proposed area. In May 2011, however, NRG announced that it was further delaying plans to install a meteorological tower and was slowing development plans given uncertainty over the future of the federal loan guarantee program and PTC.

- Maryland: Although no projects are currently at an advanced stage, in early 2011, BOEMRE received a significant number of expressions of commercial interest in response to a RFI intended to gauge interest in potential lease blocks off Maryland's coast.

- North Carolina: Duke Energy announced in August 2010 that it was canceling plans to install up to three demonstration turbines in Pamlico Sound after determining that the project was not economically viable on a pilot scale and that scaling-up the project was not possible given space constraints.

- Ohio: The Lake Erie Energy Development Corporation (LEEDCo) signed an agreement in May 2010 to purchase five 4.1 MW direct drive turbines from General Electric Corporation (GE) for its planned $20 \mathrm{MW}$ demonstration project. LEEDCo also chose Freshwater Wind LLC to develop the project, a joint venture between Bechtel, Cavallo Great Lakes Ohio Wind, and Great Lakes Wind Energy LLC. In January 2011, LEEDCo obtained a Lease Option from the State of Ohio giving LEEDCo exclusive rights to conduct testing at the proposed project site.

- New York: The New York Power Authority reported in June 2010 that it had received five responses to a request for proposals for a Great Lakes Offshore Wind project. (The request was issued in December 2009 for projects between $120 \mathrm{MW}$ to $500 \mathrm{MW}$ in Lake Erie and/or Lake Ontario). Selected developers and locations for the project had not yet been announced as of June 2011. Additionally, in June 2010, the Long Island - New York City Offshore Wind Partnership's proposed $350 \mathrm{MW}$ project on the Atlantic seaboard announced plans to apply for a federal lease from BOEMRE (the application had not been submitted as of June 2011) 
- Texas: A number of leases were issued prior to 2010 to projects in various stages of development in Texas state waters. Coastal Point Energy's intent to install an initial single turbine in 2010 as a precursor to several larger wind power projects was delayed. However, in May 2011, Coastal Point reported that plans were moving forward to install a $3 \mathrm{MW}$ turbine in state waters by the end of the year.

Finally, a major offshore infrastructure proposal came in October 2010 when transmission company Trans-Elect announced plans for the $\$ 5$ billion Atlantic Wind Connection backbone transmission project, with financial backing from Google, Good Energies, and Marubeni Corporation. The proposed underwater transmission line off the mid-Atlantic coast would be built in five phases with a capacity of up to 7,000 MW. The proposed line would run from Virginia to northern New Jersey, with an option to connect with New York City. The first phase would include a line from northern New Jersey to southern Delaware with a 2,000 MW capacity. Initial estimates from Trans-Elect indicate that phase one could be built by 2016 .

\section{Data from Interconnection Queues Demonstrate that an Enormous Amount of Wind Power Capacity Is Under Consideration}

One testament to the continued interest in wind energy is the amount of wind power capacity currently working its way through the major transmission interconnection queues across the country. Figure 7 provides this information for wind power and other resources aggregated across 32 different interconnection queues administered by independent system operators (ISOs), regional transmission organizations (RTOs), and utilities. ${ }^{15}$ These data should be interpreted with caution: though placing a project in the interconnection queue is a necessary step in project development, being in the queue does not guarantee that a project will actually get built. In fact, projects currently in interconnection queues are often very early in the development process. As a result, efforts have been and are being taken by the Federal Energy Regulatory Commission (FERC), ISOs, RTOs, and utilities to reduce the number of speculative projects that have - in recent years - clogged these queues (e.g., Porter et al. 2009).

\footnotetext{
${ }^{15}$ The queues surveyed include PJM Interconnection (PJM), Midwest Independent System Operator (MISO), New York ISO (NYISO), ISO-New England (ISO-NE), California ISO (CAISO), Electric Reliability Council of Texas (ERCOT), Southwest Power Pool (SPP), Western Area Power Administration (WAPA), Bonneville Power Administration (BPA), and 23 other individual utilities. To provide a sense of sample size and coverage, the ISOs, RTOs, and utilities whose queues are included here have an aggregated peak demand of almost $70 \%$ of the U.S. total. Figures 7 and 8 only include projects that were active in the queue at the end of 2010 but that had not yet been built; suspended projects are not included.
} 


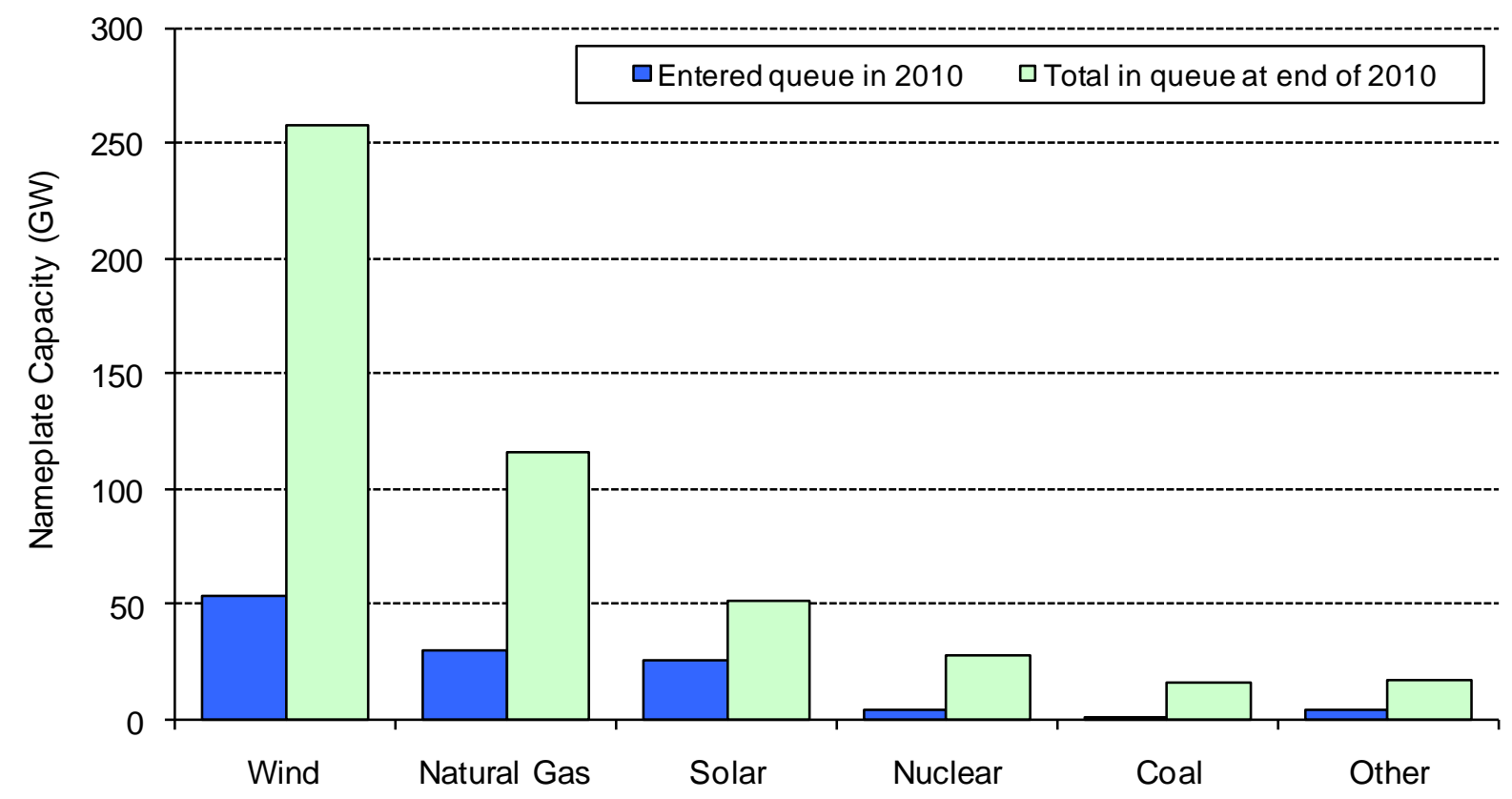

Source: Exeter Associates review of interconnection queues

\section{Figure 7. Nameplate Resource Capacity in 32 Selected Interconnection Queues}

Even with this important caveat, the amount of capacity in the nation's interconnection queues still provides at least some indication of the amount of wind power development that is in the planning phase. At the end of 2010, even after reforms by a number of ISOs, RTOs, and utilities to reduce the number of projects in their queues, there were $258 \mathrm{GW}$ of wind power capacity within the interconnection queues reviewed for this report - more than six times the installed wind power capacity in the United States. ${ }^{16}$ This wind power capacity represented more than $50 \%$ of all generating capacity within these selected queues at that time, and was more than two times as much capacity as the next-largest resource, natural gas. In 2010, $54 \mathrm{GW}$ of wind power capacity entered the interconnection queues, compared to $30 \mathrm{GW}$ of natural gas and $26 \mathrm{GW}$ of solar; relatively little nuclear and coal capacity entered these queues in 2010.

Much of this wind power capacity is planned for the Midwest, Mountain, Texas, PJM Interconnection, Northwest, and Southwest Power Pool regions: wind power projects in the interconnection queues in these regions at the end of 2010 accounted for $91 \%$ of the aggregate $258 \mathrm{GW}$ of wind power in the selected queues (Figure 8). Smaller amounts of wind power capacity were represented in the interconnection queues of the California ISO (4.4\%), New York ISO (2.7\%), ISO-New England (1.5\%), and the Southeast (0.7\%).

\footnotetext{
${ }^{16}$ As a rough benchmark, $300 \mathrm{GW}$ of wind power capacity is the approximate amount of capacity required to reach $20 \%$ wind energy penetration in the United States, as estimated in DOE (2008).
} 


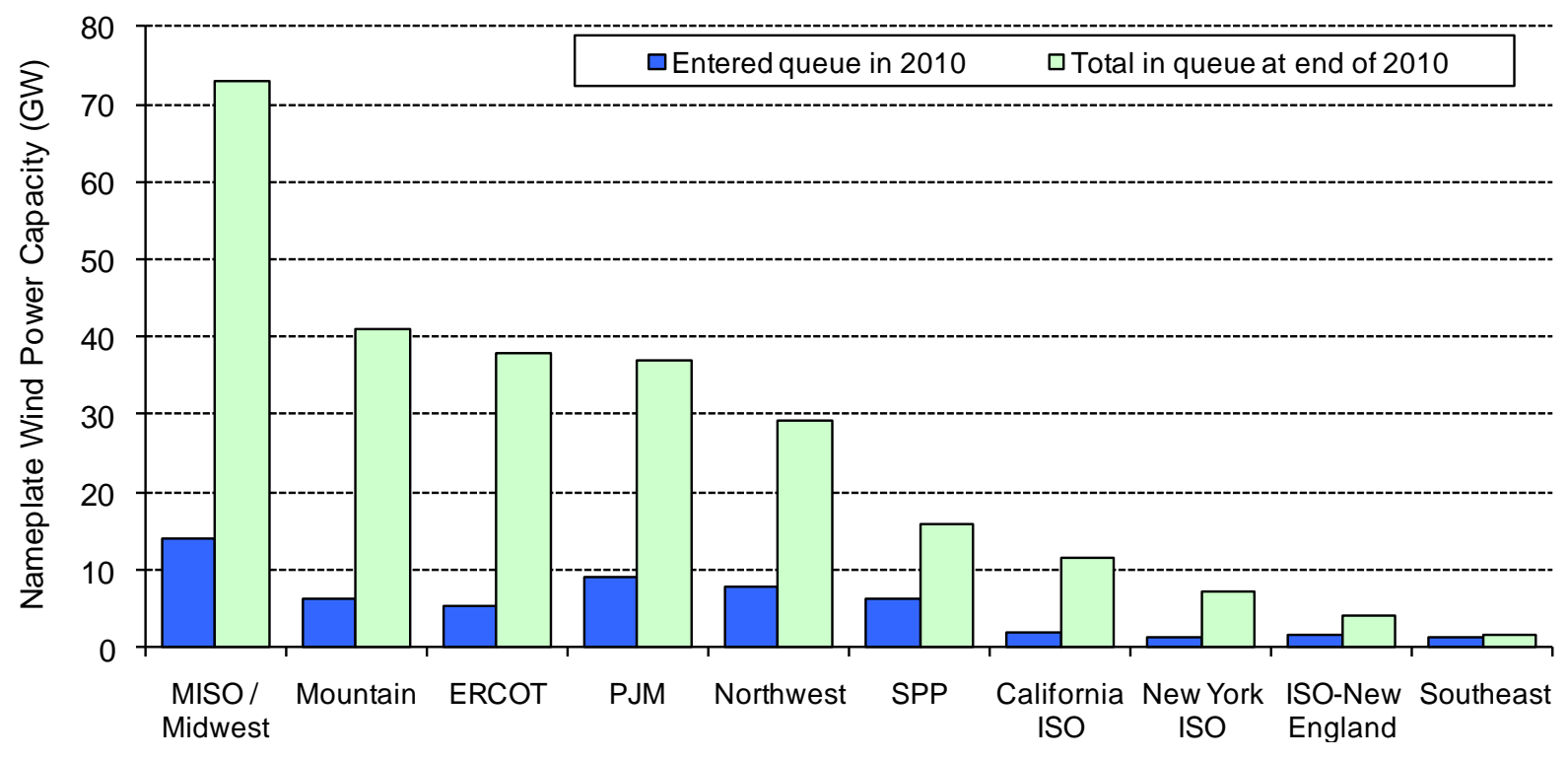

Source: Exeter Associates review of interconnection queues

\section{Figure 8. Wind Power Capacity in 32 Selected Interconnection Queues}

As another data point, the North American Electric Reliability Corporation (NERC) finds that roughly $165 \mathrm{GW}$ of new wind power capacity are projected to be added by 2019 in the United States, of which $41 \mathrm{GW}$ are "planned" and $124 \mathrm{GW}$ are "conceptual" (NERC 2010). Once again, though, it is unlikely that all of these planned projects will ultimately come to fruition within this time frame. As a measure of the near-term development pipeline, Ventyx (2011) estimates that - as of mid-May 2011 - more than $34 \mathrm{GW}$ of wind power capacity was either under construction or in site preparation ( $7 \mathrm{GW}$ of the $34 \mathrm{GW}$ total), in-development and permitted (12 GW of the $34 \mathrm{GW}$ ), or in-development with pending permit and/or regulatory applications (the remaining $15 \mathrm{GW}$ of the $34 \mathrm{GW}$ total). AWEA (2011b), meanwhile, reports $1,100 \mathrm{MW}$ of wind power capacity additions in the first quarter of 2011, with 5,600 MW under construction. 


\section{Industry Trends}

\section{GE Remained the Top Turbine Manufacturer in the U.S. Market}

General Electric (GE) remained the number one manufacturer of wind turbines supplying the U.S. market in 2010, with $50 \%$ of domestic turbine installations (up from $40 \%$ in 2009, and also higher than every year since 2005). ${ }^{17}$ Following GE were Siemens (16\%), Gamesa (11\%), Mitsubishi (7\%), Suzlon (6\%), Vestas (4\%), Acciona (2\%), Clipper (1\%), REpower (1\%), ${ }^{18}$ and Nordex and DeWind (both at $0.4 \%)$. Other utility-scale (>100 kW) wind turbines installed in the United States in 2010 (and that fall into the "Other" category in Figure 9) include turbines from Samsung (7.5 MW), Northern Power Systems (2.3 MW), TurboWinds (1.6 MW), Nordic Windpower (2 MW), Emergya Wind Technologies (1.65 MW), PowerWind (0.9 MW), and Elecon (0.6 MW).

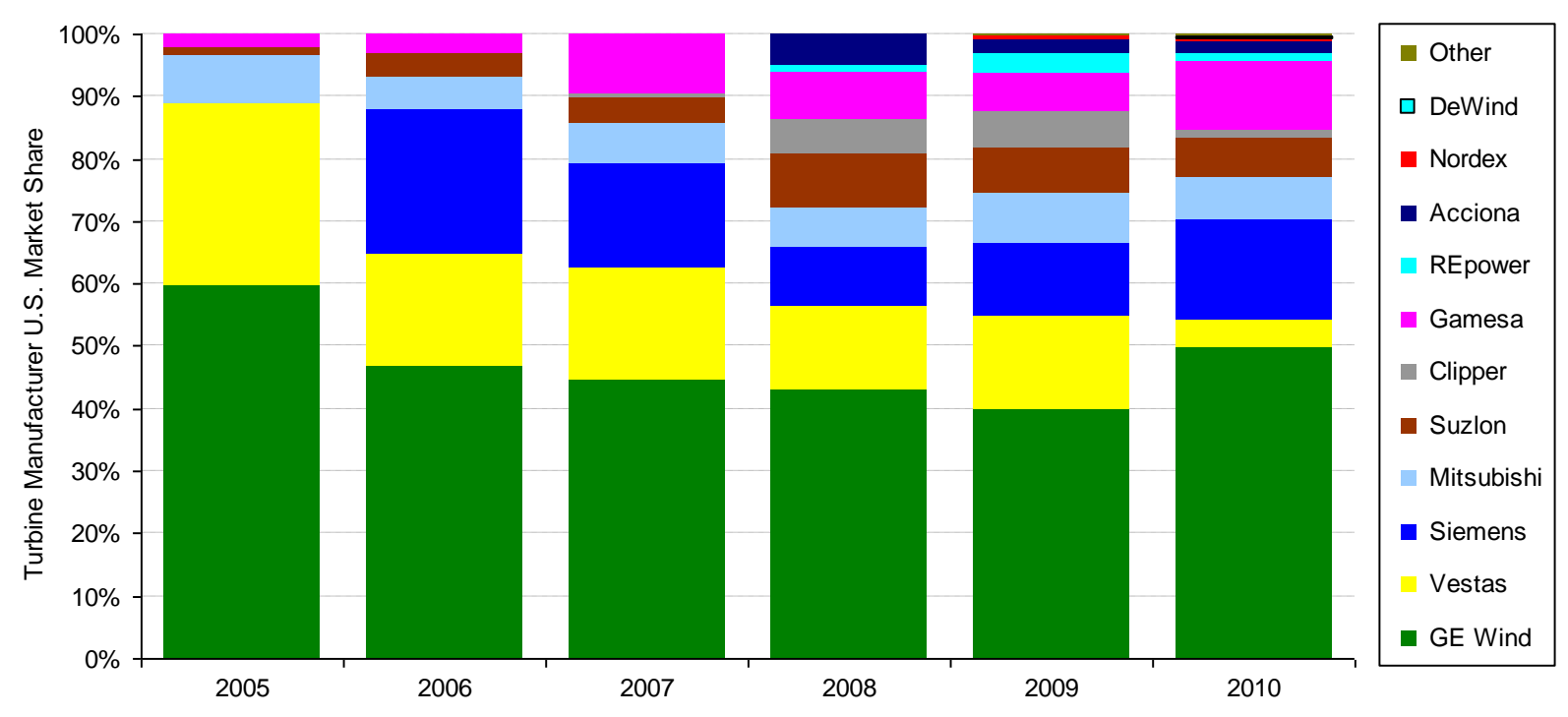

Source: AWEA project database

\section{Figure 9. Annual U.S. Market Share of Wind Manufacturers by MW, 2005-2010}

There has been a notable increase in the number of wind turbine manufacturers serving the U.S. market since 2005, with the number of manufacturers installing more than $1 \mathrm{MW}$ increasing from just 6 in 2005 to 16 manufacturers in 2010. Manufacturers with modern wind turbines installed in the United States through 2010 now hail from not just the United States, Europe, and Japan, but also from India, China, and South Korea. As a result of these trends, through 2008 at least, the market share of many of the leading manufacturers - in percentage terms - had generally declined. More recently, however, there is evidence of gains in market share by some of the leading manufacturers, with GE's 10 percentage point increase in market share from 2009 to 2010 a notable example. This consolidation may, in part, be a reflection of the financial crisis:

\footnotetext{
${ }^{17}$ Market share reported here is in MW terms, and is based on project installations in the year in question, not turbine shipments or orders.

${ }^{18}$ Suzlon owned more than $95 \%$ of REpower throughout 2010, and in April 2011 announced plans to buy out the remaining stake, which would make REpower a wholly owned subsidiary of Suzlon.
} 
ample turbine supply (relative to demand) and an increased desire for 'bankable' products may have led purchasers to favor leading turbine manufacturers.

Given the nearly 50\% drop in new installed capacity in 2010, however, virtually all turbine manufacturers saw annual installations of their turbines decline in 2010, in some cases significantly. As shown in Table 4, the most significant declines were experienced by GE (1,451 MW), Vestas (-1,267 MW), and Clipper (-535 MW). DeWind is the only turbine manufacturer listed in Table 4 to have installed more turbines in 2010 than in 2009.

Table 4. Annual U.S. Turbine Installation Capacity, by Manufacturer

\begin{tabular}{|c|c|c|c|c|c|c|}
\hline \multirow{2}{*}{ Manufacturer } & \multicolumn{6}{|c|}{ Turbine Installations (MW) } \\
\hline & 2005 & 2006 & 2007 & 2008 & 2009 & 2010 \\
\hline GE Wind & 1,433 & 1,146 & 2,342 & 3,585 & 3,995 & 2,543 \\
\hline Siemens & 0 & 573 & 863 & 791 & 1,162 & 828 \\
\hline Gamesa & 50 & 50 & 494 & 616 & 600 & 564 \\
\hline Mitsubishi & 190 & 128 & 356 & 516 & 814 & 350 \\
\hline Suzlon & 25 & 92 & 197 & 736 & 702 & 312 \\
\hline Vestas & 700 & 463 & 948 & 1,120 & 1,488 & 221 \\
\hline Acciona & 0 & 0 & 0 & 410 & 204 & 99 \\
\hline Clipper & 3 & 0 & 48 & 470 & 605 & 70 \\
\hline REPower & 0 & 0 & 0 & 94 & 330 & 68 \\
\hline Nordex & 0 & 0 & 3 & 0 & 63 & 20 \\
\hline DeWind & 0 & 0 & 0 & 2 & 6 & 20 \\
\hline Other & 2 & 2 & 0 & 10 & 25 & 17 \\
\hline TOTAL & 2,402 & 2,454 & 5,249 & 8,350 & 9,993 & 5,113 \\
\hline
\end{tabular}

In 2010, U.S.-owned GE slipped from the second- to the third-leading supplier of turbines globally, with a 9.6\% market share, behind Vestas' 14.8\% and Sinovel's 11.1\% market share. Clipper dropped from the listing of the top-15 manufacturers, and no other U.S.-owned manufacturer cracked the top-15. ${ }^{19}$ On a worldwide basis, perhaps the most significant continuing story of 2010 was the growing market share of Chinese turbine manufactures: four of the top ten (and seven of the top 15) leading global suppliers of wind turbines in 2010 hail from China, including Sinovel (second) and Goldwind (fourth). To date, that growth has been based almost entirely on sales to the Chinese market, though both Chinese (and South Korean) manufacturers continue to take steps to enter the international wind turbine market, including limited early installations in the United States.

\footnotetext{
${ }^{19}$ These statements emphasize the sale of large wind turbines. U.S. manufacturers are major players in the global market for smaller-scale turbines (AWEA 2010).
} 


\section{Domestic Wind Turbine and Component Manufacturing Activity Has Increased, but Has Also Been Challenged by the Economic Downturn}

As the cumulative capacity of wind power projects has grown in the United States, foreign and domestic turbine and component manufacturers have begun or continued to localize and expand operations across the nation. Despite the challenges faced in 2010, a similar number of new wind power manufacturing facilities (13) opened as in the previous year. Figure 10 presents a nonexhaustive list of 13 wind turbine and component manufacturing and assembly facilities that opened in 2010, 18 new manufacturing facilities announced (but not yet built) in 2010, and more than 150 existing turbine and component manufacturing facilities that were open prior to $2010 .{ }^{20}$

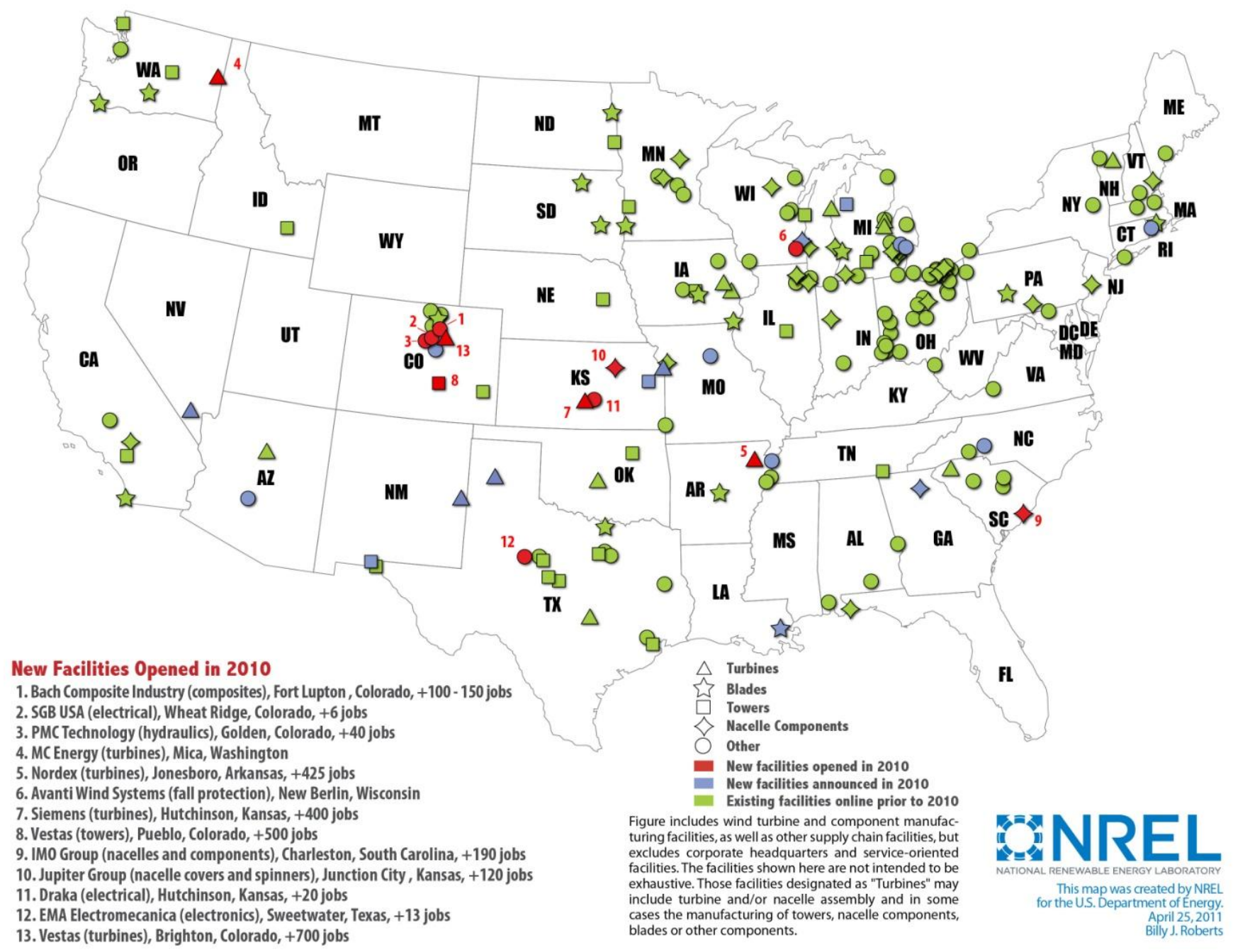

Figure 10. Location of Existing and New Turbine and Component Manufacturing Facilities

\footnotetext{
${ }^{20}$ The data on existing, new, and announced manufacturing facilities presented here differ somewhat from those presented in AWEA (2011a) due, in part, to methodological differences. In addition, AWEA (2011a) has access to data on a large set of smaller component suppliers that are not included here.
} 
Of the 31 new or announced facilities in 2010 captured in Figure 10, six are owned by major international wind turbine original equipment manufacturers (OEMs): Nordex (turbines in Jonesboro, Arkansas; opened in 2010), Siemens (turbines in Hutchinson, Kansas; opened in 2010), Vestas (turbines in Brighton, Colorado and towers in Pueblo, Colorado; opened in 2010), A-Power (turbines in Las Vegas, Nevada; announced in 2010), and Alstom Power (turbines in Amarillo, Texas; announced in 2010). In addition, GE announced plans to expand its research facility in Van Buren Township, Michigan, while Vestas opened a research and development support facility in Louisville, Colorado, adding to the growing list of already-operating or announced research facilities from previous years associated with a number of different wind turbine manufacturers. (Research facilities are not included in Figure 10). Several smaller- to mid-sized OEMs also opened or announced U.S. factories in 2010. Nordic Windpower, for example, announced a move of its production facilities (and corporate headquarters) from Pocatello, Idaho (and Berkeley, California) to Kansas City, Missouri. Still other firms have continued establishing themselves in the U.S. market based on manufacturing plans they had announced prior to 2010 .

Nine of the eleven OEMs with the largest share of the U.S. market in 2010 (Acciona, Clipper, DeWind, Gamesa, GE, Nordex, Siemens, Suzlon, and Vestas) ${ }^{21}$ already have one or more manufacturing facilities in the United States; companies with multiple facilities include Gamesa, GE, Siemens, and Vestas. Of the remaining two OEMs with the largest share of the U.S. market in 2010, at least one made strides to open a manufacturing facility - Mitsubishi broke ground on its Fort Smith, Arkansas plant in late 2010. These figures compare to just one utility-scale wind turbine OEM assembling nacelles ${ }^{22}$ in the United States in 2004 (GE). Still other active domestic and foreign OEMs that have or are seeking to sell larger turbines in the U.S. market have established U.S. manufacturing facilities (e.g., Northern Power, Nordic, Goss International) or have at least tentatively announced the location of future U.S. manufacturing facilities (e.g., Alstom, A-Power, Emergya, Fuhrlander), ${ }^{23}$ while still other companies have announced their interest in manufacturing but have not yet installed any utility-scale turbines.

Other notable developments from 2010 and early 2011 include the mixed success of emerging domestic turbine OEMs, and the increased interest in the United States market by Asian players. Clipper, for example, was acquired by United Technologies Corporation, allowing the company to maintain operations in the near term. Boulder Wind Power raised $\$ 8$ million in venture capital in early 2011, while Northern Power Systems commissioned a prototype of its new $2.3 \mathrm{MW}$ machine. Meanwhile, in addition to Mitsubishi's under-construction nacelle assembly facility, Asian OEMs from South Korea and China demonstrated continued interest in the U.S. market. South Korea's Samsung, Hyundai, and Unison, for example, have all announced interest in U.S. sales of wind turbines (with Samsung and Unison installing their first turbines in the U.S. in 2010 and 2011, respectively), while DeWind is now part of South Korea's Daewoo Shipbuilding \& Marine Engineering; other than DeWind, however, none of the other manufacturers noted here have established or announced specific plans for U.S. manufacturing facilities. China's

\footnotetext{
${ }^{21}$ DeWind and Nordex tied for tenth on the list of OEMs with the largest share of the U.S. market in 2010. Suzlon's Pipestone, Minnesota facility was idled in late 2010, but remains available for use if and when orders increase.

${ }^{22}$ Nacelle assembly is defined here as the process of combining the multitude of components included in a turbine nacelle to produce a complete turbine nacelle unit.

${ }^{23}$ Some of these announcements preceded 2010 and so are not included in Figure 10.
} 
Goldwind installed its first wind turbines on United States soil in 2009, and in 2010 began to explore manufacturing sites in the U.S. and secured a 20 year power sales contract for a $120 \mathrm{MW}$ project in Illinois slated for construction in 2011. In April 2011, Goldwind announced additional orders for 7.5 MW of turbines. A number of other Chinese manufacturers have also announced their entry into or interest in the U.S. market for turbine sales: Sany Electric, for example, has reportedly constructed a $10 \mathrm{MW}$ pilot project in Texas (to be commissioned later in 2011), Guodian United Power has reportedly shipped six 1.5 MW turbines for a $9 \mathrm{MW}$ project also in Texas, and Sinovel is similarly reportedly expecting to have a pilot project in operation in the near future, though none of these three companies has announced specific plans for U.S. manufacturing facilities. Ming Yang, meanwhile, opened an office in Dallas, Texas in 2010, and announced interest in a production plant in the area. Still other Chinese manufacturers have also taken initial steps to enter the U.S. market. Given the challenges of using conventional finance for projects relying on turbines from these new suppliers, however, initial installations have been and are likely to continue to be developed and financed, at least in part, by the turbines suppliers themselves.

The growth in U.S. wind turbine manufacturing capability and the drop in wind power plant installations led to an estimated over-capacity of U.S. turbine nacelle assembly capability of roughly $2.5 \mathrm{GW}$ in 2010, in comparison to $4 \mathrm{GW}$ of under-capacity in 2009 (Figure 11). Overcapacity is defined here as maximum turbine nacelle assembly capacity in the U.S. exceeding total turbine demand in the U.S. Because maximum factory utilization is uncommon, some level of over-capacity should not be considered problematic. On the other hand, actual over-capacity at U.S. nacelle assembly facilities likely exceeded these estimates because U.S. demand for wind turbines is also met with imports from other countries (see next section), leading to U.S. nacelle assembly facilities operating at well below their maximum capability in $2010{ }^{24}$ With maximum domestic turbine nacelle assembly capacity predicted by Bloomberg New Energy Finance (Bloomberg NEF 2011) to grow from 7.6 GW in 2010 to nearly $14 \mathrm{GW} / \mathrm{yr}$ by 2013 , overcapacity relative to U.S. turbine demand (not considering imports or exports of turbines) is anticipated to potentially grow to 5-6 GW/yr over the 2011 to 2013 period. Bloomberg NEF (2011) partially credits this increase to the support provided by the approximately $\$ 290$ million in Advanced Energy Manufacturing Tax Credits that were awarded in 2009: Siemens, Mitsubishi, Gamesa, Vestas, Nordex and Alstom were among the recipients. At the same time, under-utilization of maximum manufacturing capacity is not solely a U.S. phenomenon: UBS Limited (2010), for example, estimates a 50-60\% wind manufacturing factory utilization rate on a global basis.

\footnotetext{
${ }^{24}$ Exports of wind turbines from U.S. nacelle assembly facilities to other countries have the ability to reduce the estimated over-capacity, but as shown in the next section, U.S. exports have been relatively modest to date.
} 


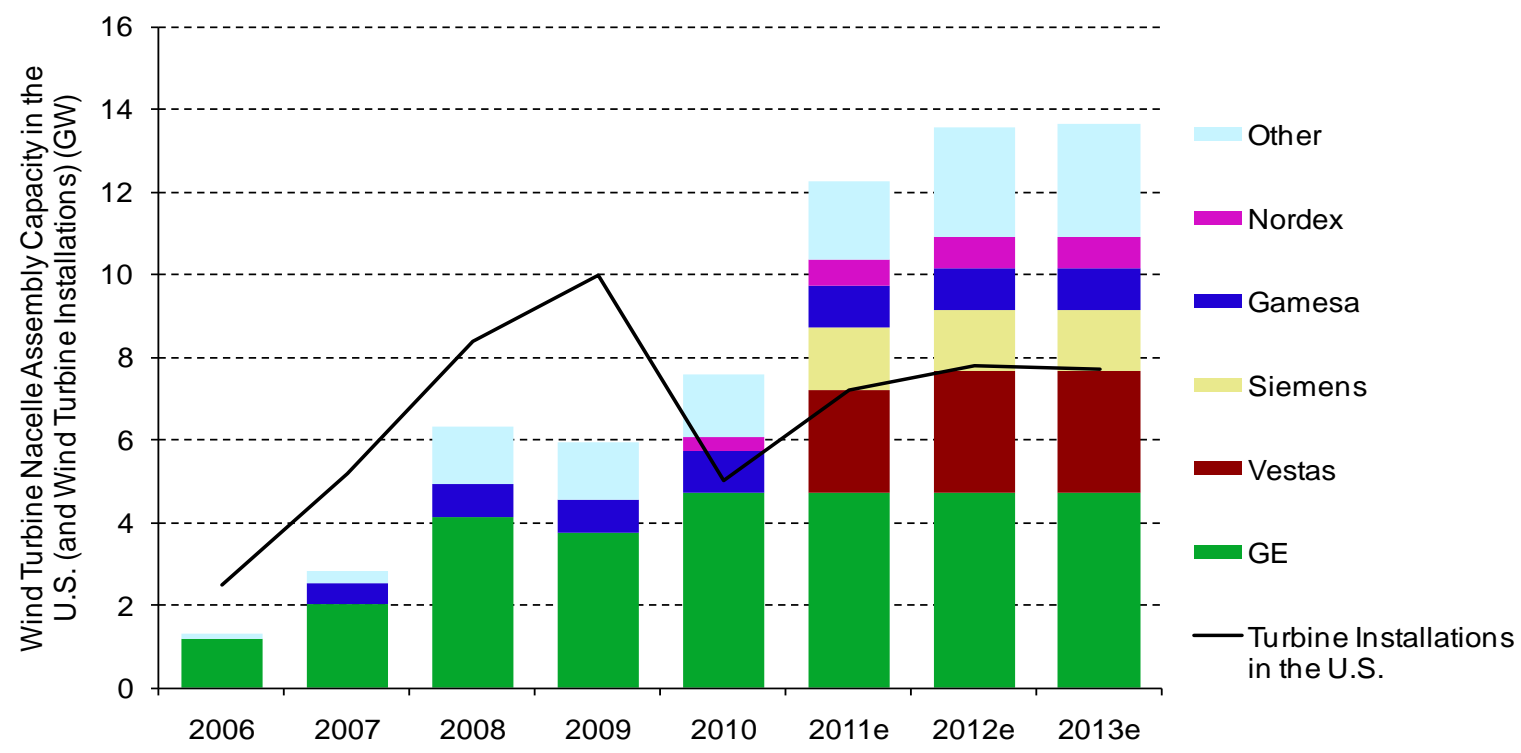

Note: "Other" includes Acciona, Alstom, Clipper, and Mitsubishi Source: Bloomberg New Energy Finance

Figure 11. Domestic Wind Turbine Nacelle Assembly Capacity and Demand

In addition to activity by OEMs, Figure 10 shows a considerable number of new component manufacturing facilities announced or opened in 2010, from both foreign and domestic firms and spanning the entire industry supply chain. Based on the data underlying Figure 10, Figure 12 segments the manufacturing facilities operating on U.S. soil by major component, including those that opened in 2010 (the figure excludes announced but not yet opened facilities). Though new and announced turbine and component manufacturing facilities are spread across the country, states that are installing substantial amounts of wind power capacity have sometimes attracted wind turbine and component manufacturing facilities. Additionally, a number of component manufacturers are choosing to locate near already-established large-scale OEMs; for example, in 2010, four component suppliers opened or announced facilities in Colorado, where Vestas has a number of manufacturing facilities, while two new component manufacturing facilities were opened (and one other announced but not yet opened) in Kansas, where the new Siemens turbine plant came on line. Even states with little installed wind power capacity have sometimes witnessed significant growth in wind-related manufacturing capacity (e.g., Arkansas), especially when those states are strategically positioned geographically near large wind power markets, or in locations that minimize transportation logistics challenges and costs. Workforce considerations, the cost of doing business, transportation costs, state and local incentives, and other factors also drive location decisions. 


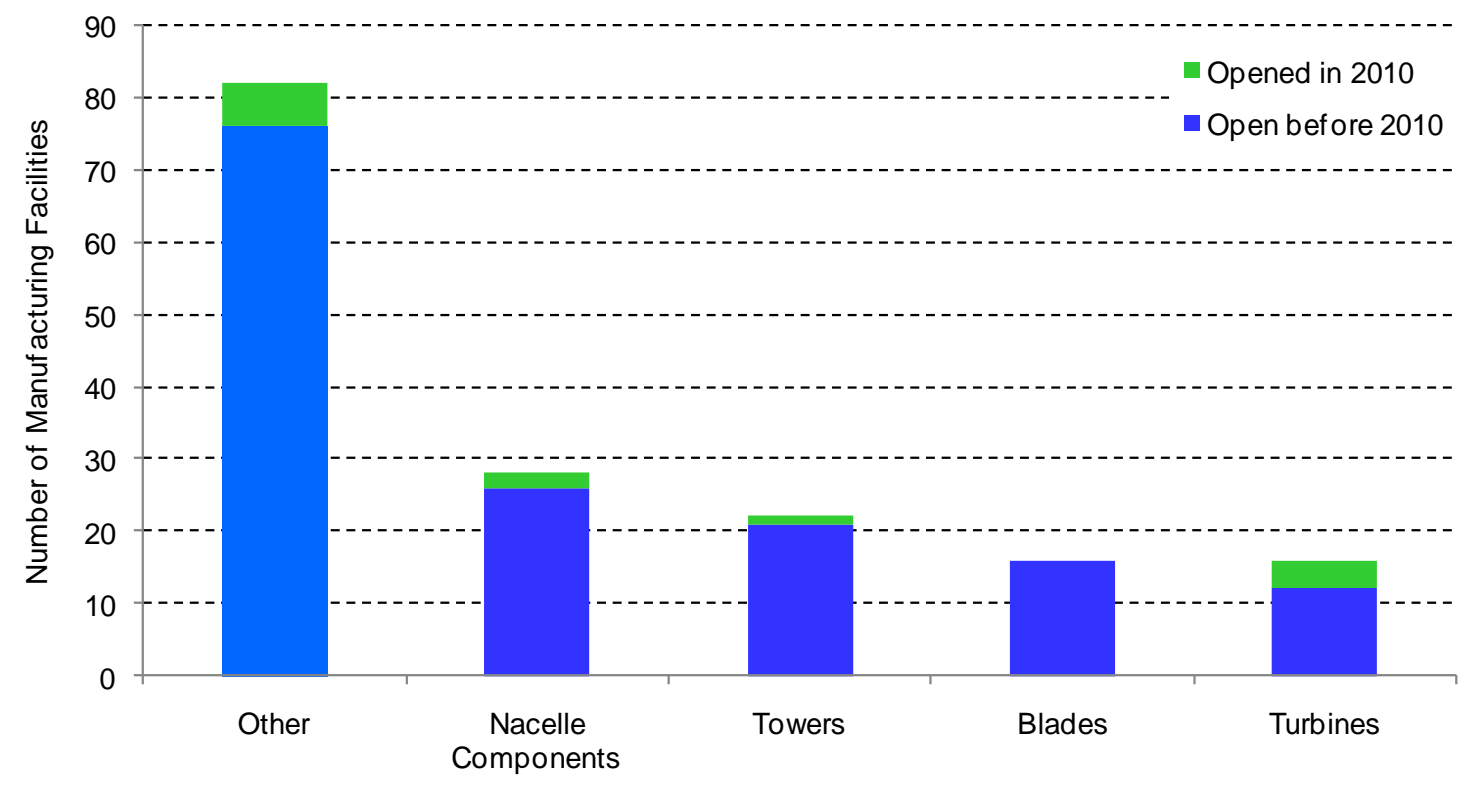

Note: Manufacturing facilities that produce multiple components are included in multiple bars.

Source: National Renewable Energy Laboratory

\section{Figure 12. Number of Operating Wind Turbine and Component Manufacturing Facilities on U.S. Soil}

Though domestic manufacturing capabilities have grown, the wind turbine and component manufacturing industry continues to face strong economic headwinds. As noted earlier, maximum nacelle assembly capacity in the U.S. (as well as component manufacturing in some cases) exceeded market demand in 2010, yielding relatively lower utilization of the production capacity of existing facilities, downward pressure on component and turbine pricing, and compressed manufacturer profit margins. In part as a result, 2010 saw the idling of Suzlon's Pipestone, Minnesota facility as well as downward revisions to revenue and profit forecasts throughout the wind turbine and component manufacturing supply chain.

AWEA (2011a) estimates that the entire wind energy sector directly and indirectly employed 75,000 full-time workers in the United States at the end of 2010 - about 10,000 fewer full-timeequivalent jobs than in 2009 , mostly due to the decrease in new wind power plant construction. The 75,000 jobs include manufacturing, project development, construction and turbine installation, operations and maintenance, transportation and logistics, and financial, legal, and consulting services. With expectations for moderate growth in wind power installations in 2011 relative to 2010, some manufacturers have begun the process of rehiring workers and resuming their expansion plans. As a result, notwithstanding the drop in total wind energy jobs in 2010 due primarily to reduced wind plant construction activity, AWEA (2011a) estimates that there was a modest increase in wind-related manufacturing jobs, bringing the total in that sub-sector back to 2008 levels of approximately 20,000 (AWEA 2011a). 


\section{A Growing Percentage of the Equipment Used in U.S. Wind Power Projects Has Been Sourced Domestically in Recent Years}

As a result of the foregoing developments in U.S.-based wind turbine and component manufacturing, the share of domestically manufactured wind turbines and components has grown in recent years, while the import share has witnessed a corresponding drop. More specifically, though the United States remains a large importer of wind power equipment, wind power capacity additions have outpaced equipment imports, yielding a growing share of domestic manufacturing content. These trends are supported by an analysis of data from the U.S. Department of Commerce. ${ }^{25}$

Figure 13 presents calendar-year data on estimated U.S. imports of wind-related equipment from 2005 through $2010 .{ }^{26}$ Specifically, the figure shows imports of wind-powered generating sets (i.e., nacelles and, when imported with the nacelle, other turbine components) as well as imports of turbine components that are shipped separately from the generating sets. ${ }^{27}$ The separate importation of selected wind turbine components includes towers as well as other wind turbine components (specifically, generators, blades and other components, and gearboxes). Estimates provided for these component-level imports in Figure 13 should be viewed with caution because the underlying data used to produce the figure are based on trade categories that are not exclusive to wind energy (e.g., they could include generators for non-wind applications). The componentlevel import estimates shown in Figure 13 therefore required assumptions about the fraction of larger trade categories likely to be represented by wind turbine components. The error bars included in Figure 13, meanwhile, account for uncertainty in these assumed fractions. ${ }^{28}$

\footnotetext{
${ }^{25}$ The Department of Commerce trade data are accessed through the U.S. International Trade Commission's (USITC) DataWeb, which compiles statistics from the Department of Commerce on imports and exports. The statistics can be queried online at: http://dataweb.usitc.gov/. The analysis presented here relies on the 'customs value' of imports as opposed to the 'landed value.' For more information on these data and their application to wind energy, see David (2009, 2010, 2011).

26 "Wind-powered generating sets" are in Harmonized Tariff Schedule (HTS) 8502.31.0000. This HTS provision includes both utility-scale and small wind turbines. Estimating separate wind turbine component imports is complicated by the fact that the HTS does not contain provisions that are exclusive to wind turbine components. Included in the analysis presented here are: HTS 7308.20.0000 - "towers and lattice masts"; HTS 8501.64.0020 "AC generators (alternators) from 750 to 10,000 kVA"; HTS 8412.90.9080 - "other parts of engines and motors"; HTS 8503.00.9545 - "parts of generators (other than commutators, stators, and rotors)"; HTS 8483.40.5010 - "fixed ratio speed changers"; and HTS 8483.40.5050 - "multiple and variable ratio speed changers."

${ }^{27}$ Wind turbine components such as blades, towers, generators, and gearboxes are included in the data on windpowered generating sets if shipped with the nacelle. Otherwise, these component imports are reported separately. ${ }^{28}$ Specifically, based on a review of the countries of origin for the imports, personal communications with USITC and AWEA staff, David (2010), and Wyden (2010), it is assumed that 95\% of the imports of "towers and lattice masts" are related to towers used in U.S. wind power plants across the entire 2005-2010 time period. The proportion of wind-related equipment in the five other relevant HTS provisions (i.e., wind turbine components other than towers) is assumed to increase linearly from $40 \%$ in 2005 to $55 \%$ in 2008, before dropping back to $40 \%$ in 2010 . This latter trend is intended to reflect the rapidly increasing imports of wind equipment from 2005-2008, and the subsequent decline in imports from 2008-2010. To reflect uncertainty in these proportions, a $\pm 15 \%$ variation is applied to the trade categories that include wind turbine components other than towers, and a $\pm 5 \%$ variation to the category that includes wind turbine towers.
} 


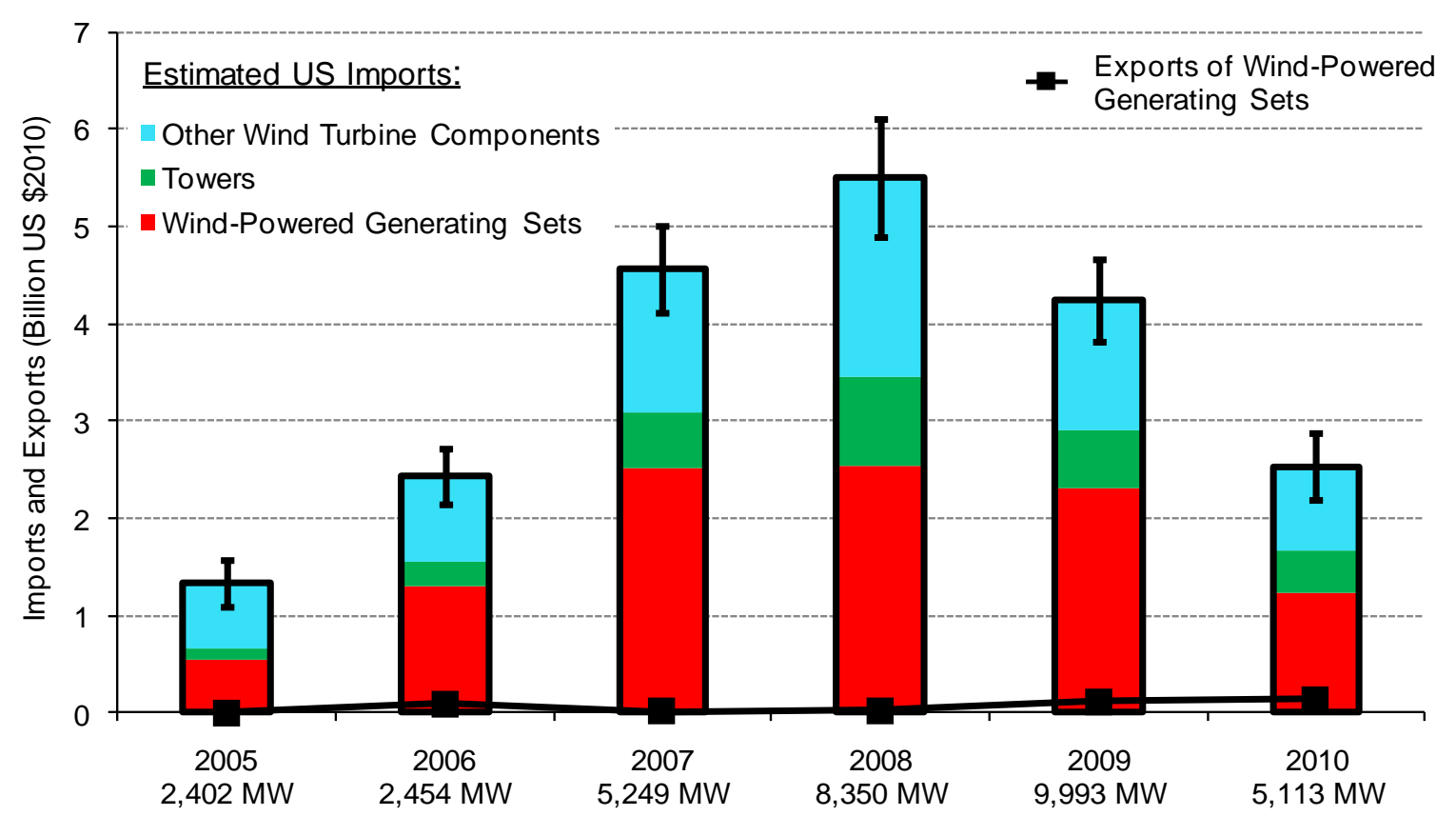

Source: Berkeley Lab analysis of data from USITC DataWeb: http://dataweb.usitc.gov

Figure 13. Estimated Imports of Wind-Powered Generating Sets, Towers, and Other Wind Turbine Components, as Well as Exports of Wind-Powered Generating Sets

As shown, estimated imports of wind-related equipment into the United States substantially increased from 2005-2008, before falling dramatically through 2010. These overall trends are driven primarily by changes in the share of domestically manufactured wind turbines and components (versus imports) as well as changes in the annual rate of wind power capacity installations and wind turbine prices.

Looking behind the import data presented in Figure 13 in more regional detail, Figure 14 shows a number of trends in the origin of the U.S. imports of wind-powered generating sets and towers. ${ }^{29}$ The primary source markets for wind-powered generating sets during the 2005-2010 period have been and continue to be the home countries of the major international turbine manufacturers: Denmark, Spain, Japan, India, and Germany, though there was a notable decline in the share of imports from Japan, Spain, and Germany from 2009 to 2010 and a simultaneous increase in the share of imports from Denmark and India. The share of imports of towers and lattice masts from Canada and Mexico, meanwhile, increased in 2010, with a corresponding drop in the share of imports from Asia, at least temporarily reversing the previous trend of increasing Asian imports, especially from China and Korea; the share of imports from Europe, meanwhile, has declined to negligible levels. ${ }^{30}$

\footnotetext{
${ }^{29}$ Only the origin of imports for "wind-powered generating" sets and "towers" are presented in Figure 14 because the other five trade categories that sum to "other wind turbine components" in Figure 13 are assumed to have smaller proportions of wind-related equipment.

${ }^{30}$ Over the entire 2005-2010 timeframe, the largest source countries for wind-powered generating sets were: Denmark (41\%), Spain (17\%), Japan (14\%), India (12\%), and Germany (8\%) (in 2010, the top three countries were Denmark (57\%), India (21\%), and Italy (7\%)). For the trade category that includes towers, the largest source
} 
Wind-Powered Generating Sets

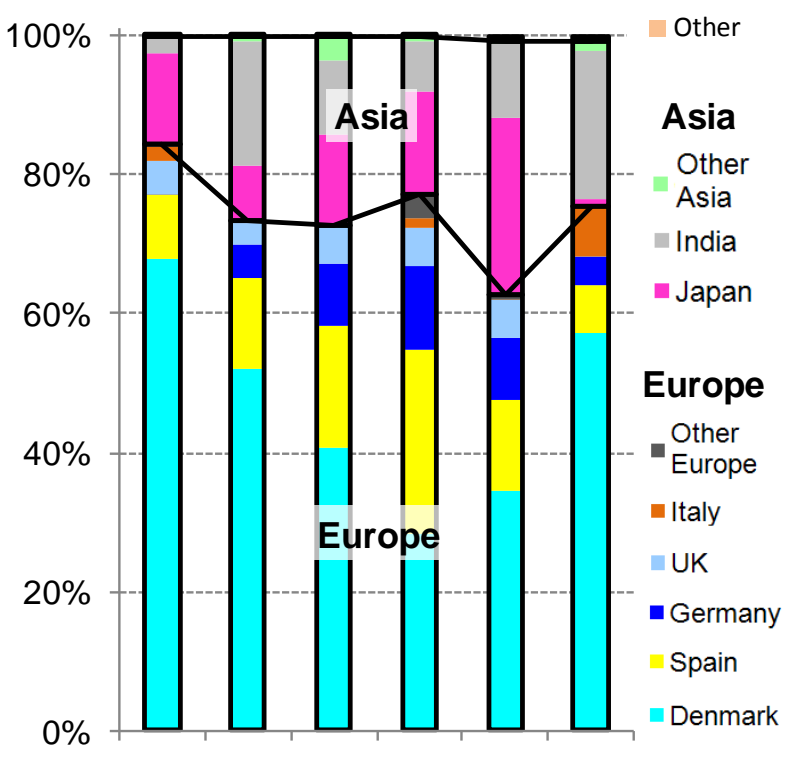

200520062007200820092010

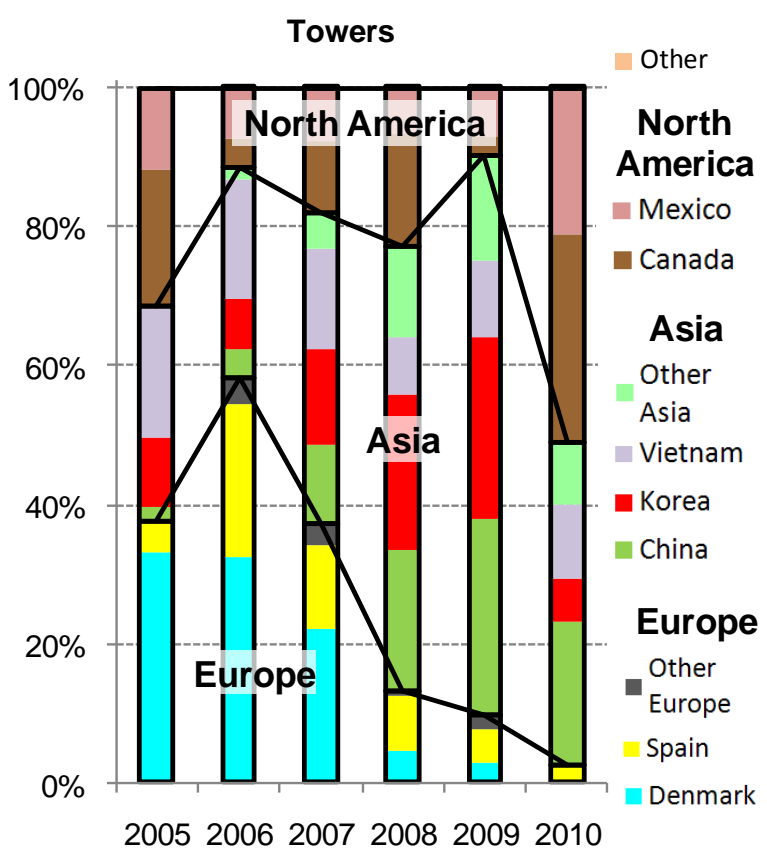

Source: Berkeley Lab analysis of data from USITC DataWeb: http://dataweb.usitc.gov

Figure 14. Origins of Imports of Wind-Powered Generating Sets and Towers

Exports of wind-powered generating sets from the United States are also shown in Figure 13, and have increased, rising from $\$ 15$ million in 2007 to $\$ 119$ million in 2009 , and again increasing to $\$ 142$ million in 2010. The largest destination markets for these exports over the entire 2005-2010 timeframe have included Canada (71\%), Mexico (11\%), China (8\%), and Chile (5\%), while 2010 exports were dominated by Canada (76\%) and Mexico (17\%). Wind turbine component exports (towers, blades, gearboxes, generators) are not shown in the figure because such exports are likely a small (and uncertain) fraction of the broader trade category totals. Regardless, it is clear from Figure 13 that the United States remained a sizable net importer of wind-powered generating sets over the entire 2005 to 2010 timeframe.

Though Figure 13 depicts a U.S. market that remains reliant on imports of wind power equipment, that reliance has declined over time as growth in installed wind power capacity has outpaced wind turbine and component imports. To estimate the percentage share of imports and domestic manufacturing over time, one must account for the fact that turbines, towers, and other components imported at the end of one year may not be installed until the following year. As such, in Figure 15 the combined imports of wind-powered generating and selected turbine components are determined by using a 4-month lag (i.e., monthly import data from September of the previous year to August of the current year are used to estimate the value of imports in wind turbine installations in the current year). Those import figures are then compared to total wind turbine equipment-related costs on a calendar-year basis. ${ }^{31}$ Data are averaged over two-year

countries from 2005-2010 were: China (18\%), Korea (17\%), Canada (13\%), Vietnam (12\%), and Denmark (11\%) (in 2010, the top three countries were Canada (30\%), Mexico (21\%), and China (21\%)).

${ }^{31}$ Total wind turbine costs $(\$ / \mathrm{kW})$ are assumed to equal approximately $75 \%$ of the average project-level costs reported later in this report in Figure 28, while wind turbine equipment-related costs are assumed to equal $85 \%$ of 
periods to further avoid "noise" in the resulting estimates. The error bars correspond to those in Figure 13, and represent the uncertainty in the proportion of wind-related equipment imports in certain larger trade categories.

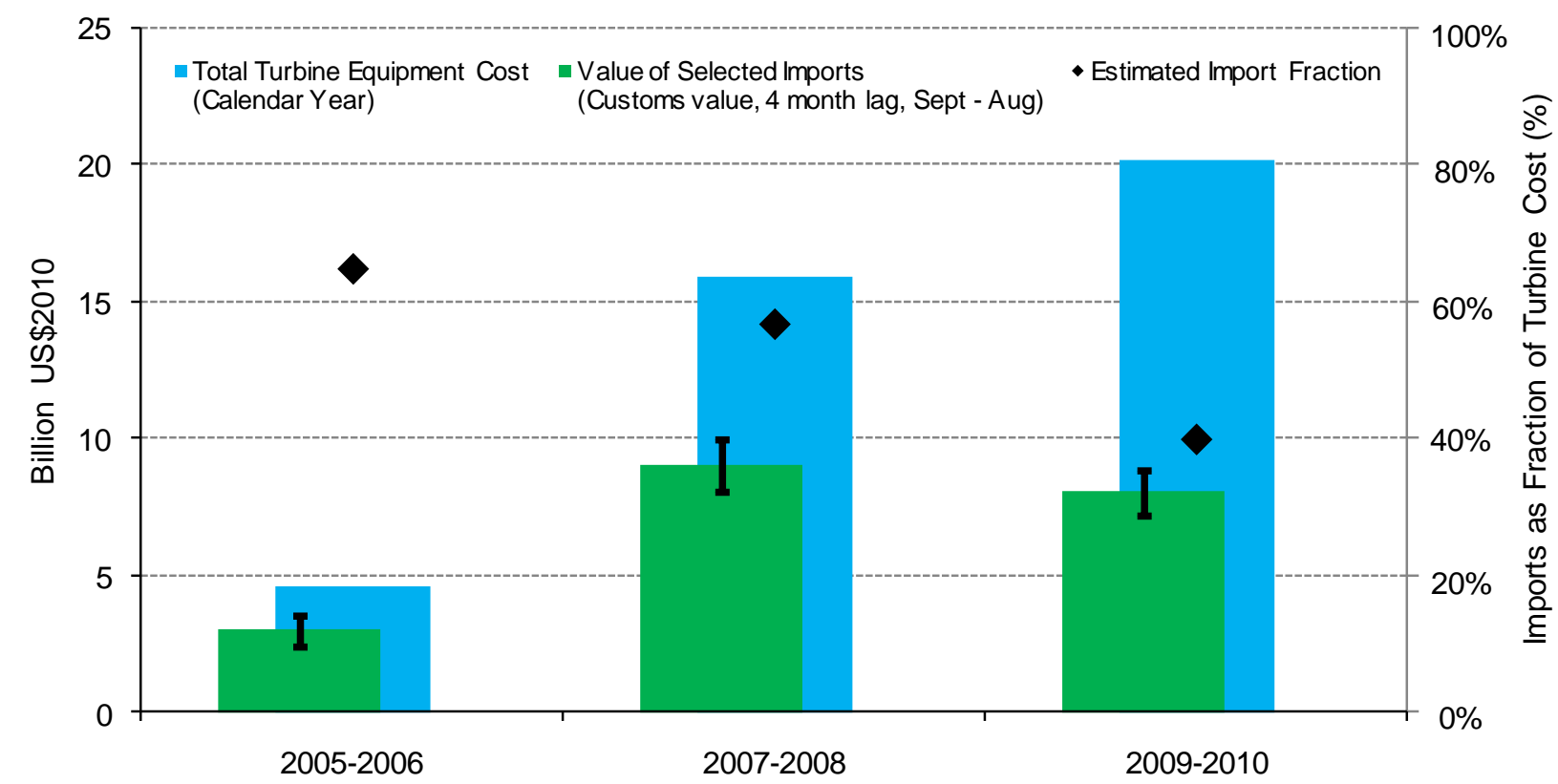

Figure 15. Estimated Wind Power Equipment Imports as a Fraction of Total Turbine Cost

Ultimately, when presented as a fraction of total equipment-related turbine costs in this fashion, the overall import fraction is found to have declined considerably, from $65 \%$ in $2005-2006$ to $40 \%$ in 2009-2010. Reporting these figures as a proportion of total wind project installed costs (not just wind turbine equipment-related costs) is also of interest, but is complicated by the fact that non-turbine balance-of-plant costs may also involve some level of imports. Nonetheless, if one simply assumes that $80 \%$ of non-turbine-equipment balance-of-plant costs derive from domestic sources with the remaining $20 \%$ from imports, then the import fraction for total wind project installed costs would equal 48\% in 2005-2006 and 32\% in 2009-2010.

These figures should be considered rough approximations for the reasons stated earlier, and may understate the wind power industry's reliance on turbine and component imports because it is possible that imports of wind power equipment are occurring under other trade categories that are not captured here. Nonetheless, these figures demonstrate that a growing amount of the equipment used in wind power projects has been sourced domestically in recent years. Whether that trend continues in the future may depend on the size and stability of the U.S. wind power market as well as the manufacturing strategies of emerging turbine manufacturers from Asia and elsewhere.

total wind turbine costs (with the remaining $15 \%$ consisting of transportation, project management, and other soft costs). To calculate total calendar-year wind turbine equipment-related costs, this wind turbine equipment-related cost figure in $\$ / \mathrm{kW}$ is multiplied by annual wind power capacity installations. 


\section{The Average Nameplate Capacity, Hub Height, and Rotor Diameter of Installed Wind Turbines Increased}

The average nameplate capacity of wind turbines installed in the United States in 2010 increased to roughly 1.79 MW (Figure 16), up from 1.74 MW in 2009 and $1.66 \mathrm{MW}$ in $2008 .{ }^{32}$ Since 1998-99, average turbine nameplate capacity has increased by $151 \%$, but growth in this metric has slowed in recent years due to the dominance of GE's 1.5 MW turbine and as a result of the logistical challenges associated with transporting larger turbines to project sites. ${ }^{33}$

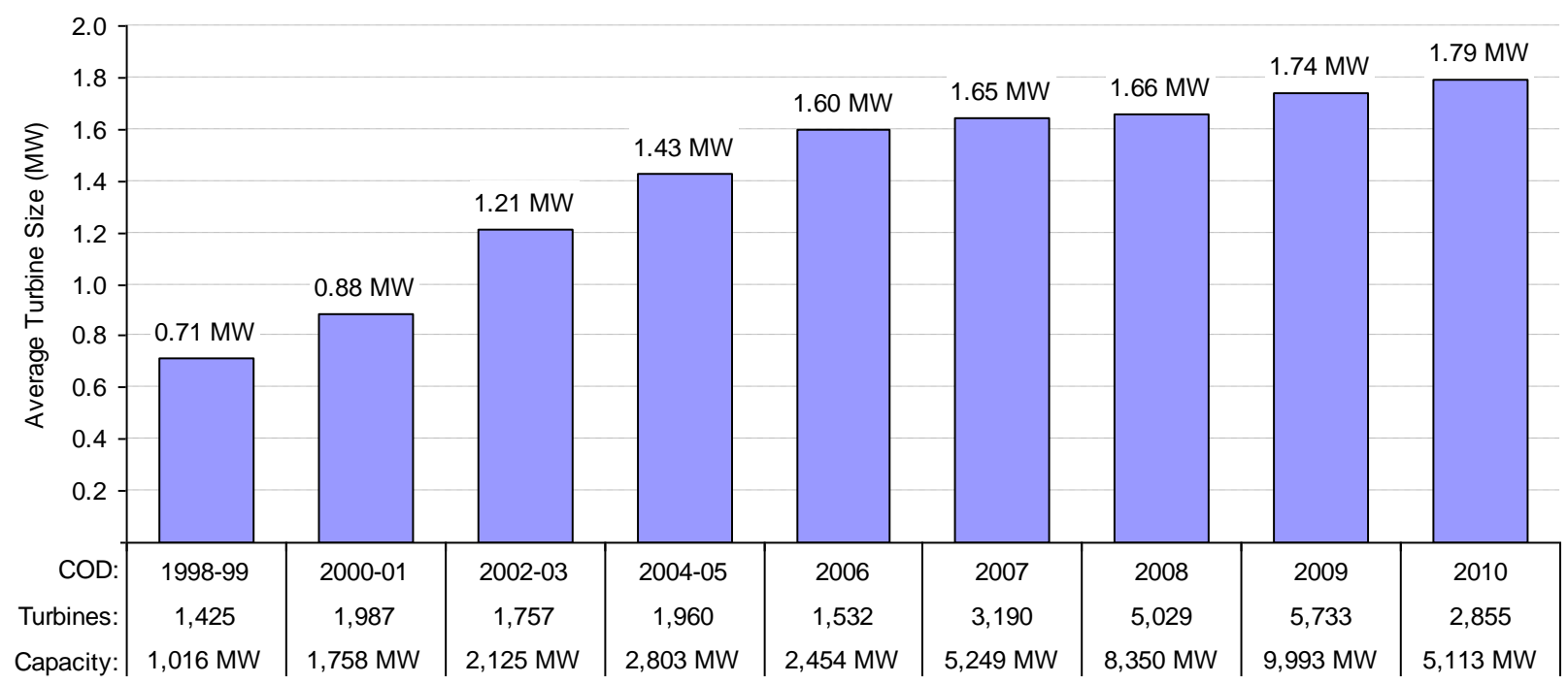

Source: AWEA project database

\section{Figure 16. Average Turbine Nameplate Capacity Installed During Period}

Table 5 shows how the distribution of turbine nameplate capacity has shifted over time: nearly $27 \%$ of all turbines installed in 2010 had a nameplate capacity larger than $2.0 \mathrm{MW}$, compared to almost $25 \%$ in $2009,19 \%$ in $2008,16 \%$ in both 2007 and 2006 , and just $0.1 \%$ or less in years prior to 2006. GE's 1.5/1.6 MW wind turbine remained by far the nation's most-popular turbine in 2010, with 1,679 units installed (1,432 of the $1.5 \mathrm{MW}$ version, and 247 of the $1.6 \mathrm{MW}$ version), equating to $50 \%$ of all wind power capacity installed in $2010 .^{34}$

\footnotetext{
${ }^{32}$ Modest differences exist between these figures and those presented by AWEA (2011a) for the reasons discussed in footnote 2.

${ }^{33}$ Figure 16 (as well as a number of the other figures and tables included in this report) combines data into both oneor two-year periods in order to avoid distortions related to small sample size in the PTC lapse years of 2000, 2002, and 2004; though not a PTC lapse year, 1998 is grouped with 1999 due to the small sample of 1998 projects.

${ }^{34}$ A number of existing GE 1.5 MW turbines installed in earlier years were also upgraded to $1.6 \mathrm{MW}$ in 2010 , but data on how many or which turbines were upgraded are not publicly available, and so this change in nameplate capacity is not reflected in the data presented in this report.
} 
Table 5. Size Distribution of Number of Turbines over Time

\begin{tabular}{|c|c|c|c|c|c|c|c|c|c|c|}
\hline & Years: & 1998-99 & 2000-01 & 2002-03 & 2004-05 & 2006 & 2007 & 2008 & 2009 & 2010 \\
\hline & \# MW: & 1,016 & 1,758 & 2,125 & 2,803 & 2,454 & 5,249 & 8,350 & 9,993 & 5,113 \\
\hline & turbines: & 1,425 & 1,987 & 1,757 & 1,960 & 1,536 & 3,190 & 5,029 &, 733 & 855 \\
\hline & $<0.5$ & $1.3 \%$ & $0.4 \%$ & $0.5 \%$ & $1.8 \%$ & $0.7 \%$ & $0.0 \%$ & $0.5 \%$ & $0.2 \%$ & $0.1 \%$ \\
\hline & $0.51-1.0$ & $98.5 \%$ & $73.9 \%$ & $43.4 \%$ & $18.5 \%$ & $10.7 \%$ & $11.2 \%$ & $10.3 \%$ & $4.6 \%$ & $0.2 \%$ \\
\hline 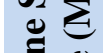 & $1.01-1.5$ & $0.0 \%$ & $25.4 \%$ & 43. & $56.0 \%$ & $54.0 \%$ & $49.2 \%$ & $53.5 \%$ & $49.4 \%$ & $52.8 \%$ \\
\hline & $1.51-2.0$ & $0.3 \%$ & $0.4 \%$ & $12.5 \%$ & $23.6 \%$ & $18.4 \%$ & $23.1 \%$ & $16.3 \%$ & $21.1 \%$ & $20.2 \%$ \\
\hline & $2.01-2.5$ & $0.0 \%$ & $0.0 \%$ & $0.0 \%$ & $0.1 \%$ & $16.2 \%$ & $15.2 \%$ & $16.8 \%$ & $23.2 \%$ & $24.1 \%$ \\
\hline & 2.51-3.0 & $0.0 \%$ & $0.0 \%$ & $0.1 \%$ & $0.0 \%$ & $0.0 \%$ & $1.3 \%$ & $2.5 \%$ & $1.4 \%$ & $2.5 \%$ \\
\hline
\end{tabular}

Source: AWEA project database

In addition to nameplate capacity ratings, average hub heights and rotor diameters have also scaled with time. The average hub height of wind turbines installed in the United States in 2010 was 79.8 meters (Figure 17), up from 78.9 meters for projects installed in 2009 and 78.5 meters for projects installed in 2008. Since 1998-99, the average turbine hub height has increased by $43 \%$ (or 24.1 meters), though year-on-year growth has slowed in the more recent years. Average rotor diameters have increased at a more rapid pace: the average rotor diameter of wind turbines installed in the United States in 2010 was 84.3 meters (Figure 17), up from 81.6 meters in 2009 and 79.3 meters in 2008. Since 1998-99, the average rotor diameter has increased by $76 \%$ (or 36.4 meters). Although the vast majority of turbines installed in 2010 (99.2\% of total capacity) and all of the turbines installed in 2009 had hub heights no greater than 80 meters, 17 turbines installed in 2010 (totaling $38.5 \mathrm{MW}$ ) had hub heights of 100 meters. With respect to rotor diameters, less than $6 \%$ of the new wind capacity installed in 2009 involved turbines with diameters of at least 95 meters, and only one turbine (equaling $0.02 \%$ of newly installed capacity) was 100 meters or larger (101 meters). In 2010, however, those percentages grew substantially, with $18 \%$ of new capacity involving rotor diameters of at least 95 meters and $10 \%$ of new capacity at 100 meters or larger.

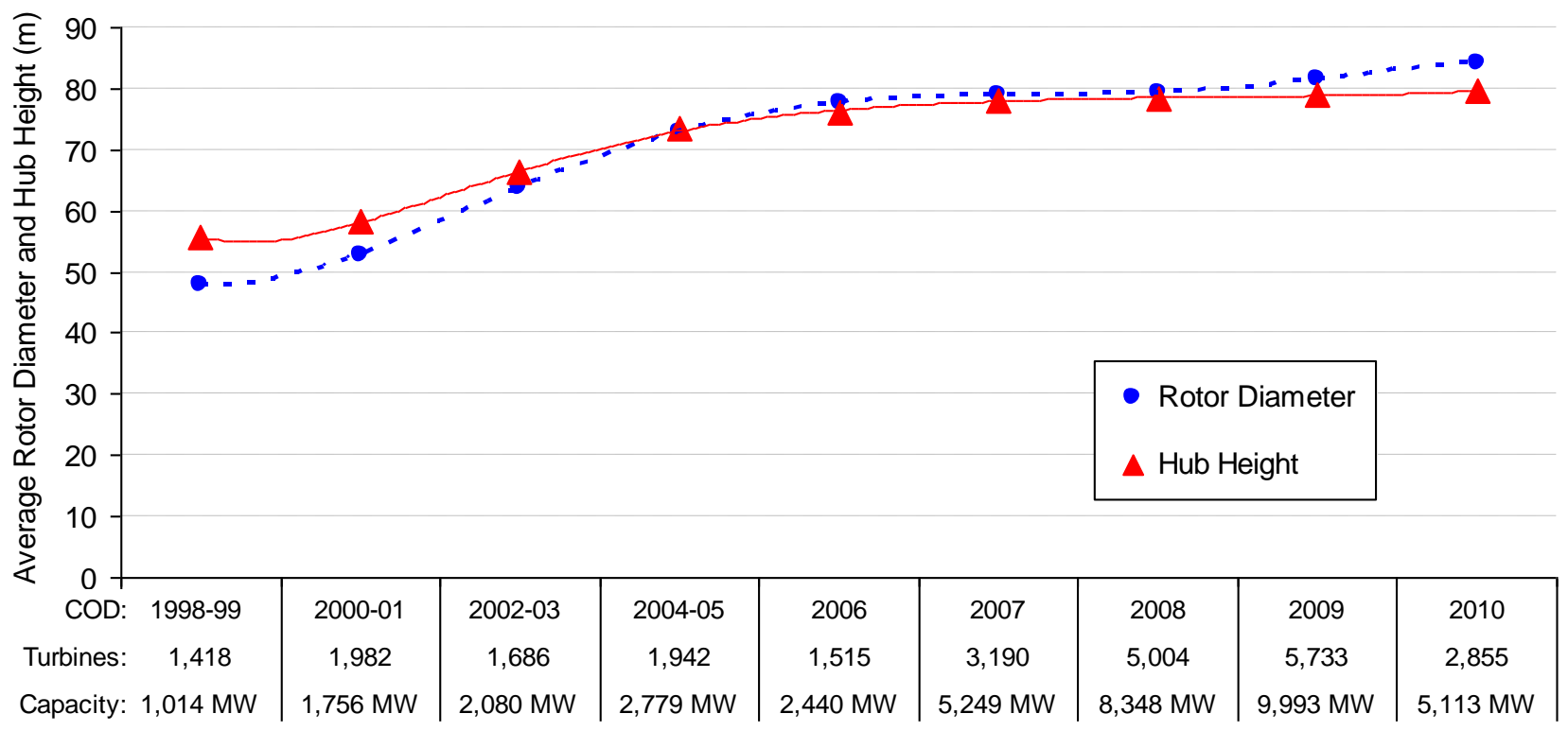

Source: Berkeley Lab

Figure 17. Average Rotor Diameter and Hub Height Installed During Period 
These trends in hub height and rotor scaling are one of several factors impacting the project-level capacity factors highlighted later in this report. Moreover, industry expectations as well new turbine announcements (especially to serve lower-wind-speed sites) suggest that significant further scaling, especially in rotor diameter, is anticipated in the near term.

\section{Consolidation among Wind Project Developers Continued, Albeit at a Slower Pace}

Consolidation on the development end of the wind power business has slowed since 2007 . Focusing on announced acquisition and investment activity among U.S. wind project developers, ${ }^{35}$ at least three significant transactions involving more than $10 \mathrm{GW}$ of indevelopment wind power projects (also called the development "pipeline") were announced in 2010. This compares to six transactions involving roughly $18 \mathrm{GW}$ of in-development wind power projects announced in 2009, five transactions and $19 \mathrm{GW}$ in 2008, 11 transactions and 37 GW in 2007, and 12 transactions and $34 \mathrm{GW}$ in 2006. In 2005, eight transactions totaling 11 GW were announced, while only four transactions totaling less than $4 \mathrm{GW}$ were completed from 2002 through 2004.

The more-subdued pace of activity since 2007 may be a reflection of several factors, including the simple fact that many of the prime targets for investment and/or acquisition were acquired in earlier years. In addition, some traditional buyers of U.S. wind assets may have decided to reign in new investments following aggressive purchases made in previous years, while some developers who might otherwise entertain offers may be holding out for better pricing as the market recovers. Finally, early-stage developers are increasingly selling portions of their project pipeline, injecting cash to continue development activity and avoiding all-out acquisition.

\section{Project Finance Environment Improved Throughout 2010}

After a rather dismal project-finance environment in 2009 (which contributed to the slowdown in 2010 wind power capacity additions due to the natural lag in capital-intensive infrastructure development), the environment for wind power project finance improved steadily throughout 2010, in both the tax equity and debt markets.

By the end of the year, there were reportedly 16 third-party tax equity providers back in the market (Chadbourne \& Parke 2010, US PREF 2010, Mintz Levin 2010) - up from just a handful that had stayed the course throughout the depths of 2009 - and the amount of tax equity committed to wind power projects was somewhere on the order of $\$ 4$ billion, ${ }^{36}$ more than twice

\footnotetext{
${ }^{35}$ Only announced transactions that are believed to involve $500 \mathrm{MW}$ or more of in-development U.S. wind power projects are included. Not included are transactions in which one developer purchases another developer's project pipeline, without an actual acquisition of or investment in that developer.

${ }^{36}$ AWEA (2011a) reports that $\$ 2.7$ billion in tax equity for wind closed in 2010 , with another $\$ 820$ million committed, for $\$ 3.5$ billion total. Meanwhile, John Eber from JPMorgan - one of the largest and most active tax equity investors in the market - notes that tax equity investments in both wind and solar approached $\$ 5$ billion in 2010 (Eber 2011), and others quote JPMorgan estimates of roughly \$4 billion in tax equity committed to wind projects in the first nine months of 2010 (Chernova 2010).
} 
as much as was invested in 2009 and exceeding levels invested in both 2007 and 2008. One testament to the rebound in the market is that NextEra Energy - which has historically absorbed the tax benefits from its wind power portfolio on its own balance sheet - tapped into third-party tax equity twice in 2010 (once through a relatively rare "pay-as-you-go" structure) to refinance four of its projects totaling $478.5 \mathrm{MW} .{ }^{37}$ Perhaps just as notable, Google is a tax equity investor in one of these NextEra partnerships, marking the entry of this unconventional investor into wind power finance. ${ }^{38}$ Other notable events include the first few lease financings of wind power projects (leasing is not compatible with the PTC, and therefore had not previously been used for wind power projects): the 25.3 MW Ridgewind project in Minnesota announced a single investor sale/leaseback with Union Bank in July 2010, followed by the 402 MW Alta II-IV projects in California (announcing a leveraged lease with Citibank, who later brought in Google to co-invest in Alta IV), the 101.2 MW Hatchet Ridge project in California (announcing a leveraged lease with MetLife), and the $150 \mathrm{MW}$ Alta 1 project (announcing a sale/leaseback with GE and Union Bank).

Digging beneath these positive developments, however, reveals a tax equity market that was somewhat more fragile in 2010 than it seemed on the surface. Although the availability of funds appeared to be back, unlevered tax equity yields remained higher than pre-crisis levels (though lower than levels seen in early 2009), and reportedly closed out the year somewhere between 7.5\% and 8.5\% for the least-risky projects (Chadbourne \& Parke 2010, Bloomberg NEF 2011). In addition, several tax equity investors active in 2010 reportedly would not have invested absent the Section 1603 30\% cash grant from the Treasury (Chadbourne \& Parke 2010, US PREF 2010), which reduces an investor's risk and time horizon relative to the PTC (not to mention the amount of tax equity required to finance a wind power project, since, with the grant, tax equity need only monetize depreciation deductions). Thus, without the $30 \%$ cash grant, there would have been greater demand for tax equity (to monetize the PTC or Investment Tax Credit (ITC) in addition to accelerated depreciation) yet fewer tax equity investors in the market - a combination that would have placed upward pressure on tax equity yields.

In part because of the Section 1603 Treasury grant program, activity in the debt market was brisk in 2010, with AWEA (2011a) reporting 29 loans totaling $\$ 8.4$ billion in support of nearly 5,600 MW of wind power capacity. By the end of the year, as many as 30 banks were reportedly active in the wind power market, providing construction financing, grant bridge loans, and term financing (Chadbourne \& Parke 2010). The tenor of term debt increased from the 5- to 7-year "mini-perms" seen in 2009 to 8- to 12-year "maxi-perms" in early 2010 and, by the end of the year, even fully amortizing loans over terms of 15 years or longer. ${ }^{39}$ Spreads over the London

\footnotetext{
${ }^{37}$ In May 2011, NextEra announced that it had raised additional third-party tax equity - also through a "pay-as-yougo" structure - for a portfolio of 483 MW of wind projects located in five states. In June 2011, NextEra announced its first third-party tax equity partnership structured around the Section 1603 cash grant, for the 150 MW White Oak project in Illinois.

${ }^{38}$ In April 2011 Google announced its second tax equity investment in a wind project - a \$100 million investment in the 845 MW Shepherds Flat project in Oregon. Its third tax equity investment in wind - \$55 million in the Alta IV project in California - followed in May 2011.

${ }^{39}$ Repayment of a "mini-perm" loan (as well as the somewhat-lengthier "maxi-perm") is based on a long-term amortization (e.g., 15 years), but such loans mature well in advance of the full amortization period (e.g., in just 7 years), requiring the borrower to make a balloon payment at maturity (the balloon payment is typically funded by
} 
Interbank Offered Rate (LIBOR) fell by $50-75$ basis points, ${ }^{40}$ to somewhere in the range of 200300 basis points depending on the quality of the deal (Project Finance 2011, Chadbourne \& Parke 2010), and with long-term fixed-for-floating swap rates below 3.5\%, all-in interest rates of around $6 \%$ were achievable. In addition to banks, institutional lenders (e.g., insurance companies) re-entered the market in 2010, offering term loans as long as 20 years at spreads of 300-350 basis points over the corresponding Treasury yield, which also equates to an all-in interest rates of roughly 6\% (Chadbourne \& Parke 2010).

Meanwhile, the Section 1705 DOE loan guarantee program - part of the Recovery Act package closed on two wind project loan guarantees in 2010 and issued conditional commitments for two more in the first half of 2011. ${ }^{41}$ A $\$ 117$ million guarantee for the $30 \mathrm{MW}$ Kahuku project in Hawaii closed in July 2010, while a partial guarantee of a \$1.3 billion loan for what would currently be the largest wind power project in the U.S. - the previously mentioned $845 \mathrm{MW}$ Shepherds Flat project in Oregon - closed in December. The highly structured Shepherds Flat loan is syndicated among 26 commercial banks and institutional lenders, and the $80 \%$ DOE guarantee reportedly reduced the cost of the financing by nearly 200 basis points (Tempkin 2010). Finally, in the first half of 2011, the DOE provided conditional guarantees for a $\$ 102$ million loan to the 50.6 MW Record Hill project in Maine, and for a \$169 million loan to the 99 MW Granite Reliable project in New Hampshire.

Looking ahead to 2011, the eligibility deadline for the Section 1603 Treasury grant program was extended for a single year as part of the Tax Relief, Unemployment Insurance Reauthorization, and Job Creation Act of 2010 that was signed into law in mid-December 2010. With the extension, wind power projects must be under construction by the end of 2011 and placed in service by the end of the 2012 in order to qualify for the grant. This extension should help the project finance environment (and in particular the tax equity market) to continue to improve through 2011, by mitigating the amount of tax equity required to finance the industry's expansion. On the other hand, the very same legislation also provided for $100 \%$ bonus depreciation for projects constructed in 2011 (and 50\% bonus depreciation for projects built in 2012). Depreciating in a single year (i.e., expensing) the cost of investment in a wind power project will immediately absorb some of the tax appetite in the market that would otherwise be spread over several years. Increased solar installations - which are also eligible for bonus depreciation - are anticipated to absorb additional tax equity that would otherwise be available to the wind energy sector. Whether these developments will have a significant negative impact on the immediate availability of tax equity for wind power projects remains to be seen.

refinancing). In contrast, fully amortizing loans are repaid completely through periodic principal and interest payments over the full term of the loan (i.e., no balloon payment required).

40 The up-front fees charged by banks also reportedly fell by a similar amount, to around 200-225 basis points (Project Finance 2011).

${ }^{41}$ As of late-June 2011, these are the only four wind projects to have received commitments through this program (and could end up being the only four, as recipients of Section 1705 loan guarantees must commence construction by September 30, 2011). Earlier, in 2009, Nordic Windpower received a \$16 million conditional commitment, but for the purpose of expanding its manufacturing facility in Idaho (i.e., the commitment was not related to a specific wind project). This loan guarantee has not closed to date, perhaps due to Nordic's recent decision to relocate its operations to the Kansas City area. 


\section{IPP Project Ownership Remained Dominant, while Utility and Community Ownership Held Steady}

Independent power producers (IPPs) continued to dominate the ownership of wind power projects in 2010, owning 83\% (4,268 MW) of all new capacity additions (Figure 18). Nearly $15 \%$ of the total wind power capacity additions in 2010 are owned by local electric utilities, with investor-owned utilities (IOUs) owning $602 \mathrm{MW}$ and publicly owned utilities (POUs) owning another $152 \mathrm{MW}$. Community wind power projects - defined here as projects using turbines over $100 \mathrm{~kW}$ in size and completely or partly owned by towns, schools, commercial customers, or farmers, but excluding publicly owned utilities - constitute the remaining $2 \%$ of new capacity, with $91 \mathrm{MW} .^{42}$ Of the cumulative installed wind power capacity at the end of 2010, IPPs owned $83 \%(33,432 \mathrm{MW})$, with utilities contributing 15\% (4,866 MW for IOUs and 1,223 MW for POUs), and community ownership just $2 \%$ (745 MW).
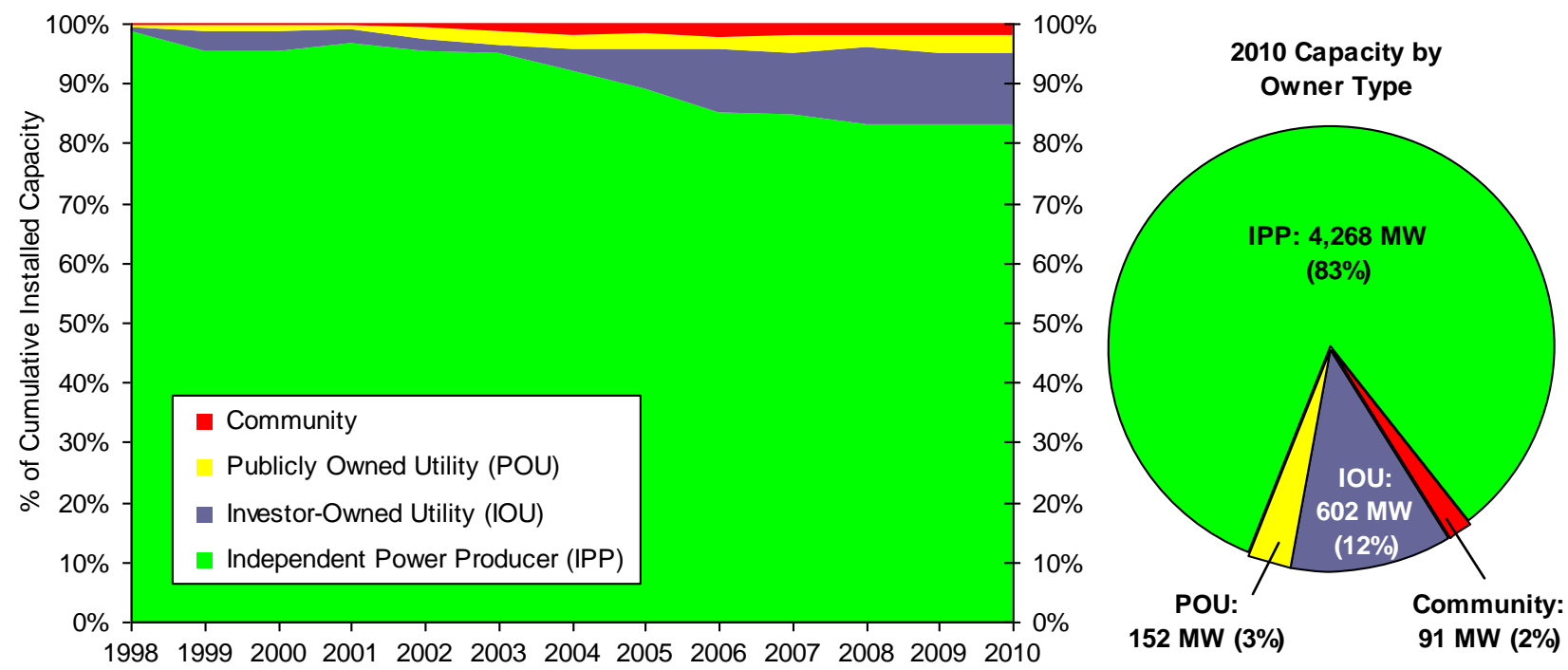

Source: Berkeley Lab estimates based on AWEA project database

Figure 18. Cumulative and 2010 Wind Power Capacity Categorized by Owner Type

The dominance of IPP ownership, and the more recent trend towards increased utility ownership since the mid 2000s, has been driven by several factors. Up until the Internal Revenue Service (IRS) clarified the issue in 2005, some IOUs were uncertain as to whether they could claim the PTC on utility-owned wind power projects (due to the requirement that PTC-eligible power must be sold to an unrelated party - in 2005 the IRS clarified that ratepayers are indeed unrelated parties). As the tax equity market dried up in the wake of the financial crisis of 2008/2009, however, IOUs were left as one of the few natural wind project investors with a steady and sizable tax liability. More broadly, when wind energy was a small part of the generation mix, some utilities felt that buying wind power was less risky than owning wind power projects. As

\footnotetext{
42 AWEA's 2010 Annual Market Report characterizes 5.6\% of 2010 capacity additions as community wind projects (AWEA 2011a), rather than the $2 \%$ presented here. This difference is attributable to the fact that AWEA's definition of community wind includes projects owned by publicly owned utilities, and AWEA also includes projects comprised of $100 \mathrm{~kW}$ turbines.
} 
utilities have gained comfort with wind power over the years, however, their interest in ownership has increased for several reasons: IOUs are typically allowed to earn a regulated return on project ownership (i.e., by adding it to their rate base) but not on power purchases; credit rating agencies have at times considered long-term power purchase agreements to be debtlike instruments, thereby potentially negatively impacting a utility's credit rating; and ownership places the utility in a position of greater control over project development and operations. As a result of these drivers, utility ownership may continue to increase in the coming years.

\section{Long-Term Contracted Sales to Utilities Remained the Most Common Off- Take Arrangement, but Scarcity of Power Purchase Agreements Drove Continued Merchant Development}

Electric utilities continued to be the dominant off-takers of wind power in 2010 (Figure 19), either owning (15\%) or buying (58\%) power from $72 \%$ of the new capacity installed last year (with the $72 \%$ split between $41 \%$ IOU and $31 \%$ POU). On a cumulative basis, utilities own $(15 \%)$ or buy $(49 \%)$ power from $64 \%$ of all wind power capacity installed in the United States (with the $64 \%$ split between $44 \%$ IOU and $20 \%$ POU). This $64 \%$ combined utility market share is unchanged from two years ago (in 2008), though the IOU/POU split has shifted since then, with the IOU market share dropping by $4 \%$ and the POU market share increasing by $4 \%$.
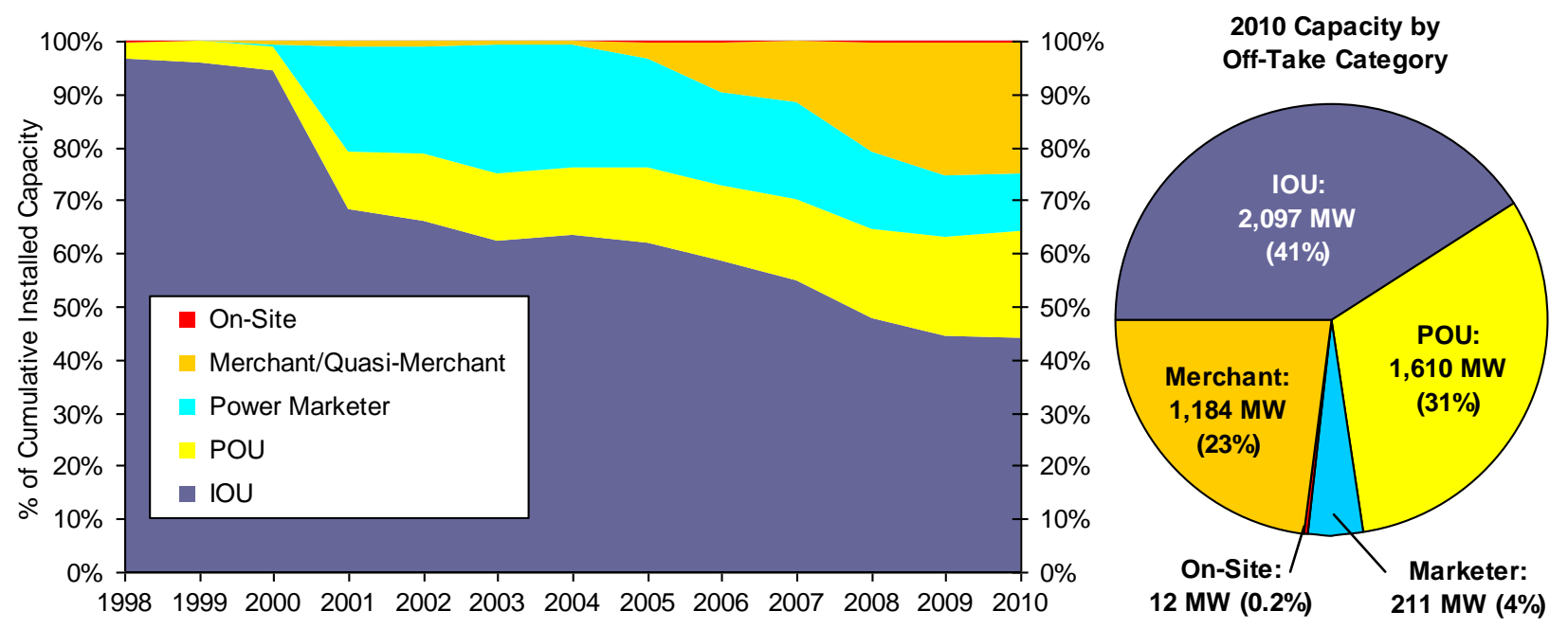

Source: Berkeley Lab estimates based on AWEA project database

Figure 19. Cumulative and 2010 Wind Power Capacity Categorized by Power Off-Take Arrangement 
The role of power marketers - defined here as corporate intermediaries that purchase power under contract and then re-sell that power to others, sometimes taking some merchant risk ${ }^{43}-$ in the wind power market has waned somewhat in recent years. In 2010, power marketers purchased the output of just $4 \%$ of the new wind power capacity, with $11 \%$ of the cumulative wind power capacity being sold to these entities.

Merchant/quasi-merchant projects were less-prevalent in 2010 than they have been in recent years, accounting for $23 \%$ of all new capacity (compared to 36\% in 2009 and 39\% in 2008) and $25 \%$ of cumulative capacity. Merchant/quasi-merchant projects are those whose electricity sales revenue is tied to short-term contracted and/or wholesale spot electricity market prices (with the resulting price risk commonly hedged over a 5- to 10 -year period ${ }^{44}$ ) rather than being locked in through a long-term PPA. With power prices remaining low in 2010 and PPAs in relatively short supply, it is likely that most of the merchant/quasi-merchant wind power projects built in 2010 are merchant by necessity rather than by choice. Specifically, many of these projects may have had to deploy turbines ordered prior to the financial crisis, or may have been built in part to take advantage of the Treasury Grant Program (which, only later, was extended for an additional year), and are presumably actively seeking long-term PPAs to provide greater revenue stability; some of these projects may therefore not remain merchant for a lengthy period.

Finally, roughly $12 \mathrm{MW}$ of the wind power additions in 2010 that used turbines over $100 \mathrm{~kW}$ in size were interconnected on the customer side of the utility meter, with the power being consumed on site rather than sold.

\footnotetext{
${ }^{43}$ Power marketers are defined here to include not only traditional marketers such as PPM Energy (now part of Iberdrola), but also the wholesale power marketing affiliates of large investor-owned utilities (e.g., PPL Energy Plus or FirstEnergy Solutions), which may buy wind power on behalf of their load-serving affiliates. Direct sales to end users (e.g., the 25.5 MW Stetson expansion project in Maine sells half of its output directly to Harvard University under a 15-year contract; the $150 \mathrm{MW}$ Garden Wind project in Iowa sells $114 \mathrm{MW}$ of power to Google under a 20 year contract) are also included in this category, because in these few limited cases the end-user is effectively acting as a power marketer.

${ }^{44}$ Hedges are often structured as a "fixed-for-floating" power price swap - a purely financial arrangement whereby the wind power project swaps the "floating" revenue stream that it earns from spot power sales for a "fixed" revenue stream based on an agreed-upon strike price. For some projects (especially where natural gas is virtually always the marginal supply unit), the hedge is structured in the natural gas market rather than the power market, in order to take advantage of the greater liquidity and longer terms available in the forward gas market.
} 


\section{Price, Cost, and Performance Trends}

\section{Wind Power Prices from Projects Installed in 2010 Were Higher, but Relief Is on the Way}

Although some of the upward cost pressures facing the industry in recent years - namely, cost pressures related to the "sellers' market" enabled by a shortage of wind turbines - have eased considerably since 2008 (e.g., see later section on wind turbine pricing), such relief has thus far been slow to work its way through the project development pipeline to impact average historical wind power prices. As such, 2010 was - overall - another year of higher wind power prices. One reason is that many projects built in 2010 may have entered into turbine supply agreements in 2008 (i.e., at the height of the market), and likely established the price terms of power purchase agreements at a similar point in time. A second driver of higher average prices from projects built in 2010 is the relative prevalence of projects built in California - by far the highestprice region in our sample, as shown later in Figure 22. Finally, there has been a general trend towards building out lower wind speed sites, as a result of various policy influences (e.g., RPS policies in low-wind states, federal cash grants not linked to performance) and other factors (e.g., transmission constraints) discussed later in the section on wind project performance. Regardless of the drivers, it should be emphasized that historical price trends need not be indicative of current or future market conditions. For example, indications suggest that lower wind power prices will accompany projects built in the near future, following the substantial declines in wind turbine prices reported later.

Berkeley Lab collects data on wind power sales prices from the sources listed in the Appendix, resulting in a dataset that consists of price data for 232 wind power projects installed between 1998 and the end of 2010 . These projects total 17,033 MW, or $44 \%$ of the wind power capacity brought on line in the United States over the 1998-2010 timeframe. ${ }^{45}$ The dataset excludes merchant plants and projects that sell renewable energy certificates (RECs) separately (see page 42 for REC pricing trends). The prices in the dataset therefore reflect the bundled price of electricity and RECs as sold by the project owner under a power purchase agreement. Because these prices are suppressed by the receipt of available state and federal incentives (e.g., the prices reported here would be at least \$20/MWh higher without the PTC / ITC / Treasury Grant), and are also influenced by various local policies and market characteristics, they do not represent wind energy generation costs.

Based on these data, the capacity-weighted average power sales price from the sample of post1997 wind power projects remains relatively low by historical standards, but has been steadily increasing in recent years. Figure 20 shows the cumulative capacity-weighted average wind power price (along with the range of individual project prices falling between the $25^{\text {th }}$ and $75^{\text {th }}$

\footnotetext{
${ }^{45}$ Three primary factors significantly restrict the size of this sample: (1) projects located within ERCOT (in Texas) fall outside of FERC's jurisdiction, and are therefore not required to report prices (reduces sample by almost 9,500 $\mathrm{MW})$; (2) the increasing number of utility-owned projects are not included, since these projects do not sell their power on the wholesale market (reduces sample by about 6,000 MW); and (3) the increasing number of merchant (or quasi-merchant) projects that sell power and RECs separately are not included in the sample, because the power price reported by these projects only represents a portion of total revenue received (reduces sample by roughly another 5,300 MW). In addition, certain "qualifying facilities" are not required to report their power sales to FERC.
} 
percentiles) in each calendar year from 1999 through 2010. Based on the limited sample of 11 projects built in 1998 or 1999 and totaling $594 \mathrm{MW}$, the weighted-average price of wind energy in 1999 was roughly $\$ 61 / \mathrm{MWh}$ (expressed in 2010 dollars). By 2010, in contrast, the cumulative sample of projects built from 1998 through 2010 had grown to 232 projects totaling 17,033 MW, with an average price of $\$ 49 / \mathrm{MWh}$ (with $50 \%$ of individual project prices falling between $\$ 34 / \mathrm{MWh}$ and $\$ 61 / \mathrm{MWh}){ }^{46}$ Although Figure 20 does show an increase in the weighted-average wind power price since 2005, reflecting rising prices from new projects, the cumulative nature of the graphic mutes the degree of increase to some degree.

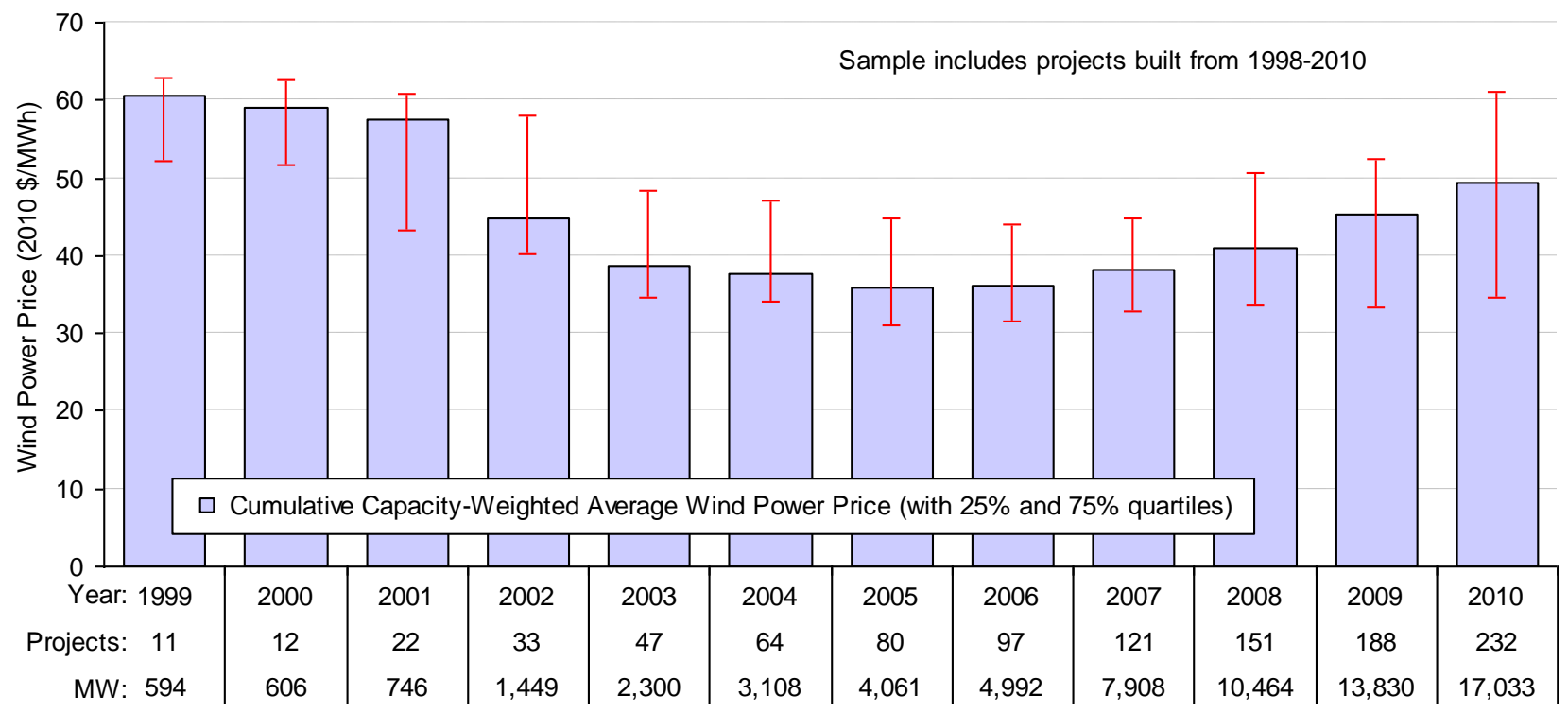

Source: Berkeley Lab

Figure 20. Cumulative Capacity-Weighted Average Wind Power Prices over Time

To better illustrate changes in the price of power from newly built wind power projects, Figure 21 shows average wind power sales prices in 2010 , grouped by project vintage (i.e., by each project's initial commercial operation date, COD) ${ }^{47}$ Although the limited project sample and the considerable variability in prices across projects installed in a given time period complicate analysis of national price trends (with averages subject to regional and other factors), the general trend exhibited by the capacity-weighted-average prices (i.e., the blue columns) nevertheless shows that prices bottomed out for projects built in 2002 and 2003, and have since risen significantly. ${ }^{48}$ Specifically, the capacity-weighted average 2010 sales price, based on projects

\footnotetext{
${ }^{46}$ All wind power pricing data presented in this report exclude the few projects located in Hawaii. Those projects are considered outliers in that they are significantly more expensive to build than projects in the continental United States, and have received power sales prices that are significantly higher-than-normal, in part because those prices have historically been linked to the price of oil.

${ }^{47}$ Prices from two individual projects - one built during the 2000-2001 period, and the other built in 2008 - are not shown in Figure 21 (due to the scale of the y-axis), but are included in the capacity-weighted averages for those periods. The omitted prices are roughly $\$ 150 / \mathrm{MWh}$ and $\$ 126 / \mathrm{MWh}$, respectively.

${ }^{48}$ Although it may seem counterintuitive, the weighted-average price in 1999 for projects built in 1998 and 1999 (shown in Figure 20 to be about $\$ 61 / \mathrm{MWh}$ ) is significantly higher than the weighted-average price in 2010 for projects built in 1998 and 1999 (shown in Figure 21 to be about $\$ 34 / \mathrm{MWh}$ ) for three reasons: (1) the sample size is larger in Figure 21, due to the fact that 2010 prices are presented, rather than 1999 prices as in Figure 20 (i.e., early-
} 
in the sample built in 2010 , was roughly $\$ 73 / \mathrm{MWh}$. This value is up from an average of $\$ 62 / \mathrm{MWh}$ for the sample of projects built in 2009, and is more than twice the average of \$32/MWh among projects built during the low point in 2002 and 2003.

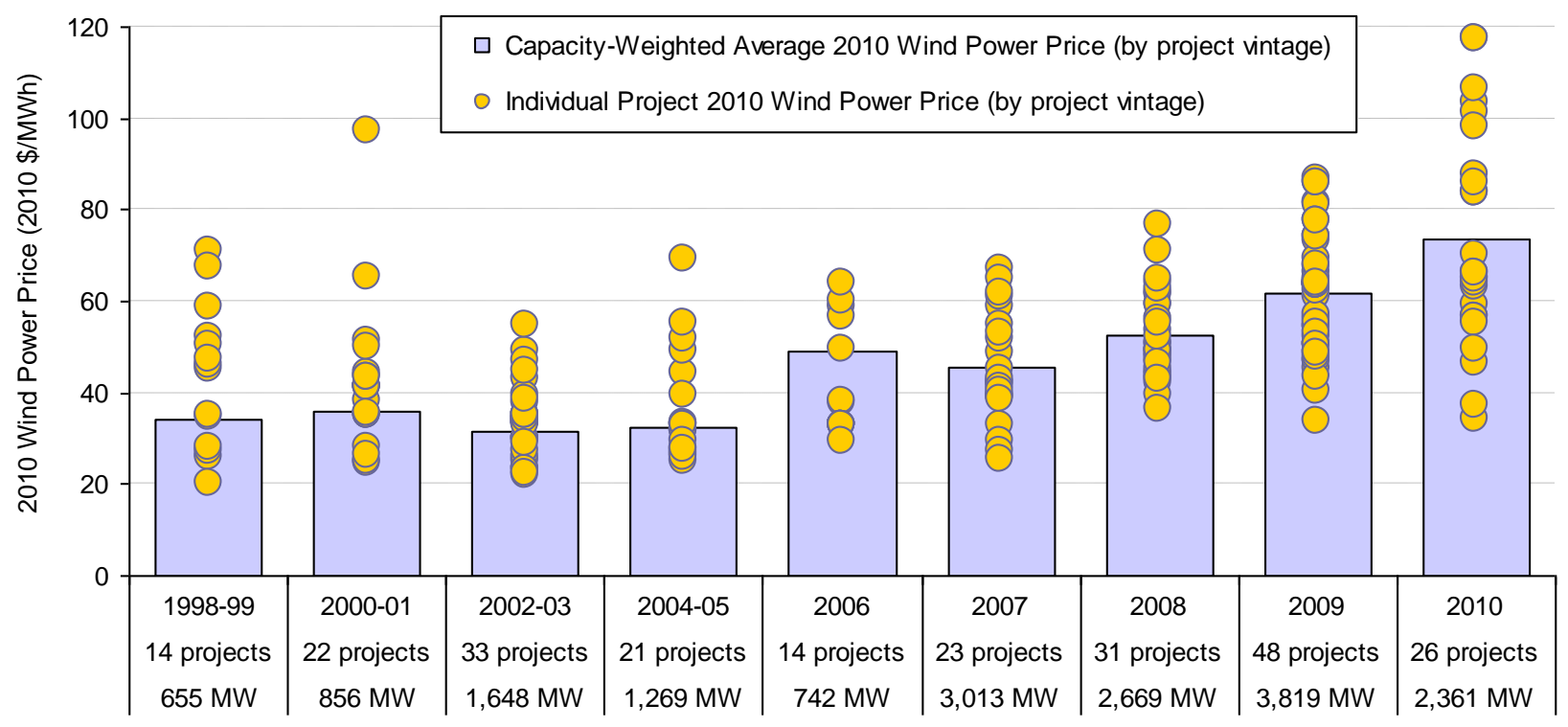

Source: Berkeley Lab database

\section{Figure 21. 2010 Wind Power Prices by Project Commercial Operation Date}

One of the primary drivers of the significant increase in average prices among 2010 projects is the high prevalence of California projects in the 2010 sample (relative to earlier years), in conjunction with the high price of many California wind power projects. Specifically, California projects make up 19\% (438 MW) of all sampled capacity in 2010, compared to just 4\% (150 MW) in 2009, 2\% (45 MW) in 2008, and 0\% (0 MW) in 2007. If the four California projects built in 2010 - each of which is priced over $\$ 100 / \mathrm{MWh}$ - are excluded from the 2010 sample, the capacity-weighted average price among the remainder of the sample drops to $\$ 64 / \mathrm{MWh}$ (i.e., much closer to the average price of the sample of projects built in 2009).

In addition to potentially influencing average price levels between years (as just discussed), regional factors also influence the underlying variability in wind power prices within a given year. Regional differences, for example, can affect not only project capacity factors (depending on the strength of the wind resource in a given region), but also development and installation costs (depending on a region's physical geography, population density, labor rates, or even regulatory processes). It is also possible that regions with higher wholesale electricity prices or with greater demand for renewable energy will, in general, yield higher wind energy contract prices due to market factors.

year pricing for some of the projects built in 1998-1999 were unavailable); (2) two of the larger projects built in 1998 and 1999 (for which both 1999 and 2010 prices are available, meaning that these projects are represented within both figures) have nominal PPA prices that actually decline, rather than remaining flat or escalating, over time; and (3) inflating all prices to constant 2010 dollar terms impacts older (i.e., 1999) prices more than it does more-recent (i.e., 2010) prices. 
Figure 22 shows individual project and average 2010 wind power prices by region for just those wind power projects installed from 2007-2010 (i.e., a more-recent period of higher prices, as shown in Figure 21), with regions as defined in Figure 23. Although sample size is quite small and therefore problematic in numerous regions, ${ }^{49}$ Texas, the Heartland, and the Mountain regions appear to be among the lowest price areas, on average, while California is, by far, the highest price region. $^{50}$

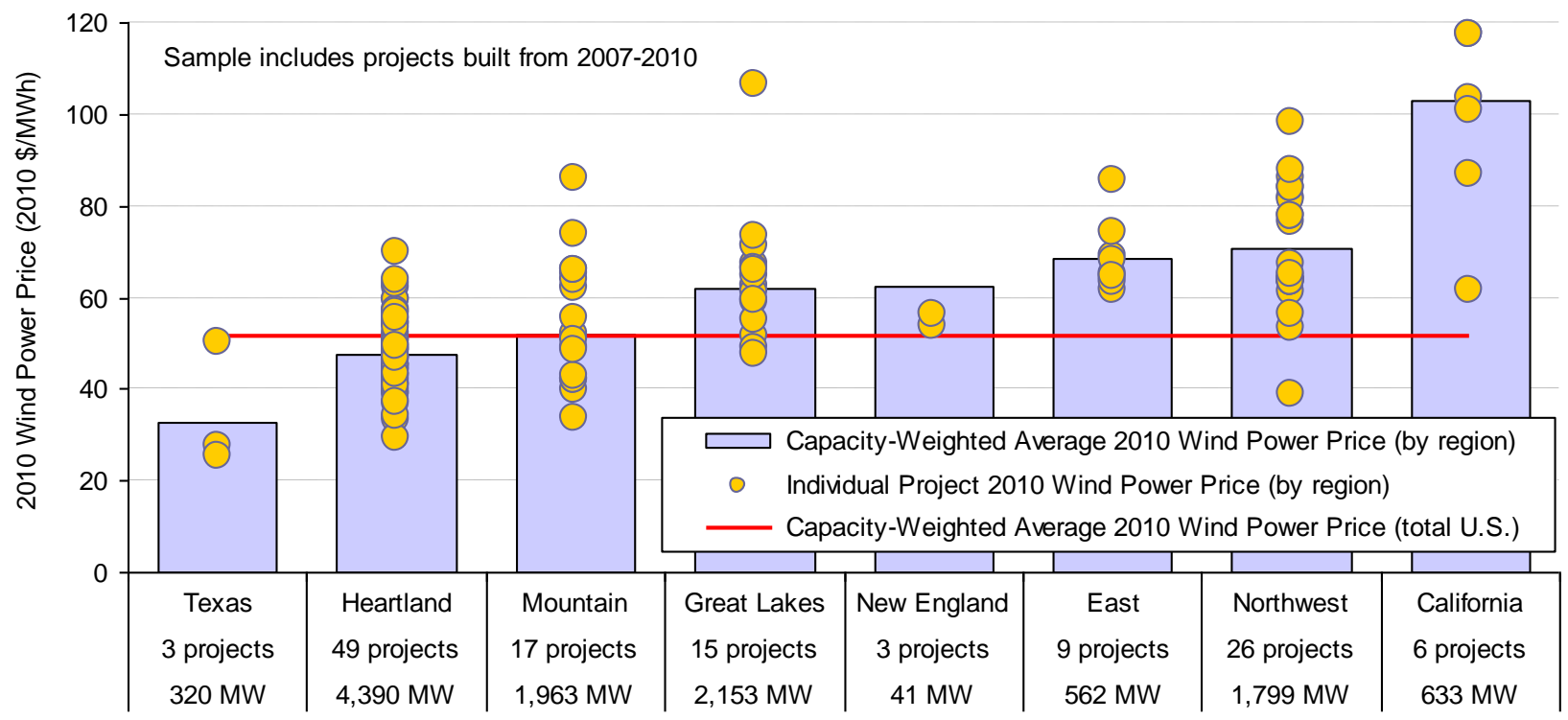

Source: Berkeley Lab

Figure 22. 2010 Wind Power Prices by Region: 2007-2010 Projects Only

\footnotetext{
${ }^{49}$ Average prices in Texas and New England, in particular, may not be representative as those averages include just three projects each. Once again, sample size in Texas is severely limited (despite the enormous growth of wind power capacity in that state) because generators located within ERCOT are not required to file pricing information with FERC. As such, the pricing information for Texas provided in this report comes primarily from projects located in the Texas panhandle, which is within the SPP rather than ERCOT. Note also that projects in this area have not experienced the same level of curtailment as is common in ERCOT, which, in combination with a strong wind resource in the region and relatively low capital costs (two of the three projects, totaling $75 \%$ of the aggregate capacity, were built in 2007 - i.e., when installed costs were lower), may have facilitated lower prices than in other parts of Texas. One of the three New England projects in the sample over this period is not shown in Figure 22 because its price $(\$ 126 / \mathrm{MWh})$ exceeds the scale of the y-axis; however, this project's price is included in the capacity-weighted average for New England.

${ }^{50}$ The higher prices in California may, in part, be due to aggressive renewable energy policies that give developers a strong negotiating position; relatively stringent permitting and regulatory requirements may also make California a particularly expensive state in which to build wind power projects.
} 


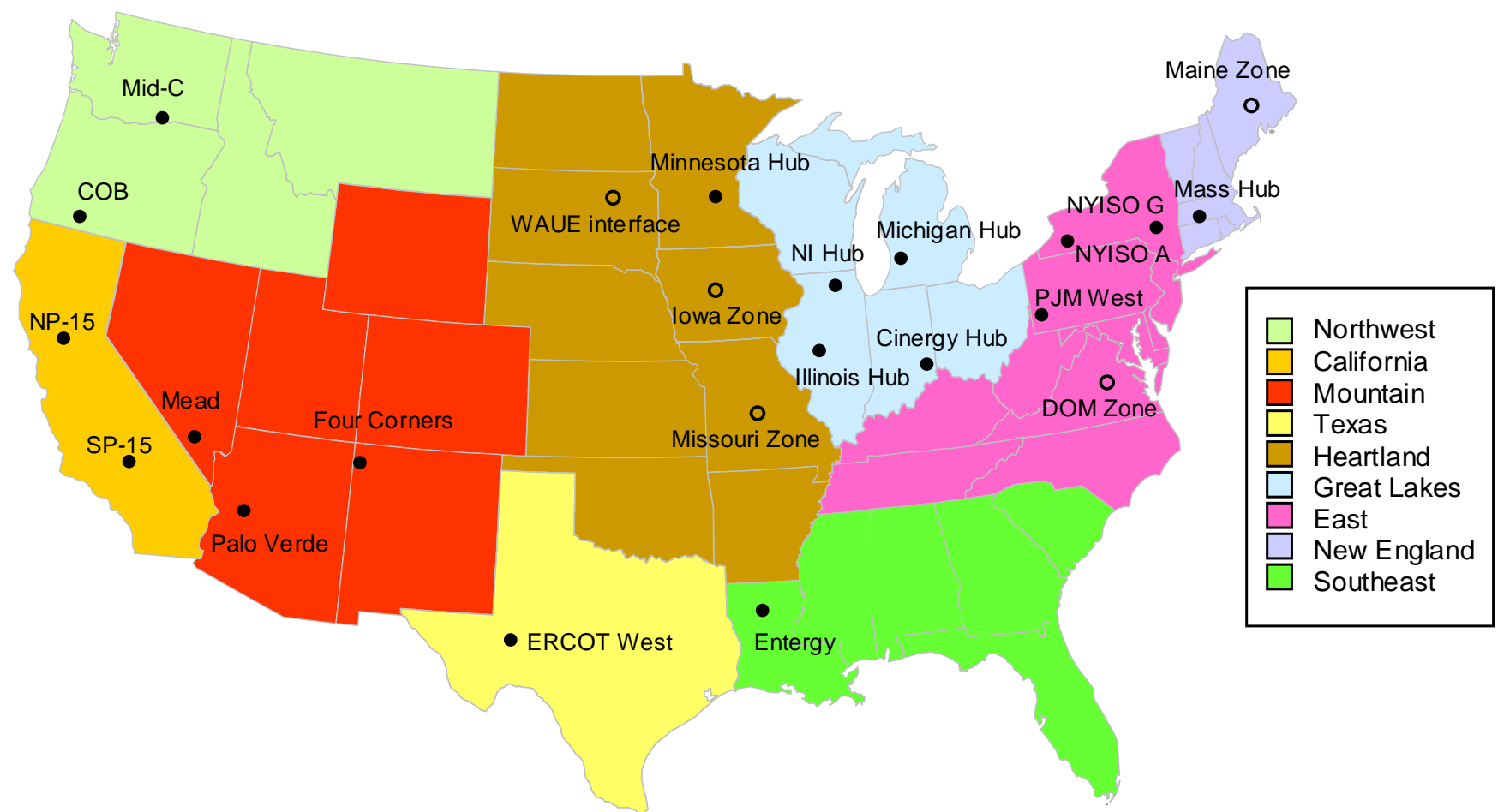

Note: The pricing nodes represented by an open, rather than closed, bullet do not have complete pricing history back through 2003.

Figure 23. Map of Regions and Wholesale Electricity Price Hubs Used in Analysis

Figures 20-22 are backward-looking (and in some sense by more than a year, to the extent that wind power prices are influenced by turbine supply agreements and PPAs signed several years ago), and so do not necessarily reflect current market conditions. Indications from projects that came online in late 2010 and early 2011 suggest a price thaw, particularly in the Heartland region, where a number of PPAs that start in the low-to-mid \$40/MWh range (and in some cases even lower) and escalate at $2 \%-2.5 \%$ per year thereafter have been witnessed. The degree to which this more-aggressive pricing spreads to other regions and continues into the future remains to be seen, but in light of recent turbine price declines that are now starting to flow through to lower installed project costs, future editions of this report are expected to show significant reductions in average wind power prices. Given the lag between changes in wind turbine prices and wind power prices, however, the recent decline in turbine prices may not be fully reflected in average wind power pricing until 2012 and later. 


\section{REC Prices Fall in Most Compliance Markets, Remain Fragmented}

The wind power sales prices presented in this report reflect only the bundled sale of both electricity and RECs; excluded are projects that sell RECs separately from electricity, thereby generating two sources of revenue. REC markets are highly fragmented in the United States, but consist of two distinct segments: compliance markets in which RECs are purchased to meet state RPS obligations, and green power markets in which RECs are purchased on a voluntary basis.

The figures below present indicative monthly data of spot-market REC prices in both compliance and voluntary markets, grouped into High-Price and Low-Price markets; data for compliance markets focus on the "Class I" or "Main Tier" of the RPS policies. Clearly, spot REC prices have varied substantially, both among states and over time within individual states. As of year-end 2010, REC prices were highest for the in-state portion of Ohio's RPS, ending the year above $\$ 30 / \mathrm{MWh}$ (note, though, that these trends may be based on a small number of actual bids/offers). Historically, REC prices have been highest in RPS compliance markets in the Northeast (Connecticut, Massachusetts, Maine, New Hampshire, and Rhode Island). Although still relatively high-priced, REC prices in Northeastern compliance markets continued their multi-year decline in 2010, falling below $\$ 20 / M W h$ by year-end. REC prices to serve RPS requirements in New Jersey, Illinois, and Delaware fell below $\$ 5 / \mathrm{MWh}$ by the end of 2010 , following declines in 2009 . REC prices remained at similarly low levels in several other compliance markets (Texas, Maryland, Pennsylvania, and Washington D.C.) due to a continued surplus of eligible renewable energy supply relative to RPS-driven demand. Prices for RECs offered in voluntary markets in 2010 ranged from an annual average of less than $\$ 1 / \mathrm{MWh}$ for national voluntary wind RECs (which continue to closely track the price of Texas RECs) to approximately $\$ 6 / \mathrm{MWh}$ for voluntary wind RECs in the West.
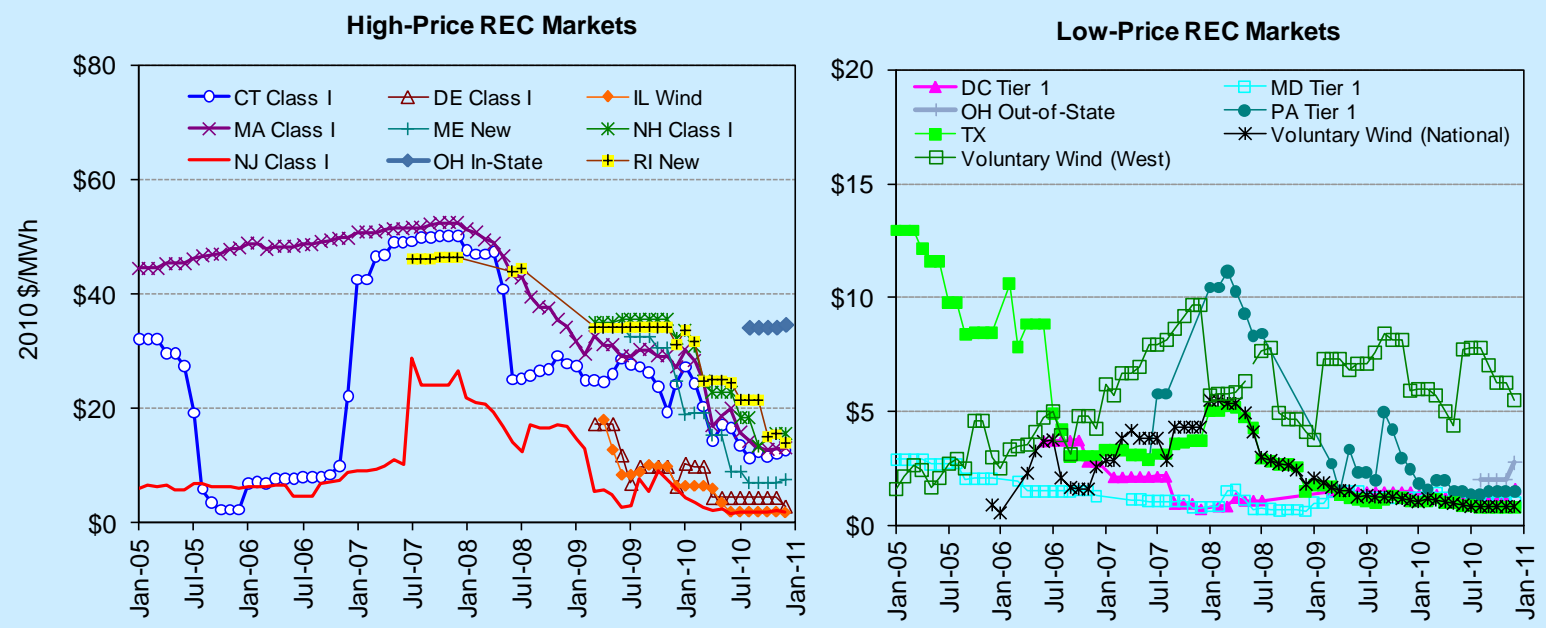

Sources: Evolution Markets and Spectron. Plotted prices represent the price of the last monthly trade (if available), or the midpoint of Bid and Offer prices, for the current or nearest compliance year.

\section{Low Wholesale Electricity Prices Continued to Challenge the Relative Economics of Wind Power Plants Installed in Recent Years}

A simple comparison of the wind power prices presented in the previous section to recent wholesale electricity prices throughout the United States demonstrates that while wind power had consistently been priced (on average) at the low end of the range of wholesale electricity prices going back through 2003, the drop in wholesale electricity prices in 2009 pushed wind energy to the top of that range, where it remained in 2010. Specifically, Figure 24 shows the range (minimum and maximum) of average annual wholesale electricity prices for a flat block of 
power $^{51}$ going back to 2003 at twenty-three different pricing nodes located throughout the country (refer to Figure 23 for the names and approximate locations of the twenty-three pricing nodes represented by the blue-shaded $\operatorname{area}^{52}$ ). The red dots show the cumulative capacityweighted average price received by wind power projects in each year among those projects in the sample with commercial operation dates of 1998 through 2010 (consistent with the data first presented in Figure 20).

At least on a cumulative basis within the sample of projects reported here, average wind power prices compared favorably to wholesale electricity prices from 2003 through 2008. Increasing wind power prices, however, combined with a sharp drop in wholesale electricity prices in 2009 (driven by lower natural gas prices), reversed this long-term trend in 2009 and 2010. Although low natural gas prices are, in part, attributable to the recession-induced drop in energy demand, the discovery and early development of significant shale gas deposits has resulted in reduced expectations for increases in natural gas prices going forward. As a result, natural gas prices may not rebound to earlier levels as the economy recovers, putting the near-term comparative economic position of wind energy at some risk, absent reductions in the price of wind power that counteract the decline in wholesale electricity prices (and absent policy drivers that support wind energy expansion without regard to its comparative economics).

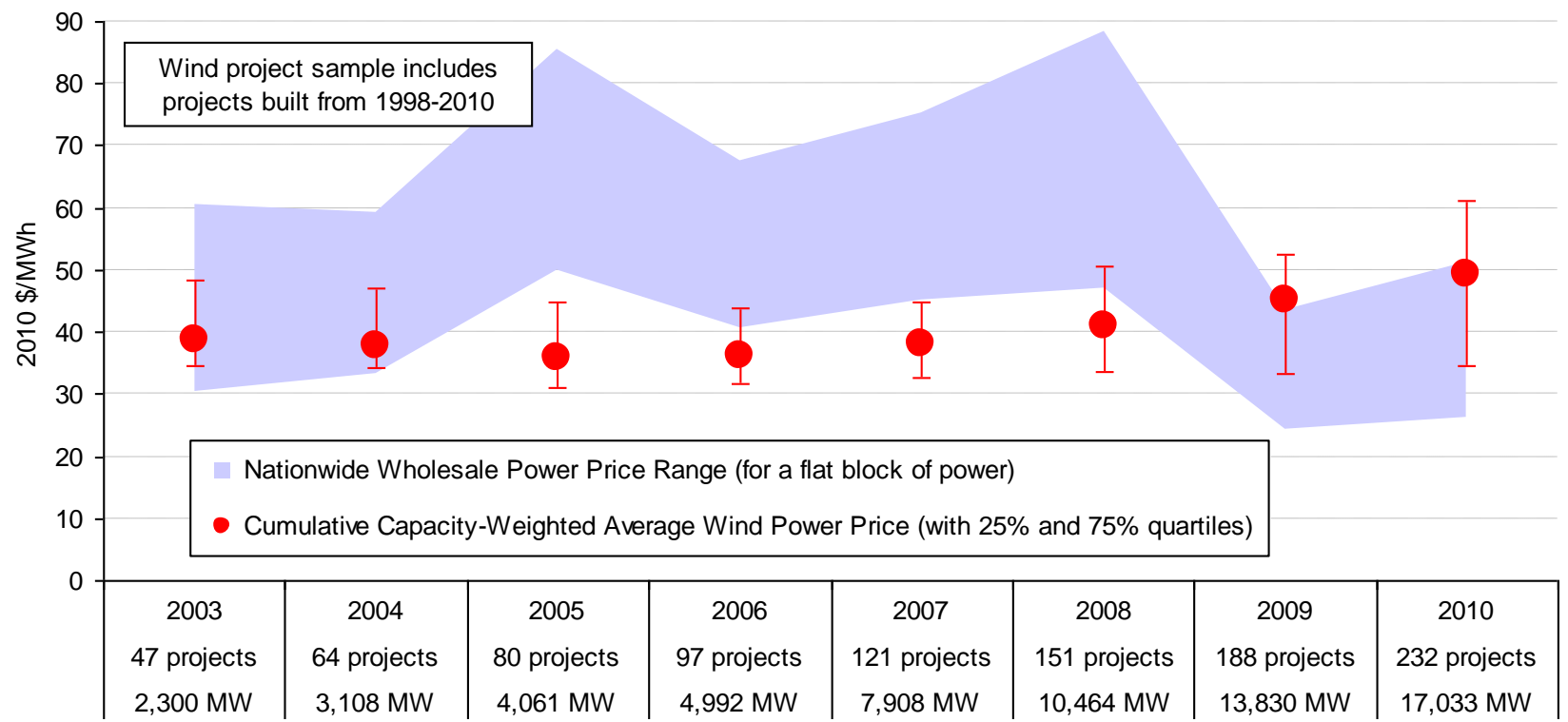

Source: Berkeley Lab, FERC, Ventyx, ICE

Figure 24. Average Cumulative Wind and Wholesale Electricity Prices over Time

\footnotetext{
${ }^{51}$ A flat block of power is defined as a constant amount of electricity generated and sold over a specified time period. Though wind power projects do not provide a perfectly flat block of power, as a common point of comparison, a flat block is not an unreasonable starting point. In other words, the time-variability of wind energy is often such that its wholesale market value is somewhat lower than, but not too dissimilar from, that of a flat block of (non-firm) power.

52 The five pricing nodes represented in Figure 23 by an open, rather than closed, bullet do not have complete pricing history back through 2003. As such, the wholesale electricity range presented in Figure 24 does not, in every year, reflect data from the complete set of hubs.
} 
Though Figure 24 portrays a national comparison, there are clearly regional differences in wholesale electricity prices and in the average price of wind power. Moreover, as shown earlier in Figure 21, wind power prices have risen for the more-recently installed projects in the sample. Figure 25 accounts for both of these considerations by focusing on 2010 wind and wholesale electricity prices in the same regions as shown earlier, based only on the sample of wind power projects installed from 2007 through 2010 (i.e., a more-recent period of higher pricing, as shown earlier in Figure 21). ${ }^{53}$ Although there is quite a bit of variability within some regions, and several regions again have limited sample size, the spread between average wind power and wholesale electricity prices (i.e., the wind power premium) in each region in 2010 is fairly consistent across much of the United States.

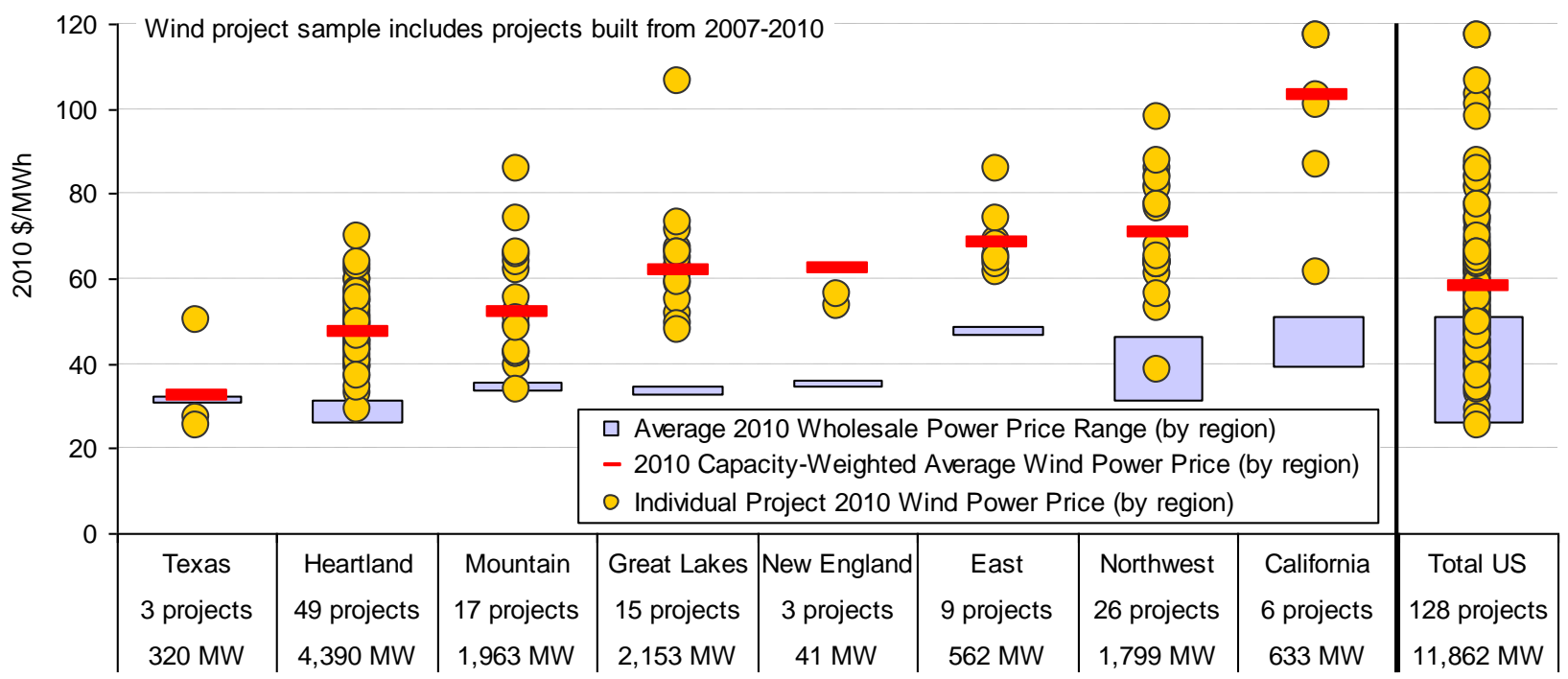

Source: Berkeley Lab, Ventyx, ICE

Figure 25. Wind and Wholesale Electricity Prices by Region: 2007-2010 Projects Only

Important Note: Notwithstanding the comparisons made in Figures 24 and 25, it should be recognized that neither the wind nor wholesale electricity prices presented in this section reflect the full social costs of power generation and delivery. Specifically, the wind power prices are suppressed by virtue of federal and, in some cases, state tax and financial incentives.

Furthermore, these prices do not fully reflect integration, resource adequacy, or transmission costs. At the same time, wholesale electricity prices do not fully reflect transmission costs, may not fully reflect capital and fixed operating costs, and are suppressed by virtue of any financial incentives provided to fossil-fueled generation and by not fully accounting for the environmental and social costs of that generation. In addition, wind power prices - once established - are typically fixed and known (because wind energy is often sold through long-term, fixed-price power purchase agreements), whereas wholesale electricity prices are short-term and therefore subject to change over time. Moreover, as discussed earlier, the historical wind power prices presented here are not necessarily representative of PPAs being negotiated today based on the

${ }^{53}$ Although its price $(\$ 126 / \mathrm{MWh})$ is factored into the capacity-weighted average wind power price (depicted by the red dash), one New England project is not shown in Figure 25, due to the compressed y-axis scale. As discussed in footnote 49, the average wind power prices for Texas and New England presented here should be viewed with caution. 
lower turbine pricing environment that now prevails. Finally, the location of the wholesale electricity nodes and the assumption of a flat-block of power are not perfectly consistent with the location and output profile of the sample of wind power projects.

In short, comparing wind and wholesale electricity prices in this manner is not appropriate if one's goal is to fully account for the costs and benefits of wind energy relative to its competition. Another way to think of Figures 24 and 25, however, is as loosely representing the decision facing wholesale electricity purchasers that are otherwise under no obligation to purchase additional amounts of wind energy - i.e., whether to contract long-term for wind power or to buy a flat block of (non-firm) spot power on the wholesale electricity market. In this sense, the costs represented in Figures 24 and 25 are reasonably comparable, in that they represent (to some degree, at least) what the power purchaser would actually pay.

\section{Project Performance and Capital Costs Drive Wind Power Prices}

Wind power sales prices are affected by a number of factors, two of the most important of which are installed project costs and project performance. ${ }^{54}$ Figures 26 and 27 illustrate the importance of these two variables.

Figure 26 shows the relationship between project-level installed costs and power sales prices in 2010 for a sample of nearly 14,400 MW of wind power projects installed in the United States from 1998 through 2010. ${ }^{55}$ Though the scatter is considerable, in general, projects with higher installed costs also have higher wind power prices.

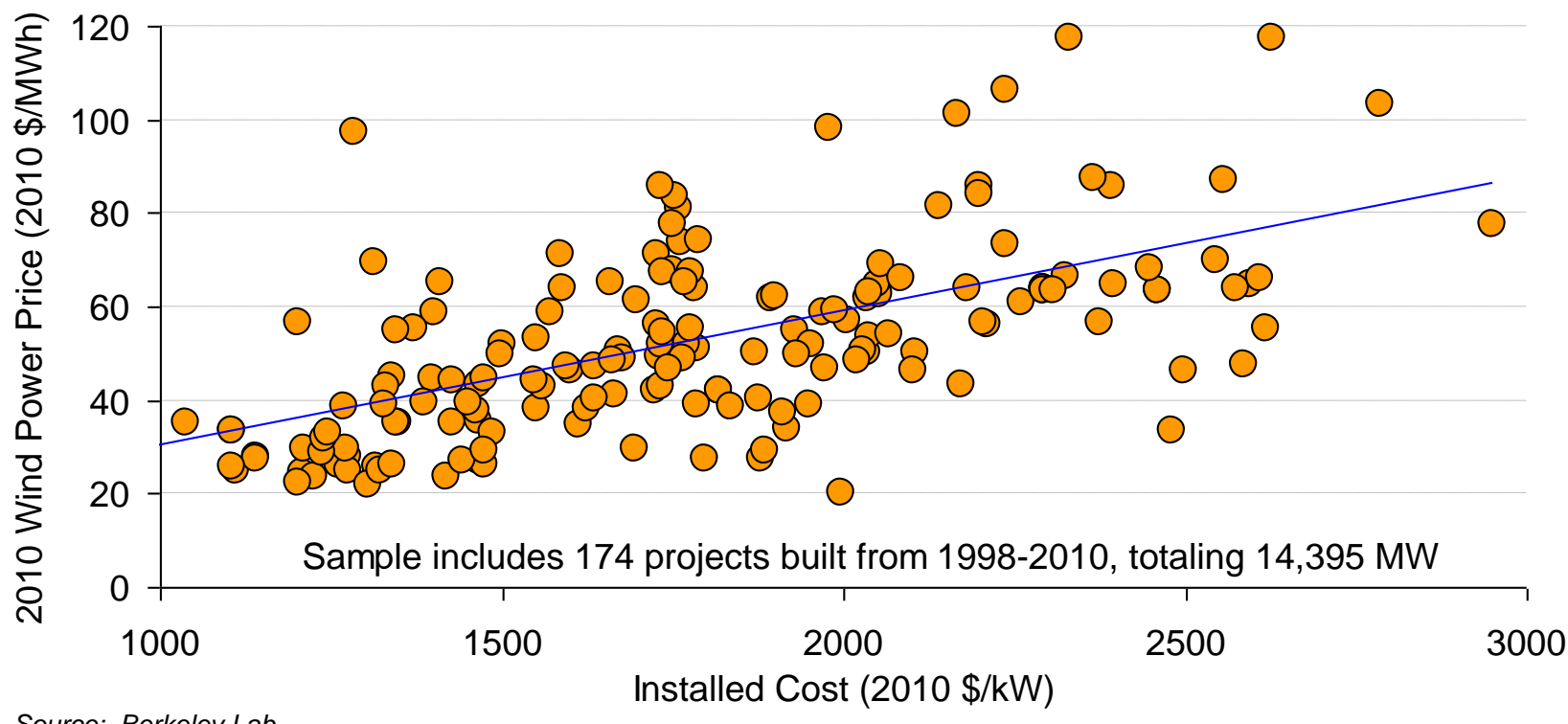

Source: Berkeley Lab

Figure 26. 2010 Wind Power Price as a Function of Installed Project Costs

\footnotetext{
${ }^{54} \mathrm{O} \& \mathrm{M}$ costs are another important variable that affects wind power prices. A later section of this report covers trends in project-level O\&M costs.

${ }^{55}$ In Figures 26 and 27, two individual project outliers (the same two described earlier in footnote 47) are obscured by the compressed y-axis scale, yet still influence the trend line.
} 
Figure 27 illustrates the relationship between project-level capacity factors in 2010 and power sales prices in that same year for a sample of nearly $14,600 \mathrm{MW}$ of wind power projects installed from 1998 through 2009. The inverse relationship shows that projects with higher capacity factors generally have lower wind power prices, though considerable scatter is again apparent.

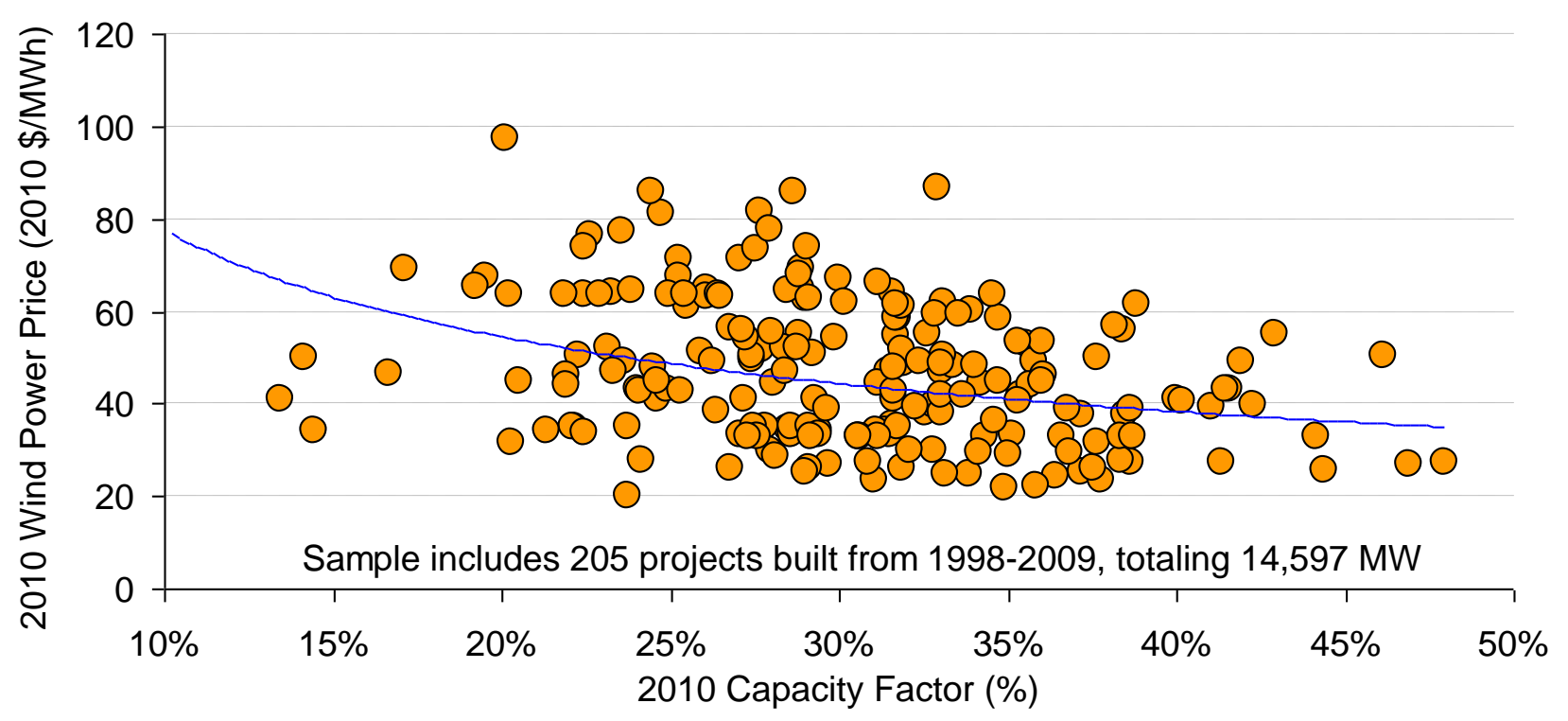

Source: Berkeley Lab

Figure 27. 2010 Wind Power Price as a Function of 2010 Capacity Factor

The next few sections of this report explore trends in installed costs and project performance in more detail, as both factors can have significant effects on wind power prices.

\section{The Average Installed Cost of Wind Power Projects Held Steady in 2010, but Is Expected to Decline in the Near Term}

Berkeley Lab compiles data on the installed cost of wind power projects in the United States, including data on 68 projects completed in 2010 totaling 5,036 MW, or $99 \%$ of the wind power capacity installed in that year. In aggregate, the dataset includes 471 completed wind power projects in the continental United States totaling 33,517 MW, and equaling roughly $83 \%$ of all wind power capacity installed in the United States at the end of 2010; also reported here are data on a small sample of projects installed in 2011. In general, reported project costs reflect turbine purchase and installation, balance of plant, and any substation and/or interconnection expenses. Data sources are diverse, however, and are not all of equal credibility, so emphasis should be placed on overall trends in the data, rather than on individual project-level estimates.

As shown in Figure 28, the installed costs of wind power projects declined dramatically from the beginning of the industry in California in the 1980s through the early 2000s, but have more recently increased. ${ }^{56}$ Among the sample of projects built in 2010, for example, the capacity-

\footnotetext{
${ }^{56}$ Learning curves have been used extensively to understand past cost trends and to forecast future cost reductions for a variety of energy technologies, including wind energy. Learning curves start with the premise that increases in
} 
weighted average installed cost was $\$ 2,155 / \mathrm{kW}$, or $\$ 845 / \mathrm{kW}(65 \%)$ higher than the average cost of projects installed from 2001 through 2004. Project costs have clearly risen, on average, over the last six years, though $2010 .^{57}$

More recently, however, installed project costs have shown signs of a potential plateau and reversal of recent increases. For example, the $\$ 2,155 / \mathrm{kW}$ capacity-weighted average installed cost in 2010 was essentially unchanged from the $\$ 2,144 / \mathrm{kW}$ seen in 2009 ; this $\$ 11 / \mathrm{kW}(0.5 \%)$ increase was by far the smallest cost increase seen in the six years leading up to 2010 . Moreover, the estimated average cost among a relatively small sample of 17 projects totaling more than $1 \mathrm{GW}$ of capacity that either have been or will be built in 2011 suggests that average installed costs may decline in 2011 (Figure 28). This is also consistent with the declining turbine prices reported in the next section, which should soon be manifest in installed project costs.

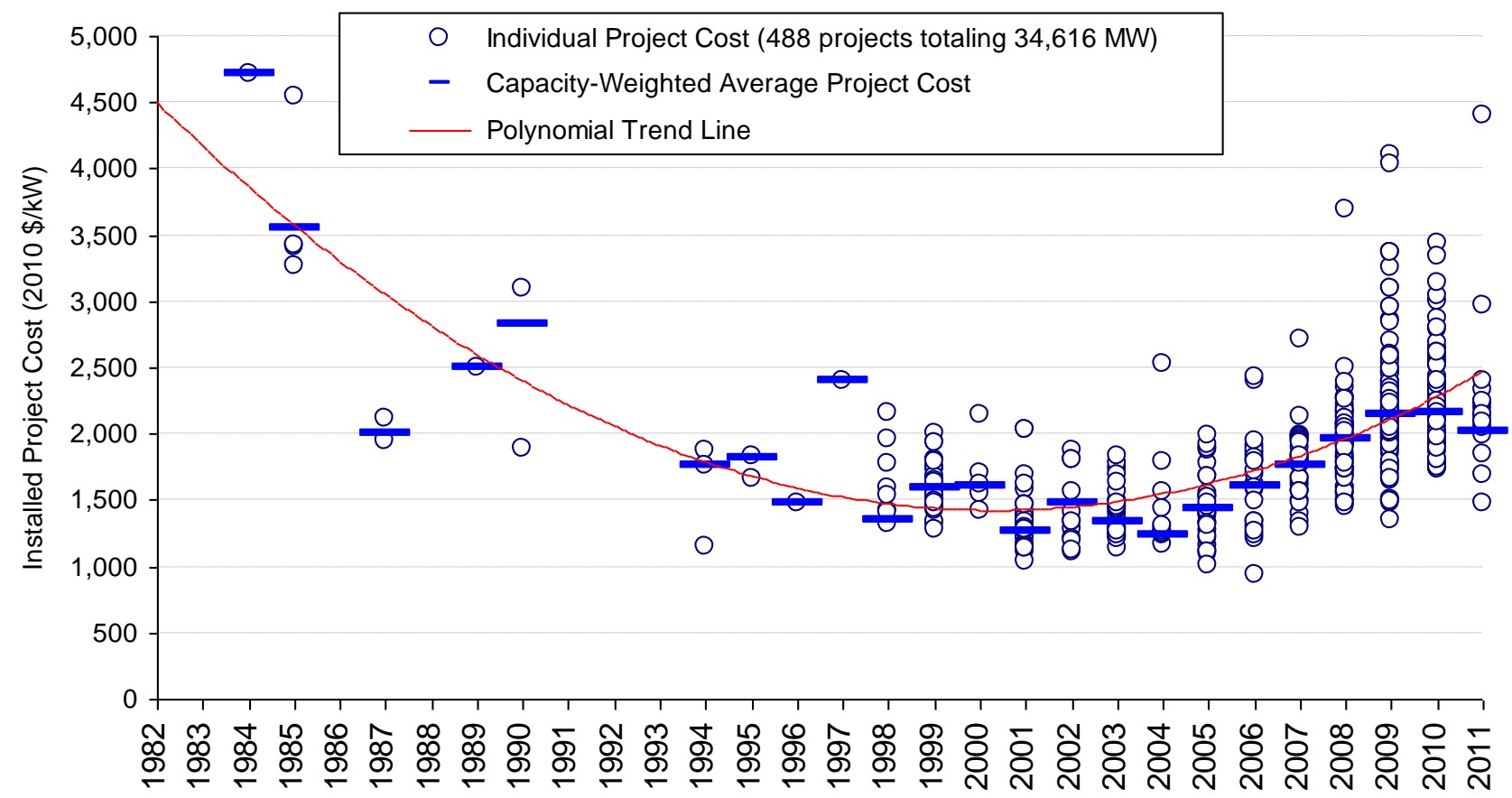

Note: 2011 data represent preliminary cost estimates for a sample of 17 projects totaling $1.1 \mathrm{GW}$ that have either already been or will be built in 2011, and for which reliable cost estimates were available.

Source: Berkeley Lab (some data points suppressed to protect confidentiality)

Figure 28. Installed Wind Power Project Costs over Time (including preliminary sample of 2011 project costs)

the cumulative production or installation of a given technology leads to a reduction in its costs. The principal parameter calculated by learning curve studies is the learning rate: for every doubling of cumulative production/installation, the learning rate specifies the associated percentage reduction in costs. Based on the installed cost data presented in Figure 28 and global cumulative wind power installations, learning rates can be calculated as follows: $8.3 \%$ (using data from 1982 through 2010) or 14.4\% (using data only during the period of cost reduction, 1982-2004).

${ }^{57}$ It is important to recognize that wind power projects were not alone in seeing upward pressure on project costs other types of power plants experienced similar increases in capital costs. For example, the IHS CERA Power Capital Cost Index of coal, gas, wind, and nuclear power plants showed a $115 \%$ capital cost increase from 2000 to 2010 (IHS CERA 2010). 
Installed project costs exhibit economies of scale, at least at the low end of the project size range. Figure 29 shows that - among the sample of projects installed in 2009-2010 - there is a significant drop in per-kW average installed project costs when moving from projects of $5 \mathrm{MW}$ or less to projects in the 5 to $20 \mathrm{MW}$ range. As project size increases beyond $20 \mathrm{MW}$, these data do not show continued economies of scale; the reason for this latter trend is unclear.

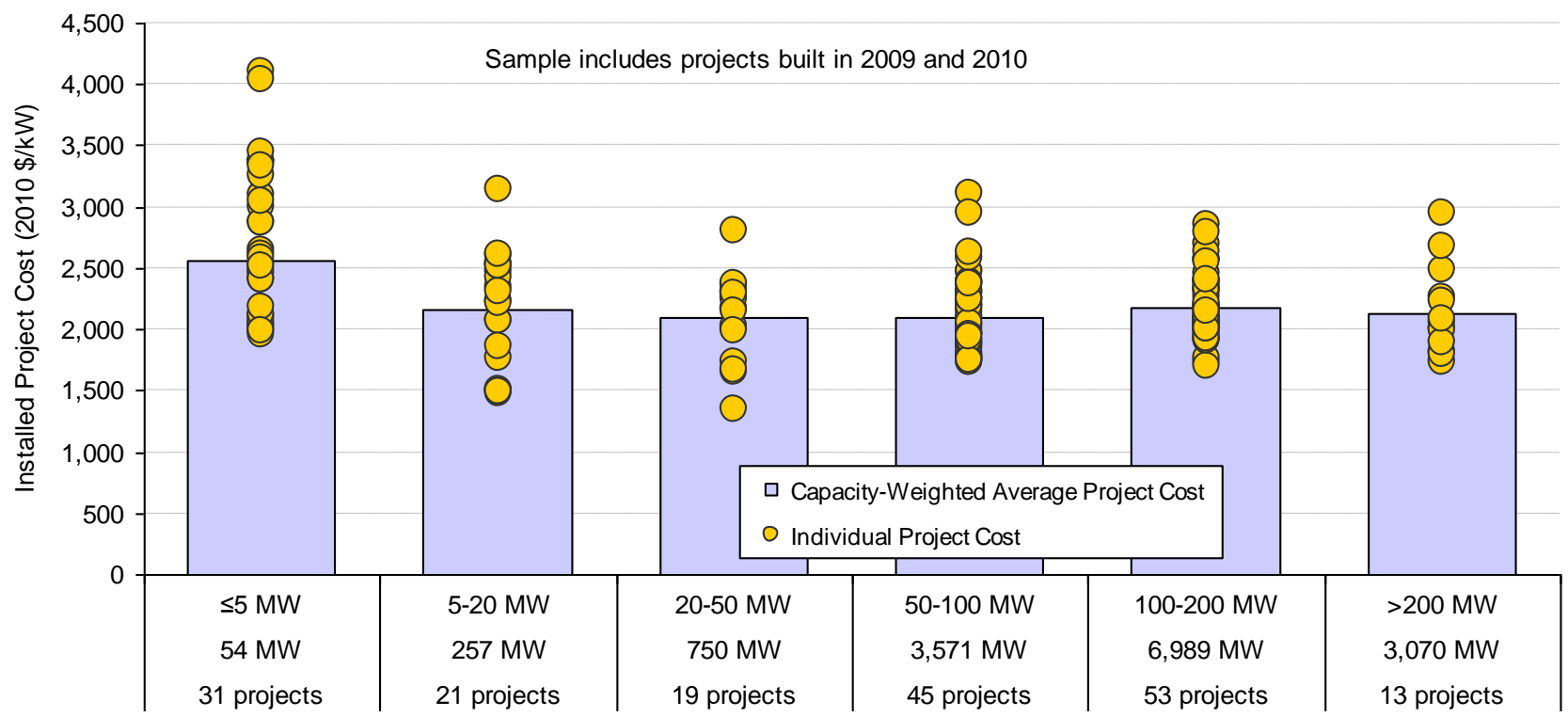

Source: Berkeley Lab

Figure 29. Installed Wind Power Project Costs by Project Size: 2009-2010 Projects

A second way to look for economies of scale is by turbine size (rather than by project size), on the theory that a given amount of capacity may be built less expensively using fewer larger turbines as opposed to a larger number of smaller turbines. Figure 30 explores this relationship, breaking down turbine size into $0.75 \mathrm{MW}$ bins. Focusing on individual project costs (the orange circles), it appears that larger turbines progressively capture scale economies, though the capacity-weighted average costs within each bin (the blue columns) suggest that these scale economies are not particularly significant. ${ }^{58}$

Regional differences in average project costs are also apparent, and may occur due to variations in development costs, transportation costs, siting and permitting requirements and timeframes, and other balance-of-plant and construction expenditures. Considering only projects in the sample that were installed in 2009 and 2010, Figure 31 shows that the capacity-weighted average cost equaled $\$ 2,150 / \mathrm{kW}$ nationwide over this period. Texas was the lowest-cost region, while California and New England were the highest-cost regions; all other regions came in close to the nationwide average..$^{59}$

\footnotetext{
${ }^{58}$ It should be noted that there is likely some correlation between turbine size and project size, at least at the low end of the range of each. In other words, projects of $5 \mathrm{MW}$ or less are perhaps more likely than larger projects to use individual turbines of less than 1 MW. As such, Figures 29 and 30 - both of which show significant scale economies at small project or turbine sizes, but diminishing as project or turbine size increases - could both be reflecting the same influence, making it difficult to tease out the unique influences of turbine size from project size.

${ }^{59}$ Permitting and regulatory compliance costs presumably play a role at both ends of the spectrum: Texas is reputed to be one of the easiest states in which to develop and build a wind power project, while California is one of the
} 


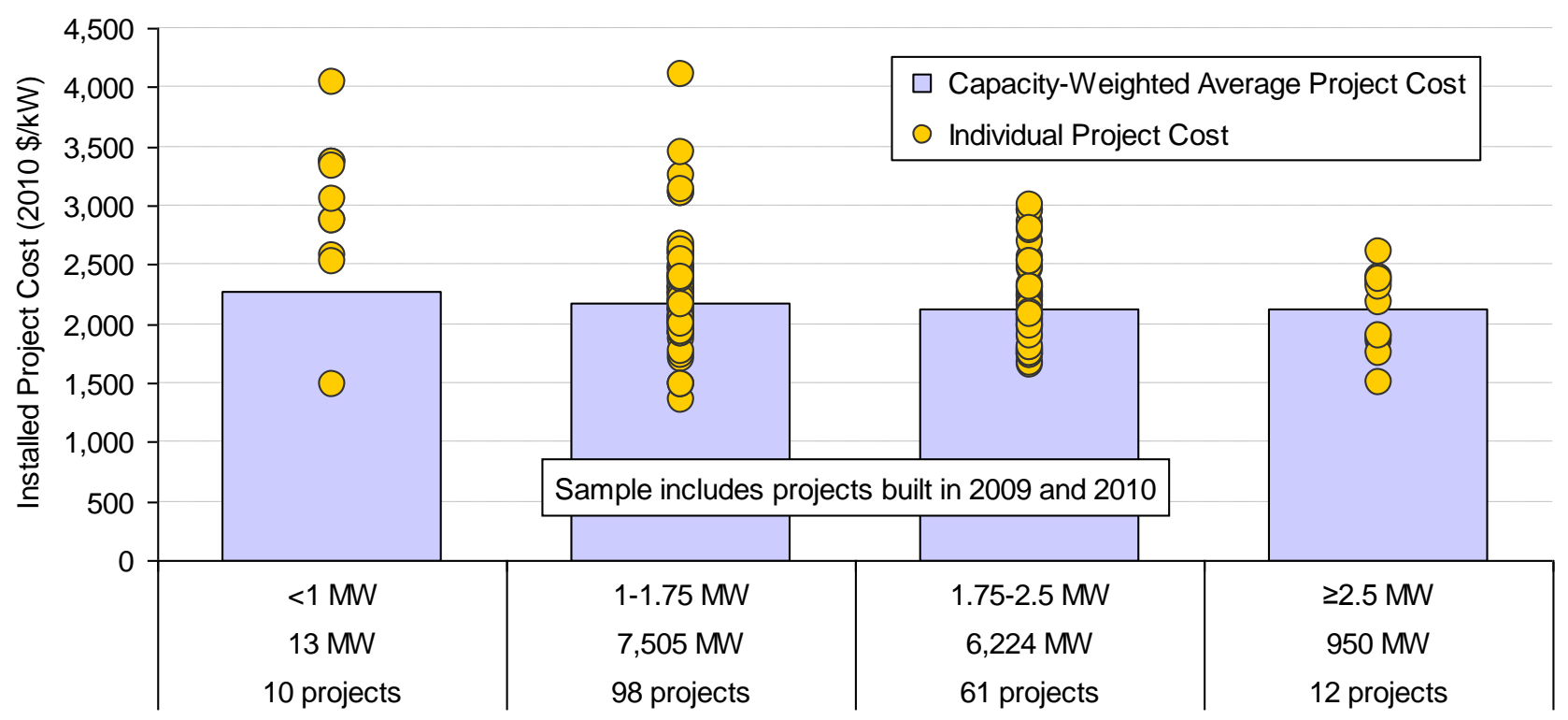

Source: Berkeley Lab

Figure 30. Installed Wind Power Project Costs by Turbine Size: 2009-2010 Projects

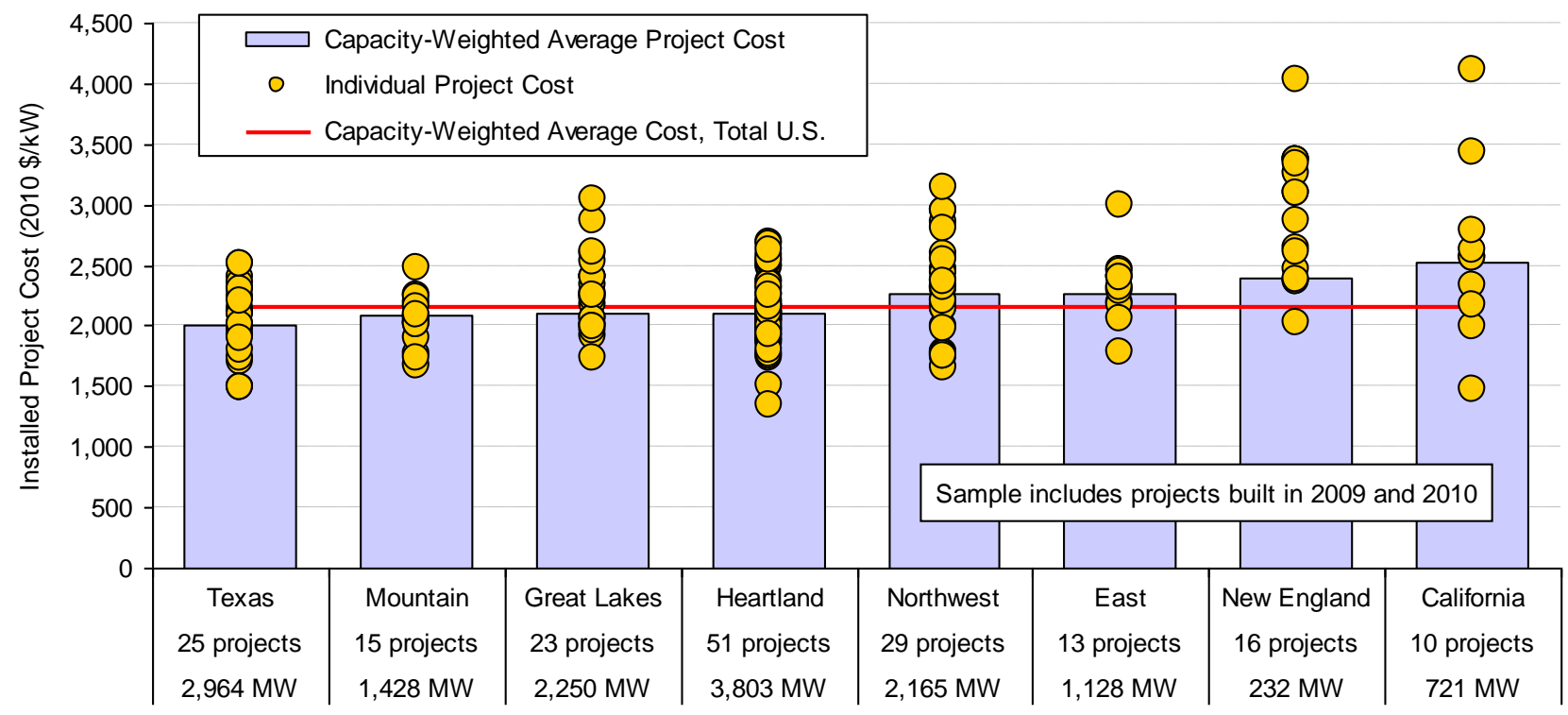

Source: Berkeley Lab

Figure 31. Installed Wind Power Project Costs by Region: 2009-2010 Projects

hardest. Graphical presentation of the data in this way, however, should be viewed with some caution, as numerous factors influence project costs (e.g., whether projects are repowered vs. "greenfield" development, etc.). Actual cost differences among some regions may therefore be more (or less) significant than they appear in Figure 31. 


\section{Wind Turbine Prices Have Declined Since 2008 and Will Yield Lower Project-Level Installed Costs and Power Sales Prices in the Years Ahead}

Wind turbine prices have dropped substantially since their peak in late 2008, despite continued technological advancements that have yielded increases in hub heights and especially rotor diameters. These wind turbine price declines are not yet readily apparent in the installed project costs and wind power prices presented earlier due to the natural temporal lag between turbine purchases (and PPA negotiations) and project installations: wind power projects installed in 2010 often relied on turbines purchased at the peak of the market in 2008. Nonetheless, installed costs and power sales prices for currently-in-development projects have reportedly dropped in line with the decline in wind turbine pricing, and future editions of this report are therefore expected to show declines in these metrics.

Berkeley Lab has gathered data on 81 U.S. wind turbine transactions totaling 23,850 MW announced from 1997 through early 2011, but including just 10 transactions summing to 907 MW announced in 2010 and early 2011. Figure 32 depicts these reported wind turbine transaction prices. Sources of transaction price data vary, but most derive from press releases and news reports. Wind turbine transactions differ in the services offered (e.g., whether towers and installation are provided, the length of the service agreement, etc.), turbine characteristics (and therefore performance), and on the timing of future turbine delivery, driving some of the observed intra-year variability in transaction prices. Nonetheless, most of the transactions included in the Berkeley Lab dataset likely include turbines, towers, erection, and limited warranty and service agreements. ${ }^{60}$ Unfortunately, visibility of wind turbine transaction prices has declined in recent years, limiting the sample size of recent deals represented in Figure 32 the sample of turbine transactions announced in 2010 for which price data were identified represents just $14 \%$ of the $6,280 \mathrm{MW}$ of new turbine orders reported by AWEA (2011a). As a result, the figure also presents a range of reported pricing for the most recent transactions signed in 2010 and early 2011, sourced from Bloomberg NEF (2011) as well as wind industry contacts.

After hitting a low of roughly $\$ 700 / \mathrm{kW}$ from 2000 to 2002, average wind turbine prices increased by approximately $\$ 800 / \mathrm{kW}(>100 \%)$ through 2008 , rising to an average of roughly $\$ 1,500 / \mathrm{kW}$. This trend of increasing turbine prices also suggests that most of the rise in installed project costs reported earlier ( $\$ 850 / \mathrm{kW}$ from 2001-04 through 2010) came from turbine price increases. Increases in turbine prices over this period were caused by several factors, including a decline in the value of the U.S. dollar relative to the Euro, increased materials and energy input prices (e.g., steel and oil), a general move by manufacturers to improve their profitability coupled with robust demand for wind turbines, shortages in certain turbine components, an upscaling of turbine size (including hub height and rotor diameter), and improved sophistication of turbine design (e.g., improved grid interactions).

\footnotetext{
${ }^{60}$ Because of data limitations, the precise content of many of the individual transactions is not known.
} 


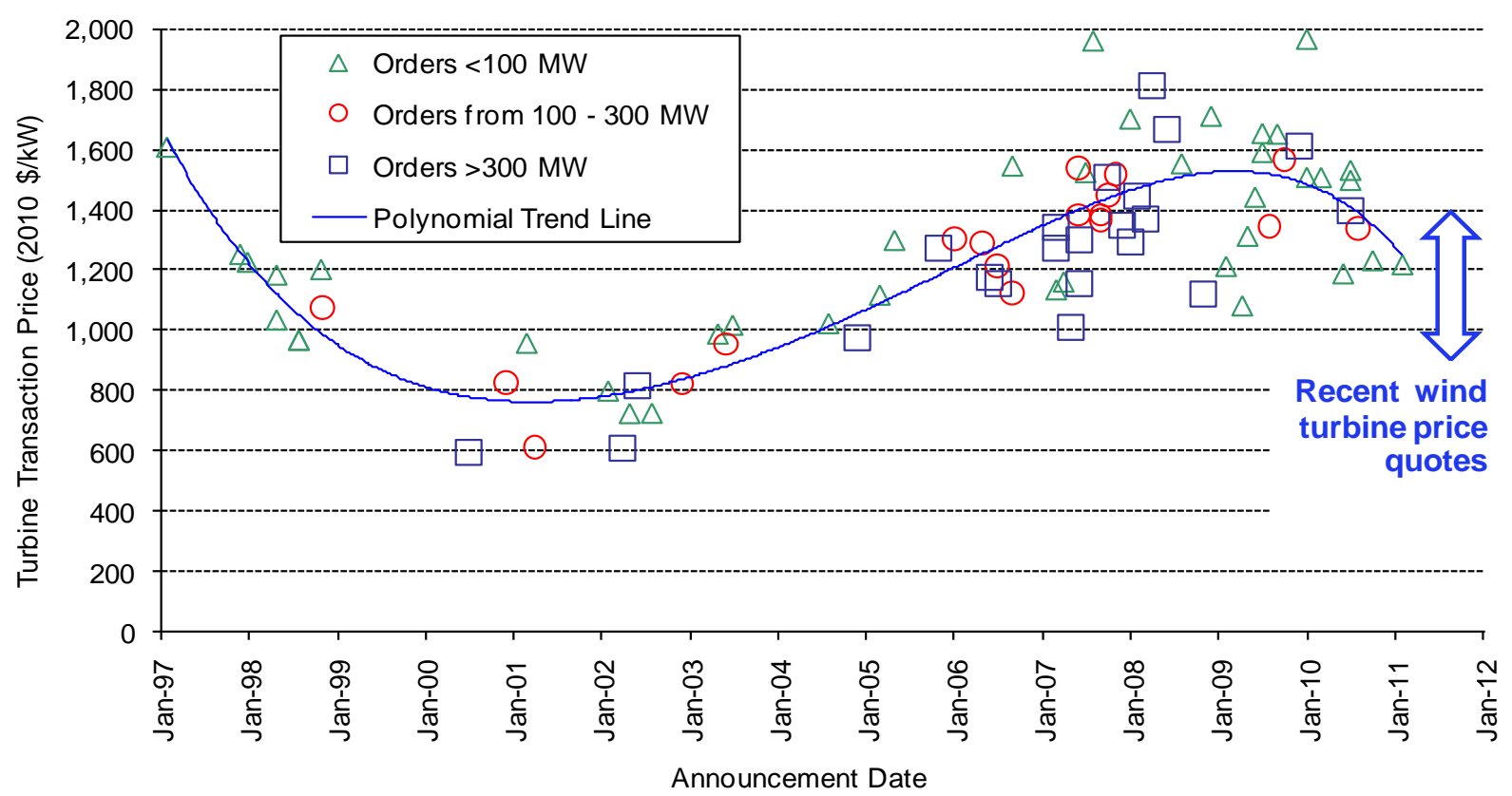

Source: Berkeley Lab

Figure 32. Reported U.S. Wind Turbine Transaction Prices over Time

Wind turbine prices have since declined substantially, partly a reflection of similar declines in energy and commodity prices but also a result of a shift in the supply-demand balance for turbines towards a buyer's market. As shown in Figure 32, price quotes for recent transactions are reported by Bloomberg NEF (2011) to be in the range of $\$ 1,100-\$ 1,400 / \mathrm{kW}$, while others have reported quotes as low as $\$ 900-1,000 / \mathrm{kW}$ from leading turbine suppliers (and sometimes even lower for second-tier suppliers). These figures suggest price declines of as much as $33 \%$ or more since late 2008, with an average decline closer to perhaps $20 \%$ for orders announced in 2010. Moreover, these declines have been coupled with: (1) improved turbine technology, as witnessed by the recent and continued growth in average hub heights and rotor diameters, and (2) more-favorable terms for turbine purchasers, including reduced turbine delivery lead times, lesser need for large frame-agreement orders, initial operations and maintenance (O\&M) contract durations that have increased from an average of 2-5 to 5-10 years, improved warranty terms, and more-stringent performance guarantees (e.g., Bloomberg NEF 2011, BTM 2011). These price reductions and improved terms are expected, over time, to exert downward pressure on total project costs and wind power prices, whereas increased rotor diameters and hub heights will simultaneously substantially improve capacity factors and further reduce wind power prices.

\section{Wind Power Project Performance Has Generally Improved Over Time, but Has Leveled Off in Recent Years}

Though turbine and installed project cost increases have driven wind power prices higher over the past several years (through 2010), improvements in wind power project performance have mitigated these impacts to some degree. In particular, capacity factors have generally increased for projects installed more recently, driven by a combination of higher hub heights, larger rotor 
diameters, and other technological advancements. ${ }^{61}$ These performance improvements appear to have leveled off in the most recent time period, but data presented earlier on increases in rotor diameters suggest that - all else being equal - continuing improvements in capacity factors can be expected in future years.

This section presents data from a Berkeley Lab compilation of project-level capacity factors. The full data sample consists of 338 wind power projects built between 1983 and 2009, and totaling 31,986 MW (91\% of nationwide installed wind power capacity at the end of 2009). ${ }^{62}$

Focusing on a progressively larger cumulative sample of projects in each calendar year, ${ }^{63}$ the blue bars in Figure 33 demonstrate that average sample-wide wind power project capacity factors have, in general, gradually increased over time, from 25\% in 1999 (for projects installed through 1998) to a high of nearly $34 \%$ in 2008 (for projects installed through 2007), before dropping to either side of $30 \%$ in 2009 and 2010 (for projects installed through 2008 and 2009, respectively). Though the blue bars reflect actual capacity factors - i.e., including the negative impact of curtailment events - the orange bars add back in the estimated amount of wind generation that has been curtailed in recent years within a limited subset of utility/ISO/RTO service territories (see Table 6, below, for a list of these territories and the estimated amount of curtailment in each), to estimate what the cumulative capacity factors would have been absent curtailment. As shown, cumulative capacity factors would have been on the order of 1-2 percentage points higher nationwide in 2008 through 2010 absent curtailment in just a subset of regions; estimated capacity factors would have been higher if comprehensive curtailment data were available for all regions. $^{64}$

The general trend of increasing capacity factors shown in Figure 33 may be due to a combination of factors, including - most prominently - the increasing hub heights and rotor diameters of more recently completed projects (documented in an earlier section). Turbines with higher hub heights and with larger rotor diameters (relative to nameplate capacity) will tend to have higher average capacity factors.

\footnotetext{
${ }^{61}$ Increased hub heights allow turbines to access higher average wind speeds and therefore achieve higher capacity factors. Capacity factors also tend to increase when the swept area of the rotors increase relative to turbine nameplate capacity.

${ }^{62}$ Though some performance data for wind power projects installed in 2010 are available, those data do not span an entire year of operations. As such, for the purpose of this section, the focus is on projects with commercial operation dates in 2009 and earlier.

${ }^{63}$ There are fewer individual projects - though more capacity - in the cumulative sample for 2010 than there were in 2009. This is due to the sampling method used by the EIA, which focuses on a subset of larger projects throughout the year, before eventually capturing the entire sample some months after the year has ended. As a result, it might be late 2011 before the EIA reports 2010 performance data for all of the wind power projects that it tracks, and in the mean time, this report is left with a smaller sample consisting mostly of the larger projects in each state.

${ }^{64}$ Though data on curtailment in other regions were not available, any such curtailment is expected to be relatively modest for 2010 and earlier years, so any further increase in estimated capacity factors is likely insubstantial.
} 


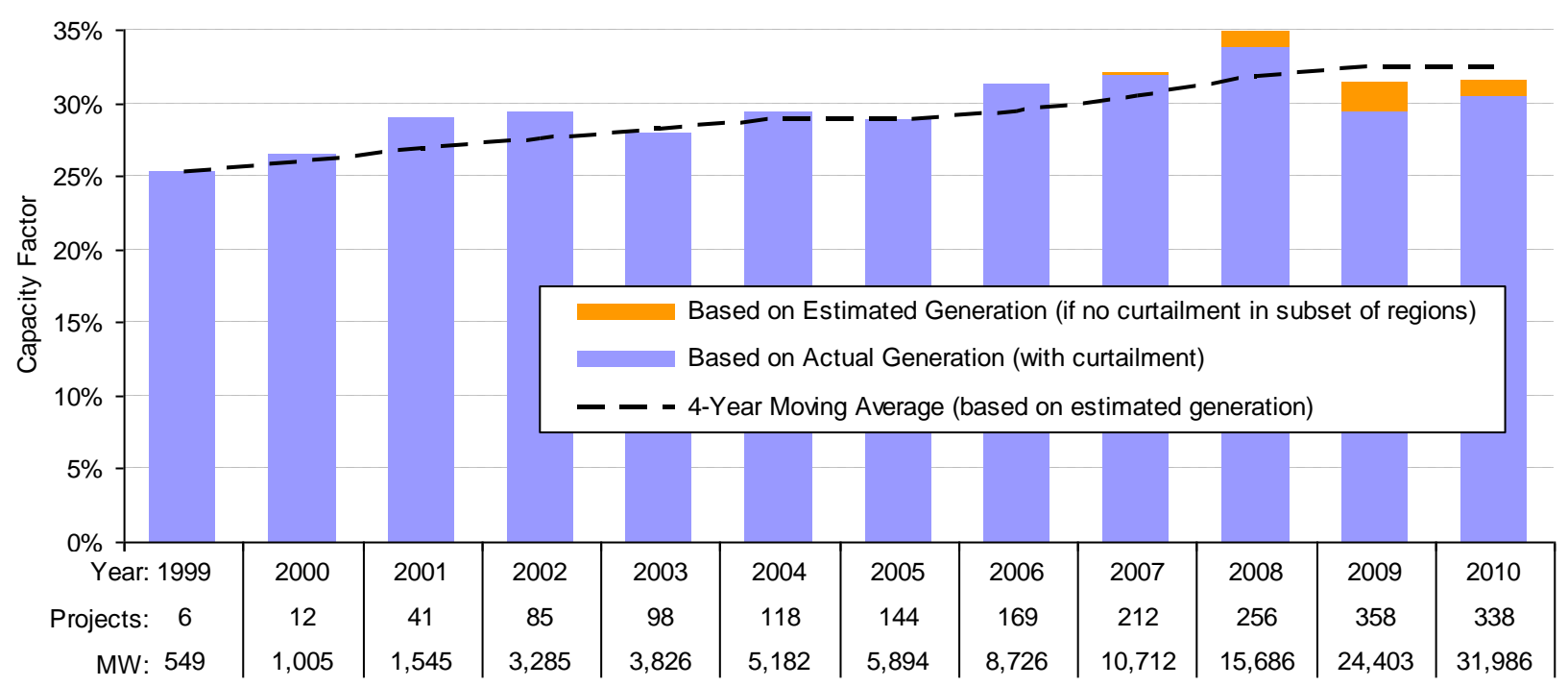

Source: Berkeley Lab

Figure 33. Average Cumulative Sample-Wide Capacity Factor by Calendar Year

The year-to-year variation in average capacity factors shown in Figure 33 is also caused by changes in the quality of the wind resource from year to year and by wind power curtailment.

Wind Resource Variation: The strength of the wind resource varies from year to year, in response to significant persistent weather patterns such as El Niño/La Niña. In 2010, the wind resource in the U.S. was reportedly "mixed," with "at or above normal" wind speeds throughout much of the continental United States, but "below normal conditions" in the northern Great Plains and upper Midwest (AWS Truepower 2011). In other words, a portion of the U.S. that normally boasts among the best wind resources had somewhat of an off-year in 2010, but the rest of the country enjoyed normal or above normal conditions. The year 2008, meanwhile, was generally considered to be a good wind year. The drop in average capacity factors between 2008 and 2009-10 is therefore, in part, a reflection of natural yearly variations in national average wind resource conditions.

Wind Power Curtailment: As already illustrated in Figure 33, significant wind power curtailment - particularly in 2009 - has reduced sample-wide average capacity factors in recent years. Curtailment of project output due primarily to transmission inadequacy (and, as a consequence, low or negative wholesale electricity prices) has become a significant problem, primarily in Texas, but also in other markets. Table 6 shows that nearly $8 \%$ of potential wind energy generation within the Electric Reliability Council of Texas (ERCOT) was curtailed in 2010 , compared to $17 \%$ in 2009 , more than $8 \%$ in 2008 , and just $1 \%$ in 2007 . The reduction in curtailment in 2010 is, in part, attributable to a private 229-mile transmission line built by NextEra Energy in late 2009 to move power from its 735.5 MW Horse Hollow project out of the congested West zone and into the uncongested South zone. ${ }^{65}$ Several minor transmission line

\footnotetext{
${ }^{65}$ Presumably mostly as a result of curtailment relief, Horse Hollow's capacity factor increased from just $20 \%$ in 2009 to $29 \%$ in 2010 .
} 
upgrades related to the Texas competitive renewable energy zone (CREZ) effort have also helped reduce curtailment in ERCOT (see later section on transmission).

Though curtailment declined in Texas in 2010 relative to 2009, other regions saw an increase. Xcel Energy, for example, experienced increasing curtailment in all three of its utility service territories, and most notably within its Public Service Company of Colorado territory, where an estimated $2.2 \%$ of all wind generation was curtailed, up from just $0.6 \%$ in 2009. The Midwest Independent System Operator (MISO) (net of Northern States Power's service territory) saw more than a doubling in the amount of wind generation curtailed in 2010, with curtailment estimated at $4.4 \%$ compared to $2.2 \%$ in 2009 . Though comparatively low at just $0.1 \%$ of total wind generation in 2010, wind energy curtailment on the Bonneville Power Administration's (BPA) system is becoming an increasing issue in the Pacific Northwest. For example, unusually high water levels on the Columbia River system in the Spring of 2011 forced BPA to curtail both wind and fossil generation in favor of hydropower. ${ }^{66}$ Between May 18 and June 14 (i.e., the time of writing), BPA had curtailed more than $78 \mathrm{GWh}$ of generation, much of which was wind generation. Thus, in just these few weeks, wind curtailment in BPA's territory greatly exceeded that seen in all of 2010.

In aggregate, assuming a $30 \%$ average capacity factor, the total amount of wind generation curtailed in 2010 within just the six territories shown in Table 6 equates to the annual output of roughly $1,130 \mathrm{MW}$ of wind power capacity.

Table 6. Wind Curtailment in Various Areas, in GWh (and \% of potential wind generation)

\begin{tabular}{|c|c|c|c|c|}
\hline & 2007 & 2008 & 2009 & 2010 \\
\hline Electric Reliability Council of Texas (ERCOT) & $\begin{array}{c}109 \\
(1.2 \%)\end{array}$ & $\begin{array}{c}1,417 \\
(8.4 \%)\end{array}$ & $\begin{array}{c}3,872 \\
(17.1 \%)\end{array}$ & $\begin{array}{c}2,067 \\
(7.7 \%)\end{array}$ \\
\hline Southwestern Public Service Company (SPS) & N/A & $\begin{array}{c}0 \\
(0.0 \%)\end{array}$ & $\begin{array}{c}0 \\
(0.0 \%)\end{array}$ & $\begin{array}{c}0.9 \\
(0.0 \%)\end{array}$ \\
\hline Public Service Company of Colorado (PSCo) & N/A & $\begin{array}{c}2.5 \\
(0.1 \%)\end{array}$ & $\begin{array}{c}19.0 \\
(0.6 \%)\end{array}$ & $\begin{array}{c}81.5 \\
(2.2 \%)\end{array}$ \\
\hline Northern States Power Company (NSP) & N/A & $\begin{array}{c}25.4 \\
(0.8 \%)\end{array}$ & $\begin{array}{c}42.4 \\
(1.2 \%)\end{array}$ & $\begin{array}{c}42.6 \\
(1.2 \%)\end{array}$ \\
\hline Midwest Independent System Operator (MISO), less NSP & N/A & N/A & $\begin{array}{c}250 \\
(2.2 \%)\end{array}$ & $\begin{array}{c}781 \\
(4.4 \%)\end{array}$ \\
\hline Bonneville Power Administration (BPA) & N/A & N/A & N/A & $\begin{array}{c}4.6^{*} \\
(0.1 \%)\end{array}$ \\
\hline Total Across These 6 Areas: & $\begin{array}{c}109 \\
(1.2 \%)\end{array}$ & $\begin{array}{c}1,445 \\
(6.4 \%)\end{array}$ & $\begin{array}{c}4,183 \\
(10.4 \%)\end{array}$ & $\begin{array}{c}2,978 \\
(5.1 \%)\end{array}$ \\
\hline
\end{tabular}

*BPA curtailment is estimated assuming that each curtailment event lasts for 25 minutes (i.e., half of the maximum 50 possible minutes for each event). The actual curtailment amount in 2010 could range from $1.7 \mathrm{GWh}$ to $8.5 \mathrm{GWh}$ if curtailment events were assumed to last the minimum of 10 minutes or the full 50 minutes, respectively.

Source: ERCOT, Xcel Energy, MISO, BPA

\footnotetext{
${ }^{66}$ Simply spilling excess water over dams is not considered to be a viable option, as it would increase dissolved gas levels in the water beyond those deemed acceptable to the health of salmon populations.
} 
Figure 33 presented cumulative, sample-wide capacity factors by calendar year. Figure 34 (as well as Figure 35 and Table 7) shows capacity factor data in a different way, by focusing just on capacity factors in the year 2010, rather than in each calendar year. ${ }^{67}$ Specifically, Figure 34 shows individual project as well as capacity-weighted average 2010 capacity factors broken out by each project's commercial operation date. The capacity-weighted average 2010 capacity factors in the Berkeley Lab sample increase from $21 \%$ for wind power projects installed before 1998 to $27 \%$ for projects installed from 1998-2001, 31\% for projects installed from 2002-2003, and 32-33\% for projects installed in 2004-2007. Once again, higher hub heights and larger rotor diameters (particularly relative to turbine nameplate capacity) are likely to be largely responsible for these increases in capacity factors.

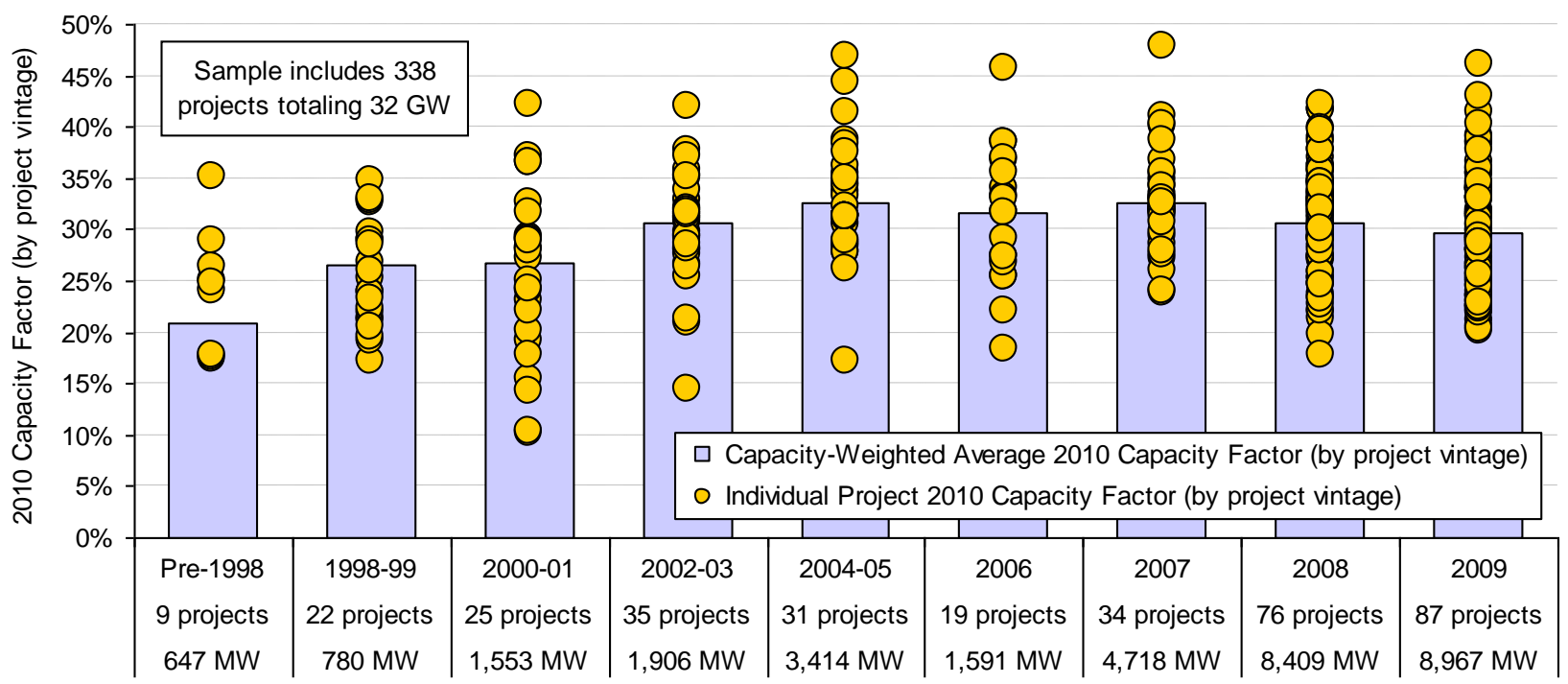

Source: Berkeley Lab

Figure 34. 2010 Project Capacity Factors by Commercial Operation Date

Projects installed in 2008 and 2009, however, feature capacity-weighted average 2010 capacity factors of $30 \%-31 \%$, and as such have bucked the general trend of rising capacity factors among newer projects. Though further analysis would be needed to fully assess the reasons for this leveling of capacity factors in recent years, potential explanations include:

- Project Siting: Developers may be reacting to increasing transmission constraints (or even just regionally differentiated wholesale electricity prices, or siting constraints) by focusing on those projects in their pipeline that may not be located in the best wind resource areas, but that do have access to transmission (or higher-priced markets or readily available sites without long permitting times).

\footnotetext{
${ }^{67}$ Although focusing just on 2010 tends to limit the effects of inter-annual fluctuations in the nationwide wind resource (which do impact the year-to-year results in Figure 33), it also means that the absolute capacity factors shown in Figure 34 may not be representative if 2010 was not a representative year in terms of the strength of the wind resource. Note also that by including only 2010 capacity factors, variations in the quality of the wind resource year in 2010 across regions could skew the regional results presented in Figure 35 and Table 7.
} 
- Policy Influence: Projects built in 2009 were able to access a 30\% ITC or cash grant in lieu of the PTC. Because the dollar amount of the ITC or grant is not dependent on how much electricity a project generates, it is possible that developers have seized this potentially limited opportunity to build out the less-energetic sites in their development pipeline. Additionally, state RPS requirements sometimes require or motivate in-state or in-region wind development in lower wind resource regimes.

- Technology Change: Though increases in average turbine hub height and rotor diameter have been substantial, and further scaling is anticipated, those increases moderated somewhat at least from 2006-2009 (as discussed in an earlier section), yielding a weaker technical push towards higher capacity factors over that time period.

- Turbine Reliability: Some turbine manufacturers have experienced blade and gearbox problems among their fleet of turbines, especially those installed in 2007 and 2008. Additionally, for the many projects completed in late 2009, the initial break-in period during which operational issues are worked out may have extended well into 2010, negatively impacting 2010 capacity factors.

- Curtailment: As shown earlier in Figure 33 and Table 6, curtailment of wind generation has increased in recent years. If curtailment impacts newer projects more so than older projects, then it would contribute to the lower capacity-weighted average capacity factors among wind projects built in 2008 and 2009.

Trends in fleet-wide average capacity factors aside, the project-level spread shown in Figure 34 is enormous, with 2010 capacity factors ranging from $20 \%$ to $46 \%$ among projects built in the same year, 2009. Some of this spread is attributable to regional variations in wind resource quality. Figure 35 shows the regional variation in 2010 capacity factors, based on a sub-sample of wind power projects built from 2007 through 2009 (i.e., the most recent period of acceptable sample size). For this sample of projects, weighted-average capacity factors are the highest in the Heartland region and California (both around 33\% on average), and lowest in the East (roughly 25\% on average) as well as the Northwest and New England (27\%-28\% on average). All other regions feature weighted-average capacity factors in 2010 that are in the $30 \%-31 \%$ range, which is similar to the $30.7 \%$ national average among the overall $2007-2009$ project sample. Given the small sample size in some regions, however, as well as the possibility that certain regions may have experienced a particularly good or bad wind resource year or different levels of wind energy curtailment in 2010 , care should be taken in extrapolating these results. ${ }^{68}$

\footnotetext{
${ }^{68}$ For example, the average 2010 capacity factor in Texas of $31.2 \%$ was depressed by the curtailment of wind generation, and would have been closer to $34 \%$ - an absolute increase of $2.8 \%$ - had there been no curtailment.
} 


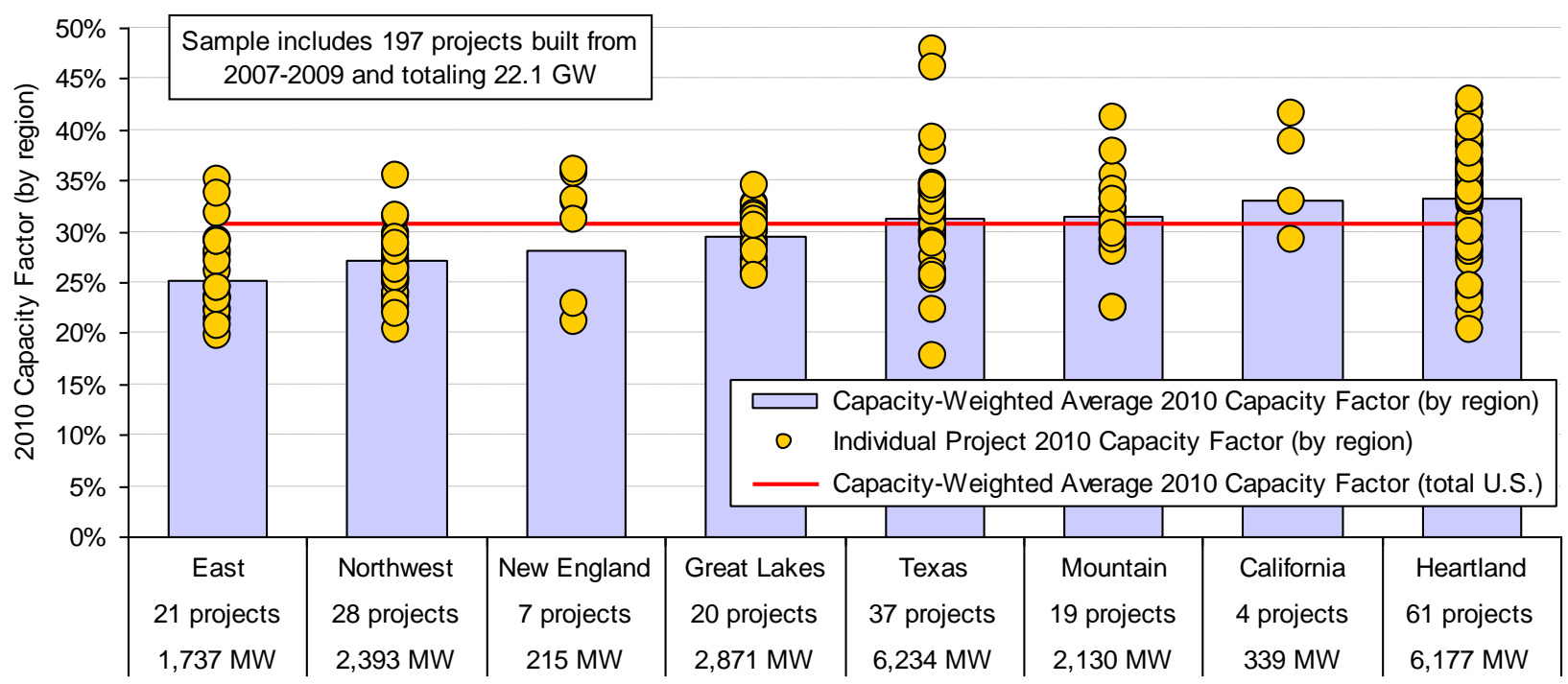

Source: Berkeley Lab

Figure 35. 2010 Project Capacity Factors by Region: 2007-2009 Projects Only

Though limited sample size is again a problem for some regions, Table 7 illustrates trends in 2010 capacity factors for projects with different commercial operation dates, by region.

Table 7. Capacity-Weighted Average 2010 Capacity Factors by Region and Commercial Operation Date

\begin{tabular}{|c|c|c|c|c|c|c|c|c|c|c|c|c|c|c|c|c|c|c|}
\hline $\begin{array}{c}\text { Capacity } \\
\text { Factor }\end{array}$ & \multicolumn{2}{|c|}{ East } & \multicolumn{2}{|c|}{ Northwest } & \multicolumn{2}{|c|}{$\begin{array}{c}\text { New } \\
\text { England }\end{array}$} & \multicolumn{2}{|c|}{$\begin{array}{l}\text { Great } \\
\text { Lakes }\end{array}$} & \multicolumn{2}{|c|}{ Texas } & \multicolumn{2}{|c|}{ California } & \multicolumn{2}{|c|}{ Mountain } & \multicolumn{2}{|c|}{ Heartland } & \multicolumn{2}{|c|}{ Hawaii } \\
\hline Pre-1998 & \multicolumn{2}{|r|}{ - } & \multicolumn{2}{|r|}{-} & \multicolumn{2}{|c|}{$28.8 \%$} & \multicolumn{2}{|c|}{ - } & \multicolumn{2}{|r|}{ - } & \multicolumn{2}{|c|}{$20.8 \%$} & \multirow{2}{*}{\multicolumn{2}{|c|}{$26.3 \%$}} & \multicolumn{2}{|c|}{ - } & \multicolumn{2}{|c|}{-} \\
\hline 1998-99 & \multicolumn{2}{|r|}{-} & \multicolumn{2}{|c|}{$34.8 \%$} & \multicolumn{2}{|c|}{-} & \multicolumn{2}{|c|}{$18.2 \%$} & \multicolumn{2}{|r|}{ - } & \multicolumn{2}{|c|}{$29.7 \%$} & & & \multicolumn{2}{|c|}{$25.4 \%$} & \multicolumn{2}{|c|}{$\begin{array}{ll}- \\
-\end{array}$} \\
\hline $2000-01$ & \multicolumn{2}{|c|}{$16.7 \%$} & \multirow{2}{*}{\multicolumn{2}{|c|}{$\begin{array}{l}18.5 \% \\
27.3 \%\end{array}$}} & . & - & & $8 \%$ & & $.7 \%$ & & - & \multicolumn{2}{|c|}{$30.6 \%$} & & $7 \%$ & & - \\
\hline 2002-03 & & $.1 \%$ & & & . & - & & $9 \%$ & & $.1 \%$ & & $2 \%$ & & $6 \%$ & 32 & $6 \%$ & & - \\
\hline $2004-05$ & & $.7 \%$ & & $9 \%$ & . & - & & $1 \%$ & & $.9 \%$ & & $1 \%$ & & $.0 \%$ & 35 & $7 \%$ & . & - \\
\hline 2006 & & $6 \%$ & & $1 \%$ & 20. & $2 \%$ & & - & & $6 \%$ & & $7 \%$ & & $8 \%$ & 35 & $2 \%$ & 45. & $7 \%$ \\
\hline 2007 & & $.8 \%$ & & $1 \%$ & 32. & $8 \%$ & & $5 \%$ & & $.2 \%$ & & - & & $0 \%$ & 35 & $7 \%$ & . & - \\
\hline 2008 & & $.5 \%$ & & $5 \%$ & 36. & $0 \%$ & & $6 \%$ & & $.2 \%$ & & $8 \%$ & & $3 \%$ & 32 & $6 \%$ & & - \\
\hline 2009 & & $3 \%$ & & $2 \%$ & 25. & $2 \%$ & & $5 \%$ & & $3 \%$ & & $3 \%$ & & $9 \%$ & 32 & $9 \%$ & & - \\
\hline Total & & $.6 \%$ & & $5 \%$ & 28. & $1 \%$ & & $1 \%$ & & $.2 \%$ & & $2 \%$ & & $.2 \%$ & 33 & $2 \%$ & 45. & $7 \%$ \\
\hline Sample & \# & MW & \# & MW & \# & MW & \# & MW & \# & MW & \# & MW & \# & MW & \# & MW & \# & MW \\
\hline Pre-1998 & 0 & 0 & 0 & 0 & 1 & 6 & 0 & 0 & 0 & 0 & 8 & 642 & 0 & 0 & 0 & 0 & 0 & 0 \\
\hline $1998-99$ & 0 & 0 & 1 & 25 & 0 & 0 & 2 & 20 & 0 & 0 & 5 & 194 & 4 & 58 & 10 & 482 & 0 & 0 \\
\hline $2000-01$ & 6 & 81 & 4 & 472 & 0 & 0 & 2 & 32 & 4 & 672 & 0 & 0 & 3 & 97 & 6 & 199 & 0 & 0 \\
\hline $2002-03$ & 3 & 161 & 2 & 137 & 0 & 0 & 1 & 50 & 1 & 160 & 4 & 287 & 4 & 512 & 20 & 599 & 0 & 0 \\
\hline 2004-05 & 2 & 349 & 4 & 431 & 0 & 0 & 1 & 54 & 5 & 1,197 & 3 & 130 & 2 & 200 & 14 & 1,053 & 0 & 0 \\
\hline 2006 & 1 & 26 & 3 & 573 & 2 & 1 & 0 & 0 & 1 & 124 & 2 & 188 & 2 & 150 & 7 & 499 & 1 & 30 \\
\hline 2007 & 4 & 169 & 5 & 964 & 2 & 44 & 4 & 626 & 6 & 1,055 & 0 & 0 & 4 & 776 & 9 & 1,086 & 0 & 0 \\
\hline 2008 & 6 & 613 & 3 & 303 & 2 & 29 & 8 & 765 & 18 & 3,036 & 2 & 69 & 6 & 446 & 31 & 3,148 & 0 & 0 \\
\hline 2009 & 11 & 955 & 20 & 1,126 & 3 & 143 & 8 & 1,480 & 13 & 2,143 & 2 & 270 & 9 & 908 & 21 & 1,943 & 0 & 0 \\
\hline Total & 33 & 2,353 & 42 & 4,031 & 10 & 221 & 26 & 3,028 & 48 & 8,386 & 26 & 1,780 & 34 & 3,146 & 118 & 9,010 & 1 & 30 \\
\hline
\end{tabular}




\section{Operations and Maintenance Costs Are Affected by the Age and Commercial Operation Date of the Project}

Operations and maintenance (O\&M) costs are a significant component of the overall cost of wind energy, but can vary substantially among projects. Market data on actual project-level O\&M costs are not readily available. Even where data are available, care must be taken in extrapolating historical O\&M costs given the dramatic changes in wind turbine technology that have occurred over the last two decades, not least of which has been the up-scaling of turbine size (see Figures 16 and 17, earlier). Anecdotal evidence suggests that O\&M costs and premature component failures continue to be key challenges for the wind power industry.

Berkeley Lab has compiled O\&M cost data for 126 installed wind power projects in the United States, totaling 7,502 MW of capacity, with commercial operation dates of 1982 through 2009. These data cover facilities owned by both independent power producers and utilities, though data since 2004 are exclusively from utility-owned projects. A full time series of O\&M cost data, by year, is available for only a small number of projects; in all other cases, O\&M cost data are available for just a subset of years of project operations. Although the data sources do not all clearly define what items are included in O\&M costs, in most cases the reported values include the costs of wages and materials associated with operating and maintaining the facility, as well as rent (i.e., land lease payments). ${ }^{69}$ Other ongoing expenses, including taxes, property insurance, and workers' compensation insurance, are generally not included; as such, the following figures are not representative of total operating expenses for wind power projects. Given the scarcity, limited content, and varying quality of the data, the results that follow may also not fully depict the industry's challenges with O\&M issues and expenditures; instead, these results should only be taken as illustrative of overall trends. Note finally that the available data are presented in $\$ / \mathrm{MWh}$ terms, as if O\&M represents a variable cost; in fact, O\&M costs are in part variable and in part fixed. Although not presented here, expressing O\&M costs in units of $\$ / \mathrm{kW}$-year yields qualitatively similar results to those presented in this section.

Figure 36 shows project-level O\&M costs according to the commercial operation date. ${ }^{70}$ Here, O\&M costs represent an average of annual project-level data available for the years 2000 through 2010. For example, for projects that reached commercial operations in 2009, only year 2010 data are available, and that is what is shown in the figure. ${ }^{71}$ Many other projects only have data for a subset of years during the 2000-10 timeframe, either because they were installed after 2000 or because a full time series is not available, so each data point in the chart may represent a different averaging period over 2000-10. The chart highlights the 43 projects, totaling 3,881 MW, for which 2010 O\&M cost data were available; those projects have either been updated or added to the chart since the previous edition of this report.

\footnotetext{
${ }^{69}$ The vast majority of the recent data derive from FERC Form 1, which uses Uniform System of Accounts definitions.

${ }^{70}$ For projects installed in multiple phases, the commercial operation date of the largest phase is used; for repowered projects, the date at which re-powering was completed is used.

${ }^{71}$ Projects installed in 2010 are not shown because only data from the first full year of project operations (and afterwards) are used, which in the case of projects installed in 2010 would be year 2011 (for which data are not yet available).
} 


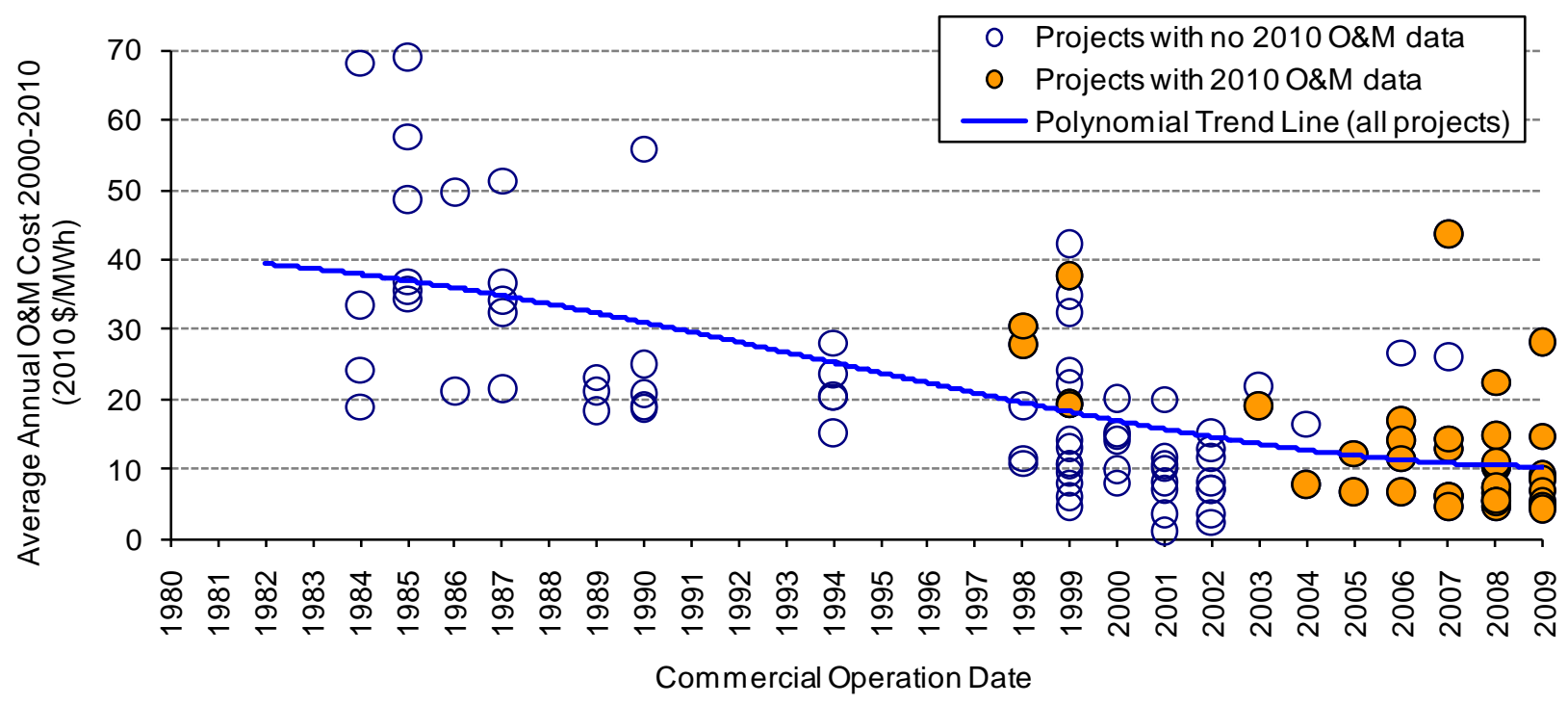

Source: Berkeley Lab; seven data points suppressed to protect confidentiality

\section{Figure 36. Average O\&M Costs for Available Data Years from 2000-2010, by Commercial Operation Date}

The data exhibit considerable spread, demonstrating that O\&M costs are far from uniform across projects. However, Figure 36 suggests that projects installed more recently have, on average, incurred lower O\&M costs. Specifically, capacity-weighted average 2000-10 O\&M costs for the 24 projects in the sample constructed in the 1980 s equal $\$ 33 / \mathrm{MWh}$, dropping to $\$ 22 / \mathrm{MWh}$ for the 37 projects installed in the 1990 s, and to $\$ 10 / \mathrm{MWh}$ for the 65 projects installed since $2000 .^{72}$ This drop in O\&M costs may be due to a combination of at least two factors: (1) O\&M costs generally increase as turbines age, component failures become more common, and manufacturer warranties expire $^{73}$; and (2) projects installed more recently, with larger turbines and more sophisticated designs, may experience lower overall O\&M costs on a per-MWh basis. Limitations in the underlying data, however, do not permit the influence of these two factors to be unambiguously distinguished.

To help illustrate the possible influence of these two factors, however, Figure 37 shows the median annual O\&M costs over time, based on the number of years since the commercial operation date. Annual data for projects grouped based on commercial operation date are averaged together, and data for projects under $5 \mathrm{MW}$ in size are excluded (to help control for the confounding influence of economies of scale). Note that, for each of the two commercial operation date based groups, the number of projects used to compute the median annual values shown in the figure is limited, and varies substantially (from 2 to 29 data points per project-year for projects installed from 1998 through 2003 and from 3 to 34 data points per project-year for

\footnotetext{
${ }^{72}$ If expressed instead in terms of $\$ / \mathrm{kW}$-yr, capacity-weighted average $2000-2010$ O\&M costs were $\$ 63 / \mathrm{kW}$-yr for projects in the sample constructed in the $1980 \mathrm{~s}$, dropping to $\$ 53 / \mathrm{kW}-\mathrm{yr}$ for projects constructed in the $1990 \mathrm{ss}$, and to $\$ 27 / \mathrm{kW}$-yr for projects constructed since 2000. Bloomberg New Energy Finance (2011) reports the cost of 5-year full-service O\&M contracts at $\$ 30-\$ 48 / \mathrm{kW}-\mathrm{yr}$.

${ }^{73}$ Many of the projects installed more-recently may still be within their turbine manufacturer warranty period, in which case the O\&M costs reported here may or may not include the costs of the turbine warranty, depending on whether the warranty is paid up-front as part of the turbine purchase, or is paid over time.
} 
projects installed from 2004 through 2009). With this limitation in mind, the figure shows that projects installed more recently have had, in general, lower O\&M costs than those installed in earlier years, at least for the first 5 years of operation. In addition, projects show an upward trend in project-level O\&M costs as they age, though the sample size after year four is quite limited.

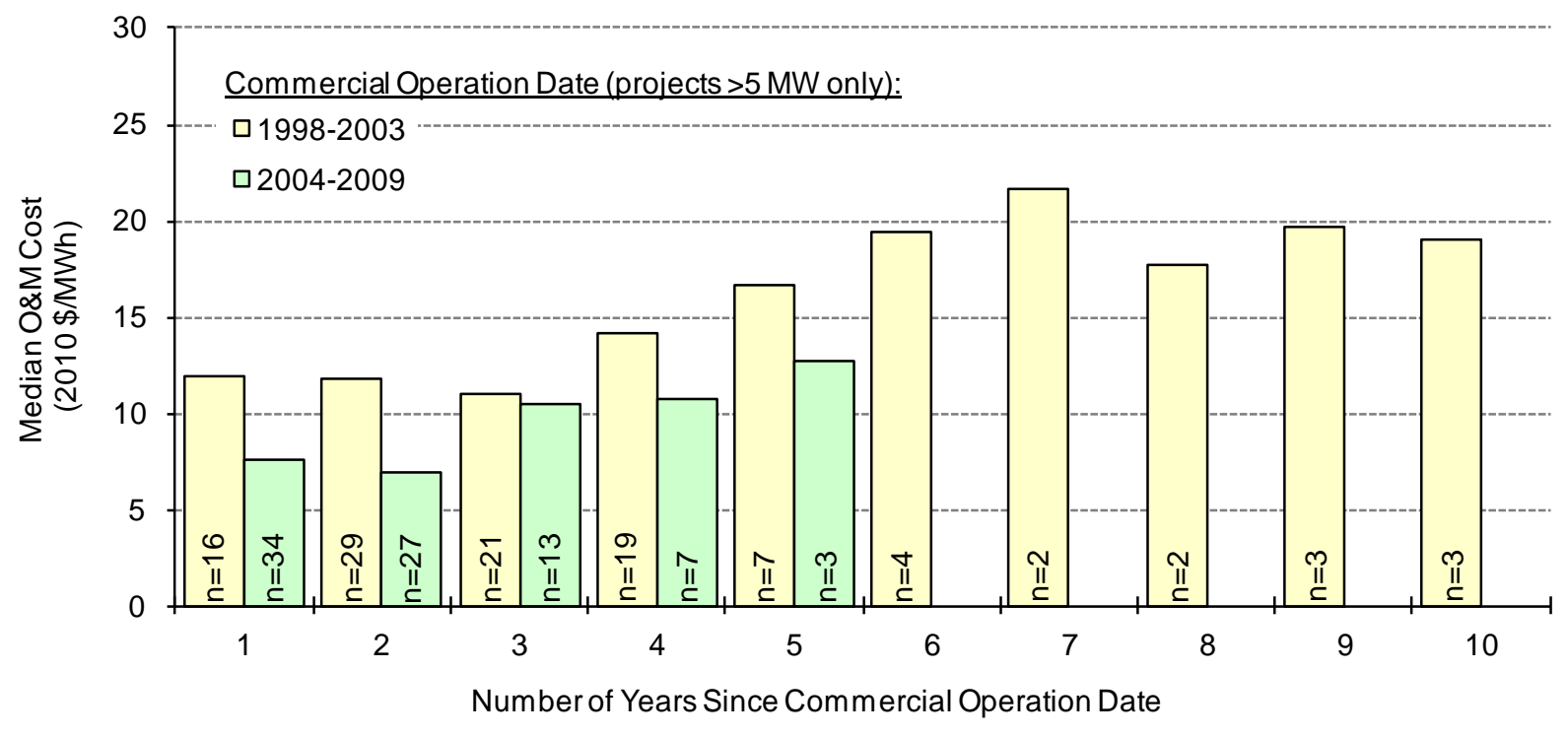

Source: Berkeley Lab; medians shown only for groups of two or more projects

Figure 37. Median Annual O\&M Costs by Project Age and Commercial Operation Date 


\section{Policy and Market Drivers ${ }^{74}$}

\section{Extension of the Treasury Grant Program and Bonus Depreciation Provides Some Measure of Federal Policy Certainty Through 2012}

A variety of policy drivers at both the federal and state levels have been important to the expansion of the wind power market in the United States. At the federal level, the most important policy incentives in recent years have been the PTC, accelerated tax depreciation, and two Recovery Act provisions that enable wind power projects to elect, for a limited time only, either a $30 \%$ investment tax credit (ITC) or a $30 \%$ cash grant in lieu of the PTC.

- First established by the Energy Policy Act of 1992, the PTC provides a 10-year, inflationadjusted credit that stood at $2.2 \varnothing / \mathrm{kWh}$ in 2010 (and will remain at that level in 2011). The historical importance of the PTC to the U.S. wind power industry is illustrated by the pronounced lulls in wind power capacity additions in the three years (2000, 2002, and 2004) in which the PTC lapsed, as well as the increased development activity often seen during the year in which the PTC is otherwise scheduled to expire (see Figure 1). Wind power projects are currently eligible for the PTC if they achieve commercial operations by the end of 2012.

- Accelerated tax depreciation enables project owners to depreciate the vast majority of their investments over a five- to six-year period for tax purposes. An even-more-attractive 50\% first-year "bonus depreciation" schedule was in place during 2008 and 2009, and in September 2010 was extended retroactively for 2010 as well. The Tax Relief, Unemployment Insurance Reauthorization, and Job Creation Act of 2010 that was signed into law in midDecember 2010 increased first-year bonus depreciation to $100 \%$ for those projects placed in service between September 8, 2010 and the end of 2011, after which the first-year bonus will revert to $50 \%$ for projects placed in service during 2012.

- The Recovery Act enables wind power projects placed in service prior to the end of 2012 to elect a 30\% ITC in lieu of the PTC. More importantly, given the relative scarcity of tax equity in the wake of the financial crisis (and in particular during 2009), Section 1603 of the Recovery Act also enables wind power projects to elect a 30\% cash grant from the Treasury in lieu of either the ITC or the PTC. More than $70 \%$ of the new wind capacity installed in 2010 elected the Section 1603 grant. Under the Recovery Act, wind power projects would have had to start construction by the end of 2010, applied for the grant by October 1, 2011, and be placed online by the end of 2012, in order to qualify for the grant. In mid-December 2010, however, the Tax Relief, Unemployment Insurance Reauthorization, and Job Creation Act of 2010 extended two of these three deadlines by one year: in order to qualify for the grant, wind power projects must now be under construction by the end of 2011, must have applied for a grant by October 1, 2012, and must be placed in service by the end of 2012 .

With the PTC, $30 \%$ ITC, $30 \%$ cash grant, and various levels of bonus depreciation all now firmly in place through $2012,{ }^{75}$ the wind energy sector currently enjoys two years of relative (and

\footnotetext{
${ }^{74}$ Though siting and permitting policies, regulations, and procedures at the local, state, and national levels can also significantly impact wind power development, these issues are not addressed comprehensively in this section or in this report.

${ }^{75}$ Although eligibility for the Treasury grant does hinge on construction having begun by the end of 2011, complying with this interim start-of-construction deadline is unlikely to be particularly onerous for most wind power
} 
relatively favorable) federal policy certainty in 2011 and 2012. Although many of the larger wind power developers had already (pre-December 2010) taken steps to qualify all of their planned 2011 projects and most of their planned 2012 projects for the Section 1603 grant under the Treasury safe harbor guidelines (Bloomberg NEF 2010), the one-year extension of the eligibility deadlines should nevertheless benefit many smaller wind power developers, most of whom do not have sizable enough balance sheets on which to carry projects for sustained lengthy construction periods.

Despite the extension of the Section 1603 Treasury grant program and the industry's success in locking in incentives through 2012, two other Recovery Act programs that had generated excitement among the industry in 2009 and 2010 were either not extended or will sunset in 2011. The Section 48C advanced energy manufacturing tax credit program, which provides a $30 \%$ investment tax credit for investments in renewable energy manufacturing facilities built in the U.S., was ultimately not extended as part of mid-December's tax package. The original allocation of $\$ 2.3$ billion in Section $48 \mathrm{C}$ credits had been heavily oversubscribed, leading to calls for an extension of the program. A second Recovery Act program, the Section 1705 loan guarantee program for commercial projects, will effectively wind down later this year, as projects must be under construction by September 30, 2011 in order to qualify. In 2010, this program closed two loan guarantees for wind projects: \$117 million for the $30 \mathrm{MW}$ Kahuku project in Hawaii, and \$1.3 billion for the 845 MW Caithness Shepherds Flat project in Oregon (two other wind projects - the 50.6 MW Record Hill project in Maine and the 99 MW Granite Reliable project in New Hampshire - received conditional guarantees for \$102 million and \$169 million loans, respectively, during the first half of 2011).

Finally, 2010 saw another year pass without any concrete action on what are seemingly the wind power industry's two highest priorities - passage of a federal renewable or clean energy portfolio standard, and a longer-term extension of federal tax (or cash) incentives.

\section{State Policies Play a Role in Directing the Location and Amount of Wind Power Development}

State policies continue to play a role in directing the location and amount of wind power development. From 1999 through 2010, for example, 63\% of wind power capacity built in the United States was located in states with RPS policies; in 2010, this proportion was $58 \%{ }^{76}$ As of June 2011, mandatory RPS programs existed in 29 states and Washington D.C. (Figure 38). Although no new state RPS policies were passed in 2010, a number of states strengthened previously established RPS programs. ${ }^{77}$ In aggregate, existing state RPS policies are estimated to require roughly $100 \mathrm{GW}$ of new renewable capacity by 2035 , representing $7 \%$ of total U.S.

projects, based on safe harbor guidance published by the Treasury in 2010. This is particularly true in conjunction with the firmer end-of-2012 placed-in-service deadline - i.e., most wind power projects planning to meet the end-of2012 placed-in-service requirement should not have much problem complying with the Treasury's safe harbor guidelines for meeting the interim end-of-2011 construction-start deadline.

${ }^{76}$ Such statistics provide only a rough indication of the impact of RPS policies on wind power development, and could either overstate or understate the actual policy effect to-date.

${ }^{77}$ Attempts to weaken RPS programs have also been initiated in some states, though those efforts have not thus far led to meaningful changes in RPS design. 
retail electricity sales in that year and $32 \%$ of projected load growth between 2000 and $2035 .^{78}$ Given the size of the RPS targets and the amount of new renewable energy capacity already built, however, existing state RPS programs are projected to drive annual average renewable energy additions of just 4-6 GW/year between 2011 and $2020,{ }^{79}$ which is roughly equivalent to the amount of renewable power capacity added in 2010 but well below the pace of renewable capacity additions in 2008 and 2009, demonstrating the limitations to relying exclusively on state RPS programs to drive future development. ${ }^{80}$

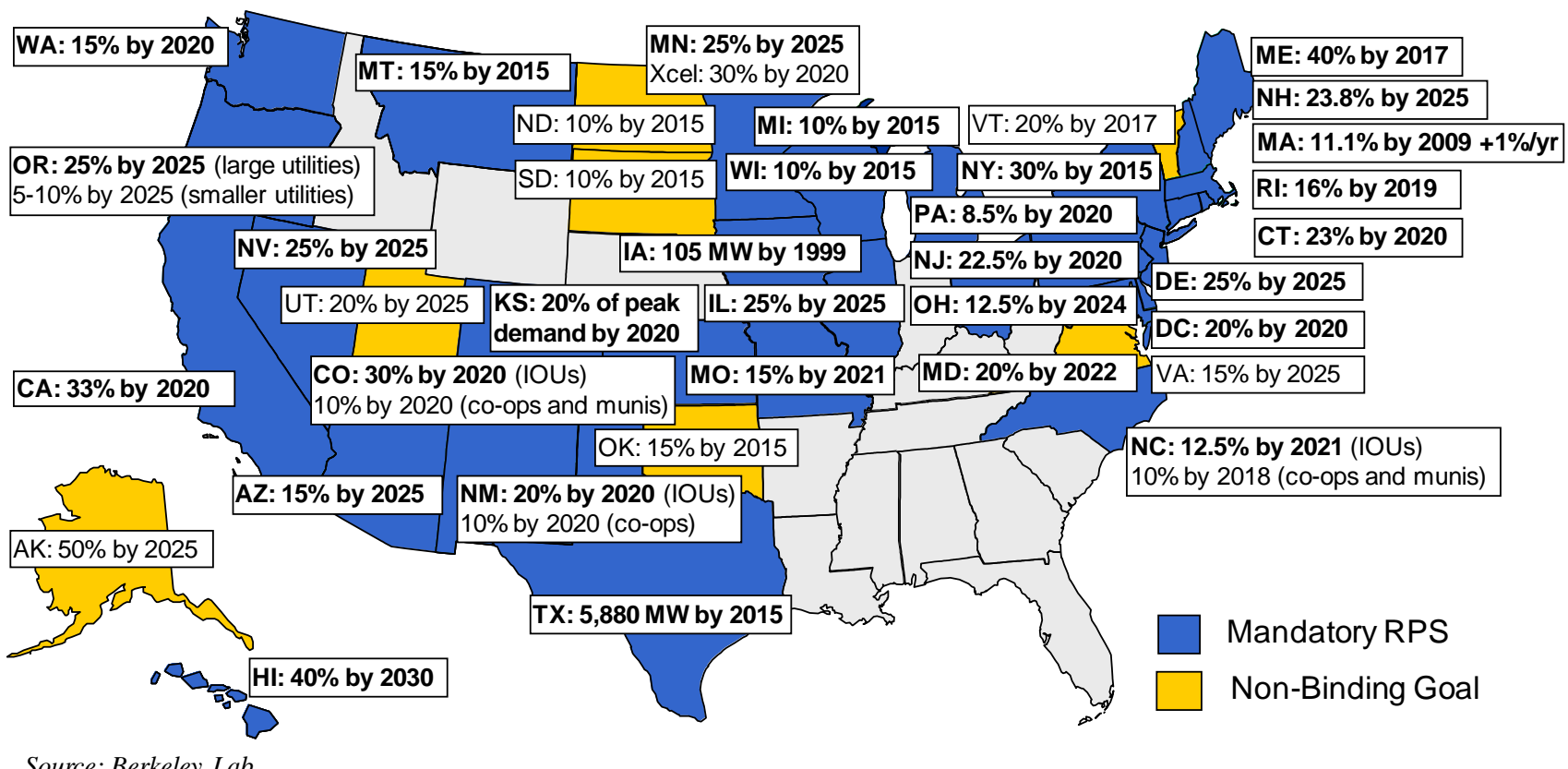

Note: The figure does not include West Virginia's mandatory "alternative and renewable energy portfolio standard" or Indiana's voluntary "clean energy standard." Under these two states' policies, both renewable and non-renewable energy resources may qualify, but neither state specifies any minimum contribution from renewable energy. Thus, for the purposes of the present report, these two states are not considered to have enacted mandatory RPS policies or non-binding renewable energy goals.

Figure 38. State RPS Policies and Non-Binding Renewable Energy Goals (as of June 2011)

Utility resource planning requirements, principally in Western and Midwestern states, have also helped spur wind power additions in recent years (especially as the prospect of future carbon regulations has been included as a variable in resource selection), as has growing voluntary customer demand for "green" power, especially among commercial customers. State renewable energy funds provide support for wind power projects (both financial and technical), as do a variety of state tax incentives. Finally, concerns about the possible impacts of global climate

\footnotetext{
${ }^{78}$ Berkeley Lab's projections of new renewable capacity required to meet each state's RPS requirements assume different combinations of renewable resource types for each RPS state, though they do not assume any biomass cofiring at existing thermal plants. To the extent that RPS requirements are met with a larger proportion of highcapacity-factor resources than assumed in this analysis or with biomass co-firing at existing thermal plants, the required new renewable capacity would be lower than the projected amount presented here.

${ }^{79}$ Again, varying combinations of renewable resource types for each RPS state were assumed in estimating the 4-6 GW/year of annual renewable capacity additions that are required to meet RPS obligations through 2020.

${ }^{80}$ Capacity additions in 2008 and 2009 were based, in part, on the market's willingness to construct merchant wind power projects, but that willingness began to diminish for projects installed in 2010 .
} 
change continue to fuel interest in some states and regions to implement and enforce carbon reduction policies. The Northeast's Regional Greenhouse Gas Initiative (RGGI) cap-and-trade policy is operational, for example, and carbon policies are also under discussion and being implemented in other regions, though still other states have expressed growing skepticism of these efforts and the carbon pricing seen to date under RGGI has been too low to drive wind energy growth.

\section{Despite Progress on Overcoming Transmission Barriers, Constraints Remain}

Transmission development has continued to gain some traction. The North American Electric Reliability Corporation (NERC), for example, reported that about 8,800 circuit miles of new transmission were added in 2010, with another 3,100 miles under construction. An additional 39,000 circuit miles of new transmission are projected by 2020 (NERC 2010). The Brattle Group, meanwhile, has tallied about 130 proposed transmission projects at various stages of development, representing over $\$ 180$ billion in potential investment (Pfeifenberger 2010), while AWEA (2011a) has identified near-term transmission projects that - if all were completed could carry 29,000 MW of wind power capacity.

Lack of transmission can be a barrier to wind power development, as illustrated by the data on wind energy curtailment reported earlier. New transmission is particularly important for wind energy because wind power projects are constrained to areas with adequate wind speeds, which are often located at a distance from load centers. There is also a mismatch between the relatively short timeframe often needed to develop a wind power project compared to the longer timeframe typically required to build new transmission. Uncertainty over siting and cost allocation, particularly for multi-state transmission lines, further complicates transmission development.

To address some of these concerns, FERC issued a proposed transmission cost allocation rule in June 2010 that, among other things, would require that local and regional transmission planning processes incorporate the transmission needs that emanate from state or federal policies (such as RPS programs) and would establish principles that cost allocation proposals from grid providers must meet. The FERC proposal also indicates that, if agreement cannot be reached on cost allocation, FERC would itself develop a cost allocation method based on the record in the particular case (FERC 2010a). As of June 2011, FERC has yet to issue a final rule.

States, grid operators, utilities, regional organizations, and DOE also continue to take proactive steps to encourage transmission investment to improve access to renewable resources. A nonexhaustive list of examples of these initiatives is presented below:

- Bonneville Power Administration (BPA): On June 30, 2010, BPA closed the window for its 2010 Network Open Season. BPA received 121 transmission service requests for 7,304 MW. BPA eventually received signed transmission agreements for 3,759 MW, including 2,493 MW of wind power (Johnson 2011). Overall, from 2008 through 2010, BPA processed 263 transmission service requests for 11,722 MW, including 7,105 MW associated with wind power (Tansey 2011). BPA is also constructing two transmission lines: the 500-kV McNary-John Day project, which is expected to go into service in 2012 and will support up to $700 \mathrm{MW}$ of new wind power capacity (BPA 2011a); and the 38-mile Central 
Ferry-Lower Monumental line in Southeastern Washington, which will support up to 840 MW of wind power when completed in 2013 (BPA 2011b). In May 2011, BPA indefinitely delayed plans for future Network Open Seasons until a review of transmission planning and wind energy integration issues is conducted (Tansey 2011).

- Southwest Power Pool (SPP): SPP received FERC approval for its Highway-Byway transmission cost allocation methodology where costs will be paid by load and allocated among regions based on transmission voltage. Transmission projects of $300 \mathrm{kV}$ and above will be funded in their entirety across all of SPP, whereas the costs for transmission projects between $100 \mathrm{kV}$ and $300 \mathrm{kV}$ will be allocated 1/3 across all of SPP and 2/3 locally. Costs for transmission projects below $100 \mathrm{kV}$ will be entirely recovered locally (SPP 2010a). Also in 2010, SPP authorized construction of $\$ 1.14$ billion of high-voltage transmission projects. The six priority projects are intended to transmit wind power to load centers in the eastern portion of SPP (SPP 2010b). The estimated cost for developing these projects has since increased to $\$ 1.42$ billion, sparking an investigation by the Missouri Public Service Commission (Missouri 2010). Finally, in July 2010, FERC approved SPP's new Integrated Transmission Planning Process (ITP). The ITP is a three-year iterative process that includes 20-year, 10-year and near-term transmission and reliability assessments.

- Midwest Independent Transmission System Operator (MISO): In December 2010, FERC approved MISO's proposal to use regional cost allocation for large transmission lines that meet at least one of three criteria: the transmission project is part of MISO's transmission planning process and is intended to meet state and/or federal energy policy requirements; it has a total benefit-to-cost ratio of 1 or higher; or it addresses at least one reliability-based transmission issue and one economic transmission issue and provides economic benefits across multiple pricing zones within MISO (FERC 2010b). Several parties have petitioned FERC for rehearing. FERC's approval prompted Xcel Energy to resume planning a 240-mile, 345-kV line from Brookings County, South Dakota to Hampton, Minnesota that could transmit 1,000 MW, much of it wind power (Xcel 2010). The Minnesota Public Utilities Commission granted a route permit for the proposed line in February 2011 (CapX2020 2011), while the South Dakota Public Utilities Commission granted a facility permit in June 2011. The $\$ 725$ million line is a part of CapX2020, a joint initiative of 11 transmission-owning utilities in Minnesota and the surrounding region to expand the transmission grid.

- Texas Competitive Renewable Energy Zones (CREZ): Several minor transmission and system upgrades related to the Texas CREZ effort have been completed, in part resulting in the lower amount of wind curtailment experienced in 2010 relative to 2009. A full year of operation of NextEra's 345-kV transmission line in west Texas, completed in October 2009, further contributed to this reduction. The Public Utility Commission of Texas (PUCT) also approved Lower Colorado River Authority's proposed 345-kV transmission line to transmit wind power from a substation in Schleicher County to a substation in Kendall County; one part of the project was dropped in favor of upgrading existing transmission lines (LCRA 2011). The line is expected to be in operation by December 2013. The PUCT approved two other transmission proposals in March 2011: Cross Texas Transmission's line, approximately 40 miles in length, which will extend from Lefors to the Panhandle area (Welch 2011); and Sharyland Utilities' 345-kV line that consist of two segments between three planned collection stations (Sharyland Utilities 2011). Separately, the PUCT denied a proposed project from Kendall to Newton, determining that alternative projects eliminated 
the need for the lines (Almon 2011). In total, the CREZ lines will accommodate about another 9,000 MW of wind power capacity when fully completed by 2013.

- California ISO (CAISO): In addition to revising elements of its interconnection process for small generators, FERC accepted the CAISO's revised state-wide transmission planning process that creates a new category of policy-driven transmission projects needed to meet state and federal policy requirements, such as California's greenhouse gas requirements and RPS. Competitive solicitations will be used to allow transmission developers to compete to construct economic- and policy-driven transmission projects, whereas transmission owners within the footprint of the CAISO will continue to have the responsibility to construct transmission projects necessitated by reliability, large generator interconnections, and to maintain the feasibility of congestion revenue rights (FERC 2010c).

A variety of efforts to proactively plan for transmission on a state and regional basis also continued in 2010, with interconnection-wide planning supported in part by previous grants by the DOE. Finally, numerous transmission projects have been proposed to in part accommodate the growth of wind energy throughout the country. Examples of these projects, with some focus on projects in the later stages of planning and development, are described below:

- In California, San Diego Gas \& Electric began building the $500 \mathrm{kV}$ Sunrise Powerlink line that will transmit up to 1,000 MW upon completion in 2012. Southern California Edison (SCE), meanwhile, has completed the first three segments of the Tehachapi transmission project (SCE 2010). SCE also began construction of the remaining eight segments (Rayl 2011, US Forest Service 2010). Once fully operational in 2015, the project is expected to be able to accommodate about 4,500 MW of renewable power (SCE 2010).

- The capacity of the Southern Transmission System that runs from Utah to California was uprated from 1,920 MW to 2,400 MW, allowing for the expansion of the Milford Wind project from $204 \mathrm{MW}$ to $306 \mathrm{MW}$ as well as further incremental use (LADWP 2011, First Wind 2011).

- PacifiCorp is developing the Energy Gateway Transmission Project, which will add approximately 2,000 miles of new transmission across the West. The first segment of the project, Populus-to-Terminal, went into service in November 2010 (PacifiCorp 2011).

- Construction began in late 2010 on the 500-kV One Nevada Transmission Line (ON Line) that will interconnect northern and southern Nevada (BLM 2011, NV Energy 2010). DOE approved a $\$ 343$ million loan guarantee for the ON Line project in February 2011, the first loan guarantee issued for a transmission project (DOE 2011).

- Central Maine Power began work in 2011 on its \$1.4 billion Maine Power Reliability Program, consisting of 500 miles of new or upgraded transmission lines that, among other things, will provide Maine wind power projects with greater access to southern New England markets upon completion in 2015 (CMP 2011). The Maine PUC approved the project in May 2010 (CMP 2010).

- In February 2011, the Michigan Public Service Commission approved ITC Transmission's proposed Thumb Loop Transmission Line Project, which is intended to tap the 2,367 to 4,236 MW of wind power potential in northeastern Michigan (ITC 2010). The project consists of 140 miles of double-circuit $345-\mathrm{kV}$ transmission lines and four new substations 
(Huron 2011). The first segment is expected to be completed by late 2013, with the entire project finished by 2015 (ITC 2010).

- TransCanada concluded an open season for the 500-kV Zephyr line that could transmit 3,000 MW between Wyoming and southern Nevada (TransCanada 2011). Three wind power developers - Horizon, BP, and Pathfinder - agreed to transmit on the Zephyr line, which is planned to be in service by 2015 or 2016. TransCanada suspended development of another $500-\mathrm{kV}$ line, the Chinook project, for lack of market interest.

\section{Integrating Wind Energy into Power Systems Is Manageable, but Not Free of Costs, and System Operators Are Implementing Methods to Accommodate Increased Penetration}

During the past several years, there has been a considerable amount of attention paid to the potential impacts of wind energy on power systems. Concerns about, and solutions to, these issues have affected, and continue to impact, the pace of wind power deployment in the United States.

In addition to activities at the state and regional level, wind integration is increasingly being evaluated at the national level by both FERC and NERC. In late 2010, FERC issued a notice of proposed rulemaking (NOPR) to remove barriers to the integration of variable energy resources, including wind energy. The proposed rules would affect three existing practices: transmission scheduling, forecasting, and balancing services. In particular, the reforms specify that: transmission providers would need to provide intra-hourly transmission scheduling; variable generators would need to provide meteorological and operational data to transmission operators for improving forecasting; and transmission providers would establish a rate to recover capacity costs incurred by the transmission operator to provide balancing between scheduling periods to a generator in a transmission provider's balancing area (i.e., generator regulation service). The transmission operator could require different volumes of generator regulation service for variable generators, relative to conventional generators, only after implementing intra-hour scheduling and power production forecasting (FERC 2010d). Meanwhile, the NERC Integration of Variable Generation Task Force continues to refine recommendations for changing planning and operational procedures to maintain reliable power system operation with high levels of variable generation. $^{81}$

Figure 39 provides a selective listing of estimated wind integration costs ${ }^{82}$ and Figure 40 summarizes the estimated increase in balancing reserves ${ }^{83}$ associated with increased wind energy

\footnotetext{
${ }^{81}$ Status updates and special reports from various tasks of the NERC Integration of Variable Generation Task Force are available at http://www.nerc.com/filez/ivgtf.html.

${ }^{82}$ The integration costs considered in these studies typically refer to the costs associated with accommodating the variability and uncertainty associated with wind energy. Generally, these costs are associated with three different time frames: regulation - from seconds to a few minutes; load-following - tens of minutes to a few hours; and unit commitment - out to the next day or two. Studies often, but not always, estimate these costs as the difference in overall electric system production costs between a scenario that captures the variability and unpredictability of wind energy and a scenario with an energy-equivalent block of power having no variability or uncertainty.

${ }^{83}$ In general, these balancing reserves reflect the resources required to maintain system balance between schedules. Often studies have balancing reserve requirements that change depending on the level of wind electricity generation
} 
from integration studies completed from 2003 through 2010 at various levels of wind power capacity penetration. ${ }^{84,85}$ System operators use reserves to balance variability and uncertainty between scheduling periods, and scheduling periods vary, so Figure 40 separates balancing reserves by the duration of the scheduling period assumed in the study. Regions with fast energy markets, for example, change the schedule of dispatchable generators over 5-minute periods while other regions often use hourly schedules. ${ }^{86}$ Because methods vary and a consistent set of operational impacts has not been included in each study, results from the different analyses of integration costs (Figure 39) and balancing reserves (Figure 40) are not fully comparable. Note also that the rigor with which the various studies have been conducted varies, as does the degree of peer review.

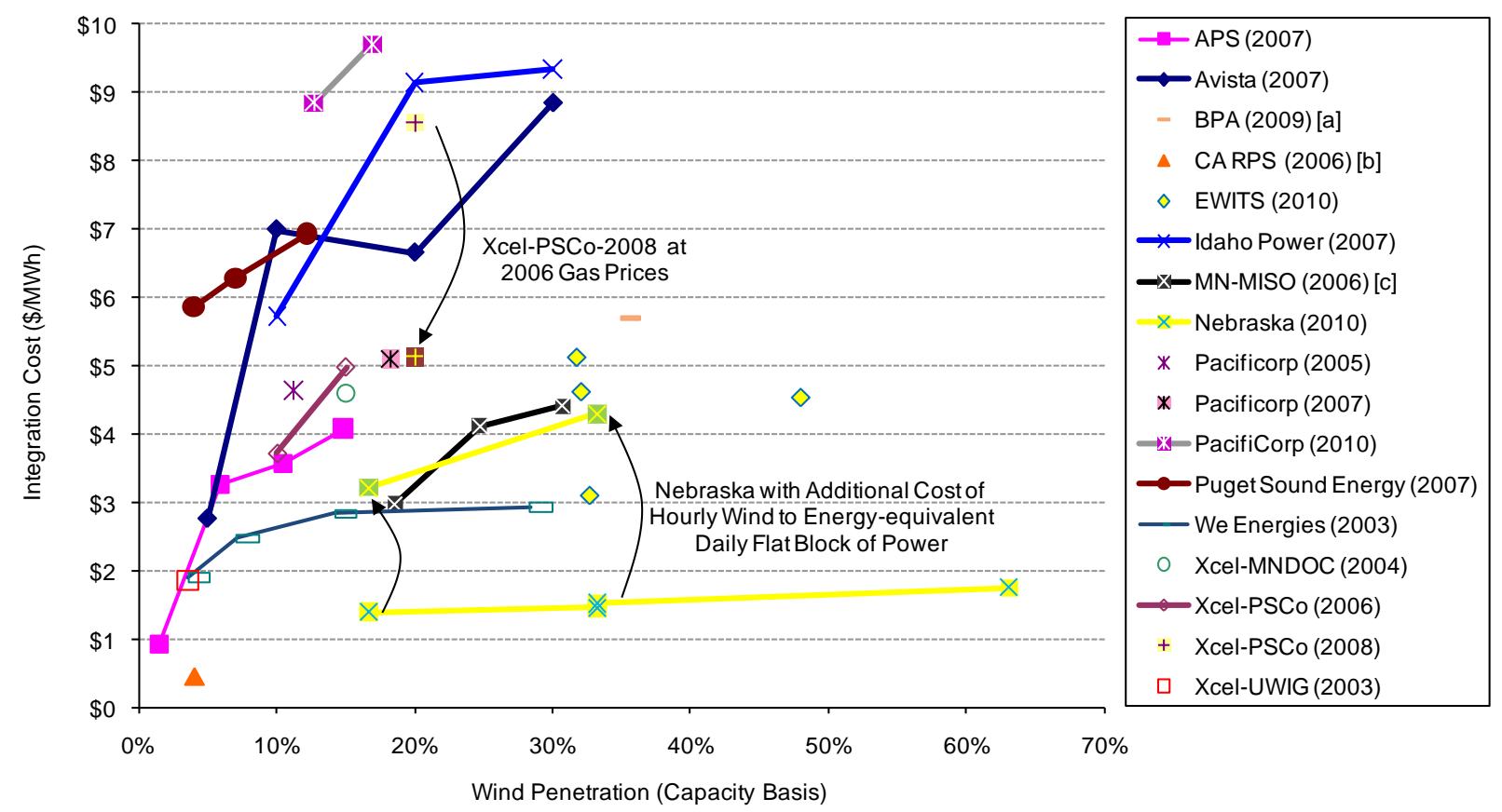

[a] Costs in \$/MWh assume 31\% capacity factor.

[b] Costs represent 3-year average.

[c] Highest over 3-year evaluation period.

Sources: Acker (2007) [APS (2007)]; EnerNex Corp. (2007) [Avista (2007)]; BPA (2009); Shiu et al. (2006) [CA RPS (2006)]; EnerNex Corp (2010) [EWITS (2010)]; EnerNex Corp. and Idaho Power Co. (2007) [ldaho Power (2007)]; EnerNex Corp. and WindLogics Inc. (2006) [MN-MISO (2006)]; EnerNex et al. (2010) [Nebraska (2010)]; PacifiCorp (2005); PacifiCorp (2007); PacifiCorp (2010); Puget Sound Energy (2007); Electrotek Concepts, Inc. (2003) [We Energies (2003)]; EnerNex Corp. and WindLogics, Inc. (2004) [Xcel-MNDOC (2004)]; EnerNex Corp. (2006) [Xcel-PSCo (2006)]; EnerNex Corp. (2008) [Xcel-PSCo (2008)]; Brooks et al. (2003) [Xcel-UWIG (2003)]

\section{Figure 39. Integration Costs at Various Levels of Wind Power Capacity Penetration}

or the time of day. The balancing reserves in the figure represent either the average reserves or the maximum increase in reserves depending on which statistics are reported by the study authors.

${ }^{84}$ Wind power penetration on a capacity basis (defined as nameplate wind power capacity serving a region divided by that region's peak electricity demand) was frequently used in earlier integration studies. For a given amount of wind power capacity, penetration on a capacity basis is typically higher than the comparable wind penetration in energy terms (because, over the course of a year, wind power projects generally operate at a lower percentage of their rated capacity, on average, than does aggregate load).

${ }^{85}$ Some studies address capacity valuation for resource adequacy purposes; those results are not presented here.

${ }^{86}$ Over half the load in the U.S. is now in regions with 5-minute scheduling: PJM, MISO, ERCOT, NYISO, ISONE, and CAISO. 


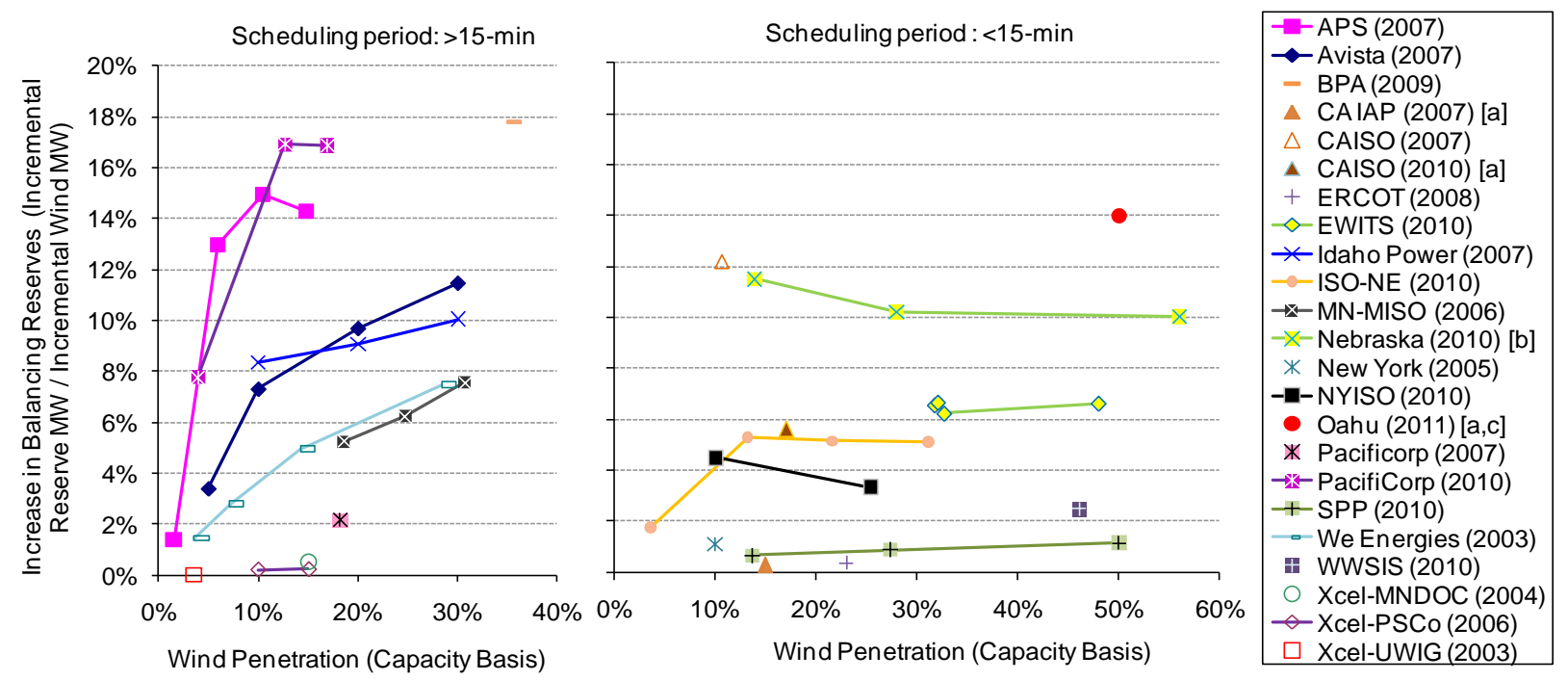

[a] Includes some solar energy in addition to wind energy.

[b] 3-year average.

[c] Small, isolated island system

Sources: See Figure 39; GE (2007) [CA IAP (2007)] ; CAISO (2007); CAISO (2010); GE (2008) [ERCOT (2008)]; GE (2010a) [ISONE (2010)]; GE (2005) [New York (2005)]; NYISO (2010); GE (2011) [Oahu (2011)]; Charles River Associates (2010) [SPP(2010)]; GE (2010b) [WWSIS (2010)]

\section{Figure 40. Incremental Balancing Reserves at Various Levels of Wind Power Capacity Penetration}

In addition to balancing reserve requirements and wind integration costs, a growing body of studies is focused on identifying the required changes to existing practices in power system operations, the role of forecasting, and the capability of thermal and hydropower generators to provide the needed flexibility to integrate wind power. An increasing portion of the wind integration studies are being conducted by or commissioned by RTOs and ISOs (e.g. CAISO, ERCOT, SPP, New York Independent System Operator (NYISO), and Independent System Operator - New England (ISO-NE); PJM recently initiated its own integration study). Key conclusions that continue to emerge from the growing body of integration literature include the following:

- Wind energy integration costs are below $\$ 10 / \mathrm{MWh}$ - and often below $\$ 5 / \mathrm{MWh}$ - for wind power capacity penetrations up to about $40 \%$ of the peak load of the system in which the wind power is delivered. ${ }^{87}$ Variations in estimated costs across studies are due, in part, to differences in methodologies, definitions of integration costs, power system and market characteristics, wind energy penetration levels, and fuel price assumptions.

\footnotetext{
${ }^{87}$ The relatively low cost estimates in the 2006 Minnesota study and the 2010 Nebraska study, despite aggressive levels of wind power penetration, are partly a result of relying on the broader regional electricity market to accommodate certain elements of integrating wind energy into system operations. Conversely, the higher integration costs found by Avista, Idaho Power, and PacifiCorp are, in part, caused by the relatively smaller markets in which the wind energy is being absorbed and by those utilities' operating practices. Specifically, the Northwest currently uses hourly scheduling intervals rather than the sub-hourly markets common in ISOs and RTOs. A sensitivity case in the Avista Utilities study demonstrates that the use of a 10-minute transaction scheduling interval would decrease the cost of integrating wind energy by $40-60 \%$.
} 
- Larger balancing areas, such as those found in RTOs and ISOs, make it possible to integrate wind energy more easily and at lower cost than is the case in smaller balancing areas.

- The successful use of wind power forecasts by system operators can significantly reduce integration challenges and costs. Wind forecasts aggregated across large, electrically interconnected areas are more accurate than non-aggregated wind forecasts for individual wind plants.

- Intra-hour scheduling (e.g., 5-minute scheduling) provides access to flexibility in conventional power plants that lowers the costs of integrating wind energy.

- The increase in balancing reserves with increased wind power penetration is projected to be a maximum of $18 \%$ of the nameplate capacity of wind power, and typically considerably less than this figure, particularly in studies that use intra-hour scheduling. A number of studies indicate that the amount of balancing reserves needed at any particular time changes with different wind and load conditions.

Aside from the recent proposed reforms from FERC, ISOs and utilities are also continuing to take important steps to mitigate the challenges faced with integrating larger quantities of wind energy. Centralized wind energy forecasting systems are currently in place in PJM, ERCOT, MISO, NYISO, CAISO, SPP, Southern California Edison and Xcel Energy, while the BPA is currently evaluating wind forecasting systems (Porter and Rogers 2010). FERC conditionally approved Midwest ISO's proposal to require wind generators to register as Dispatchable Intermittent Resources that can be dispatched by the real-time market dispatch system up to a forecast maximum limit, similar to the treatment of wind in NYISO and PJM (FERC 2011). As a first step towards better coordination across balancing areas, the Western Electricity Coordinating Council (WECC) authorized a cost benefit analysis of an Energy Imbalance Market (EIM). The proposed EIM has many similarities to the current SPP imbalance market and, if developed, would provide a sub-hourly, real-time energy market providing centralized, automated, interconnection-wide generation dispatch within the Western Interconnection (WECC 2010).

Some utilities are now directly charging wind power projects for balancing services. ${ }^{88}$ BPA, for example, includes a wind energy balancing charge in its transmission tariff equivalent to about \$5.70/MWh. FERC has also approved a higher generator regulation and frequency response services charge for wind energy in the Westar Energy balancing area, equivalent to about $\$ 0.80 / \mathrm{MWh}$; this interim tariff will be in place until it is rendered unnecessary through the anticipated implementation of an ancillary services market and balancing authority area consolidation in SPP (FERC 2010e). The proposed FERC reforms in the recent NOPR on variable generation noted earlier may lead to other transmission providers establishing rates for generator regulation service similar to the rate from Westar Energy. FERC did, however, reject a similar proposal by Puget Sound Energy (PSE) due to a cost estimation methodology that relied on the capacity cost of a generation unit that PSE may never construct (FERC 2010d).

\footnotetext{
${ }^{88}$ In addition, Idaho Power, Avista, and PacifiCorp all discount their published avoided cost payments for qualifying wind power projects in Idaho by an integration rate that ranges from 7-9\% of the avoided cost rate, up to \$6.50/MWh (IPUC 2010). In early 2011, however, the Idaho PUC reduced the maximum size of a qualifying wind power facility from $10 \mathrm{MW}$ to $100 \mathrm{~kW}$. Projects larger than $100 \mathrm{~kW}$ will need to directly negotiate individual project PPA prices rather than obtaining the published avoided cost rate.
} 
Finally, a new study commissioned by FERC and completed in 2010 highlighted one area that deserves attention due to potential reliability implications: frequency response. Among other conclusions, the study found that, although the declining quantity of frequency control in the U.S. is a significant reliability concern, wind generation has not contributed to the declines observed over the past decade. Furthermore, projected levels of wind energy in 2012 could be reliably integrated with current operating reserve practices. The report highlighted that adequate primary and secondary frequency control reserves to manage both wind variations and the sudden loss of generation must be scheduled at all times. In order to ensure adequate response, frequency control capabilities, potentially including controls that could be provided by wind power generators to provide frequency response, should be expanded in the future (Eto et al. 2010). ${ }^{89}$

\footnotetext{
${ }^{89}$ An additional study commissioned by the Interstate Natural Gas Association of America calls attention to the interdependencies between the electric power system and the natural gas delivery system, with particular attention to variable generation. Though more detailed analysis is required to accurately quantify cost implications, the report illustrates the challenge of ensuring adequate flexibility in the natural gas pipeline and storage system, including increased use of compressors and potentially pipeline expansion, to accommodate increased variability and uncertainty in the power system (ICF International 2011). The 2006 Xcel-PSCo wind integration study estimated the cost of expanding natural gas storage to accommodate increased day-ahead forecast errors in a scenario with $15 \%$ wind capacity penetration. The cost of expanding the natural gas storage system was estimated at $\$ 1.45 / \mathrm{MWh}$, which is included in the total integration cost estimate of \$4.97/MWh (EnerNex Corp. 2006).
} 


\section{Future Outlook}

At 5,113 MW, wind power capacity additions in 2010 fell below every market forecast for 2010 (which ranged from 5,500-8,000 MW) as presented in last year's edition of the Wind Technologies Market Report. The combination of the delayed impact of the global financial crisis, relatively low natural gas and wholesale electricity prices, and slumping overall demand for energy outweighed the ongoing availability of existing federal and state incentives for wind energy deployment, resulting in a steep drop in capacity additions relative to both 2008 and 2009.90

Nevertheless, with federal incentives for wind energy in place through 2012, an improved project finance environment in 2010 and early 2011, and lower wind turbine and wind power pricing, modest growth in annual wind power capacity appears likely in 2011 relative to 2010 . Additions are expected to remain well below the 2009 high, however, due in part to relatively low wholesale electricity prices and limited need for new electric capacity additions (which are likely to reduce merchant wind power development and utility demand for wind energy PPAs), and in part to existing state-level RPS programs that, in aggregate, are not sizable enough to support continued wind power capacity additions at 2008 and 2009 levels. As shown in Table 8, a variety of forecasts suggest that wind power installations in 2011 may fall within the range of 4,450 MW to 8,000 MW. With the exceptions of the EIA (2011) forecast, the remaining forecasts show an increase in capacity additions compared to the 5,113 MW installed in 2010, but all forecasts are substantially below the 2009 high of 9,993 MW.

Table 8. Forecasts for Annual U.S. Wind Capacity Additions (MW)

\begin{tabular}{|l|c|c|c|c|}
\hline Source & $\mathbf{2 0 1 1}$ & $\mathbf{2 0 1 2}$ & $\mathbf{2 0 1 3}$ & $\begin{array}{c}\text { Cumulative Additions } \\
\mathbf{2 0 1 1 - 2 0 1 3}\end{array}$ \\
\hline EIA (2011) & 4,450 & 7,480 & 170 & 12,100 \\
\hline BTM (2011) & 8,000 & 10,000 & 8,000 & 26,000 \\
\hline IHS EER (2011) & 5,700 & 6,100 & 6,300 & 18,100 \\
\hline Bloomberg NEF (2011) & 7,300 & 7,800 & 7,700 & 22,800 \\
\hline MAKE Consulting (2011) & 6,250 & 8,000 & 6,500 & 20,750 \\
\hline UBS Limited (2011) & 5,400 & 5,600 & 5,900 & 16,900 \\
\hline
\end{tabular}

Most predictions show further growth in 2012, as the cost of wind energy continues to decline as a result of lower wind turbine pricing and as developers rush to capture federal incentives currently slated to expire at the end of that year. Specifically, projections for 2012 summarized in Table 8 range from 5,600 to 10,000 MW. Forecasts for 2013, meanwhile, span a particularly wide range, depending in part on assumptions about the possible extension of federal incentives beyond 2012, but in general are weighed down by current policy uncertainty as well as the expected limited need for new electric capacity additions. The EIA (2011) reference case

\footnotetext{
90 The fact that these same drivers did not impact capacity additions in 2009 can be explained, in part, by the "inertia" in capital-intensive infrastructure investments: 2009 capacity additions were largely determined by decisions made prior to the economy-wide financial crisis that was at its peak in late 2008 and early 2009, whereas decisions on 2010 capacity additions were often made at the height of the financial crisis.
} 
forecast, for example, assumes no extension of federal tax incentives beyond 2012 and forecasts little need for new electric capacity additions over this period, resulting in a precipitous drop in projected 2013 wind installations. The remaining 2013 forecasts predict wind power capacity additions of 5,900-8,000 MW, presumably on the basis of an assumed continued extension of federal policy incentives of some form. In total, from 2011 through 2013, these forecasts predict cumulative wind power additions of 12,100 to $26,000 \mathrm{MW}$; this amount of new wind power capacity would be capable of providing roughly 30-60\% of EIA's projected growth in total U.S. electricity demand over the 2011-2014 timeframe.

These growth projections, even if below the high witnessed in 2009, are expected to ensure that the United States retains its position as the second-largest wind energy market in the world in terms of annual capacity additions. Driven by rapidly growing energy demands and strong policy support, China is widely anticipated to continue to dominate annual wind power capacity additions by a wide margin in the coming years. Industrial policy and market conditions have also resulted in the growing dominance of Chinese wind turbine manufacturers within the Chinese market, and those manufacturers have begun to explore export strategies. In part as a result, and in a continuation of recent trends, the historically-dominant wind turbine suppliers in the United States market are likely to face growing competition from new entrants, though widespread entry by Chinese suppliers is unlikely within the next few years as uncertainty in turbine quality and bankability concerns exist.

Uncertainties about market performance even over the 2011-2013 timeframe are the result of underlying uncertainties about market and policy drivers. On the positive side, the wind power industry benefits from some certainty on the available of federal incentives for projects installed through 2012, and state policies have become more aggressive. Moreover, financing conditions have improved since 2009, and the availability of power purchase agreements has also begun to improve. With wind turbine prices having dropped substantially, the recent trend of increasing project-level costs and prices will reverse. Negotiated power sales prices for wind power projects to be built in the near future have experienced steep declines and, as a result, the comparative economic position of wind energy has improved.

On the other hand, with the window of eligibility for the Treasury Grant program scheduled to close at the end of 2011 (though most projects built in 2012 are also likely to qualify) and with federal tax credits slated to expire at the end of 2012, growth beyond 2012 is highly uncertain. Wind energy industry hopes for a federal renewable or clean energy standard, or climate legislation, have dimmed in the near term. Even before 2012, growth may continue to be negatively impacted by the limited need for new electric capacity additions to meet demand. With relatively low natural gas prices and reduced near-term price expectations, wind energy's primary competitor is more economically attractive than in previous years. The significant wind energy growth in recent years has also exceeded aggregate state RPS demands, resulting in softer incremental demand from RPS markets in the near term. Wind power additions are increasingly constrained by inadequate transmission infrastructure, and while progress is being made to alleviate those constraints, the build-out of transmission infrastructure will take time. Siting and permitting procedures at the local, state, and national level can also delay and constrain wind 
power development. ${ }^{91}$ Finally, in California and the Southwest in particular, wind energy is beginning to face stiff competition with solar in meeting state renewable energy requirements, as the cost of solar energy has declined substantially in recent years.

Regardless of these competing trends, wind power capacity additions over the past several years, and a number of projections for future additions from 2011-2013, put the United States on a trajectory that may lead to $20 \%$ of the nation's electricity demand coming from wind energy by 2030. In May 2008, the U.S. Department of Energy, in collaboration with its national laboratories, the wind power industry, and others, published a report that analyzed the technical and economic feasibility of achieving $20 \%$ wind energy penetration by 2030 (DOE 2008). In addition to finding no insurmountable barriers to reaching $20 \%$ wind energy penetration, the report also laid out a potential wind power deployment path that started at $3.3 \mathrm{GW} /$ year in 2007 , increasing to $4.2 \mathrm{GW} /$ year by $2009,6.4 \mathrm{GW} /$ year by $2011,9.6 \mathrm{GW} /$ year by $2013,13.4 \mathrm{GW} /$ year by 2015, and roughly $16 \mathrm{GW} / y e a r$ by 2017 and thereafter, yielding cumulative wind power capacity of $305 \mathrm{GW}$ by 2030 . Historical growth over the last five years puts the United States on a trajectory exceeding this deployment path, and the projected growth presented in Table 8 would, if met, ensure that the United States remains in that position through 2013, at least on a cumulative basis. Nonetheless, all of the projections for annual capacity additions in 2013 fall short of the annual growth envisioned in the $20 \%$ wind energy report for that year (Figure 41), suggesting that there is a risk that the market will not grow rapidly enough to maintain a longterm trajectory consistent with a 20\% wind energy penetration level by 2030 .

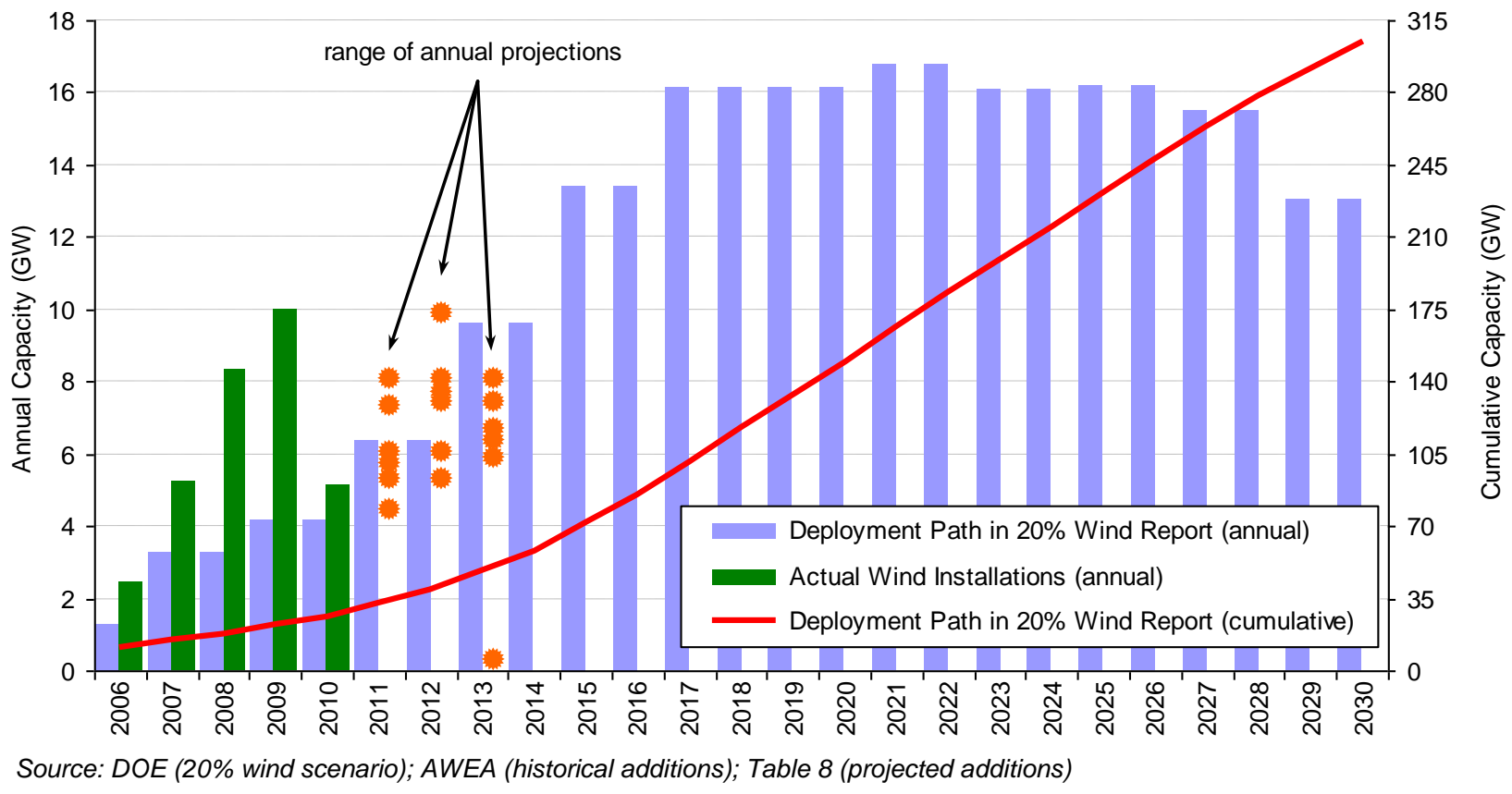

Figure 41. Wind Power Capacity Growth: 20\% Wind Report, Actual Installations, Projected Growth

\footnotetext{
${ }^{91}$ As with other forms of energy development, a variety of concerns about public acceptance and wildlife impacts are addressed in the planning, siting, and permitting process for wind power plants. At the national level, in May 2011, the wind power industry expressed particular concern about the U.S. Fish and Wildlife Service's Draft LandBased Wind Energy Guidelines and the Eagle Conservation Plan Guidance.
} 
Ramping up to an annual installation rate of $16 \mathrm{GW}$ per year, and maintaining that rate for a decade, is far from pre-determined, as demonstrated by the lull experienced in 2010 and the moderate growth expected for 2011-13. Whether the roughly $16 \mathrm{GW}$ per year pace needed for wind power to contribute $20 \%$ of the nation's electricity by 2030 can be achieved and maintained remains to be seen, though uncertainty in federal policy towards wind energy after 2012 places such an outcome at risk. In addition to stable, long-term promotional policies, the DOE (2008) report suggests four other areas where supportive actions may be needed in order to reach such annual installation rates. First, the nation will need to invest in significant amounts of new transmission infrastructure designed to access remote wind resources. Second, to moreeffectively integrate wind power into electricity markets, larger power control regions, better wind forecasting, and increased investment in fast-responding generating plants will be required. Third, siting and permitting procedures will need to be designed to allow wind power developers to identify appropriate project locations and move from wind resource prospecting to construction quickly. Finally, enhanced research and development efforts in both the public and private sector will be required to lower the cost of offshore wind power, and incrementally improve conventional land-based wind energy technology. 


\section{Appendix: Sources of Data Presented in this Report}

\section{Installation Trends}

Data on wind power additions in the United States come from AWEA, though methodological differences noted throughout this report result in some discrepancies in the data presented here relative to AWEA (2011a). Annual wind power capital investment estimates derive from multiplying these wind power capacity data by weighted-average capital cost data, provided elsewhere in the report. Data on non-wind electric capacity additions come primarily from EIA (for years prior to 2010) and Ventyx's Velocity database (for 2010), except that solar data come from the Interstate Renewable Energy Council (IREC) and SEIA/GTM (Solar Energy Industries Association / GTM Research). Data on the small wind turbine market - through 2009 - come from AWEA (2010); data for 2010 installations are expected later in 2011. Information on offshore wind power development activity in the United States was compiled by Energetics, Berkeley Lab, and the National Renewable Energy Laboratory (NREL), based in part on a variety of publically available sources, including press releases, news articles, and federal and state regulatory filings.

Global cumulative (and 2010 annual) wind power capacity data come from BTM (2011), but are revised to include the U.S. wind power capacity used in the present report. Wind energy as a percentage of country-specific electricity consumption is based on end-of-2010 (and end-of2006/07/08/09) wind power capacity data and country-specific assumed capacity factors that come primarily from BTM (2011), as revised based on a review of EIA country-specific wind power data. For the United States, the performance data presented in this report are used to estimate wind energy production. Country-specific projected wind generation is then divided by projected electricity consumption in 2011 (and 2007/08/09/10), based on actual 2008 consumption and a country-specific growth rate assumed to be the same as the rate of growth from 2005 through 2008 (these data come from EIA).

The wind power project installation map was created by NREL, based in part on AWEA's database of projects and in part on data from Platts on the location of individual projects. Effort was taken to reconcile the AWEA project database and the Platts-provided project locations, though some discrepancies remain. Estimated wind energy as a percentage contribution to statewide electricity generation is based on AWEA installed capacity data for the end of 2010 and the underlying wind power project performance data presented in this report. Where necessary, judgment was used to estimate state-specific capacity factors. The resulting state wind generation is then divided by in-state total electricity generation in 2010, based on EIA data. Actual state-level wind energy penetration figures for 2010 are derived from EIA data.

Data on wind power capacity in various interconnection queues come from a review of publicly available data provided by each ISO, RTO, or utility. Only projects that were active in the queue at the end of 2010, but that had not yet been built, are included. Suspended projects are not included in these listings. Data on projects that are in the nearer-term development pipeline come from Ventyx (2011) and other sources. 


\section{Industry Trends}

Turbine manufacturer market share and average turbine size are derived from the AWEA wind power project database, with some processing by Berkeley Lab. Information on turbine hub heights and rotor diameters were compiled by Berkeley Lab based on information provided by turbine manufacturers, standard turbine specifications, Federal Aviation Administration data, web searches, and other sources.

Information on wind turbine and component manufacturing come from NREL, AWEA, and Berkeley Lab, based on a review of press reports, personal communications, and other sources. Data on U.S. nacelle assembly capacity came from Bloomberg NEF (2011). The listings of manufacturing and supply chain facilities are not intended to be exhaustive. Data on aggregate U.S. imports and exports of wind power equipment come primarily from the U.S. International Trade Commission (USITC), and can be obtained from the USITC's DataWeb (http://dataweb.usitc.gov/).

Information on wind power developer consolidation and financing trends were compiled by Berkeley Lab. Wind project ownership and power purchaser trends are based on a Berkeley Lab analysis of the AWEA project database.

\section{Price, Cost, and Performance Trends}

Wind power price data are based on multiple sources, including prices reported in FERC's Electronic Quarterly Reports, FERC Form 1, avoided cost data filed by utilities, pre-offering research conducted by bond rating agencies, and a Berkeley Lab collection of power purchase agreements. Wholesale electricity price data were compiled by Berkeley Lab from the IntercontinentalExchange (ICE) as well as Ventyx's Velocity database (which itself derives wholesale price data from the ICE and the various ISOs). Earlier years' wholesale electricity price data come from FERC $(2007,2005)$. REC price data were compiled by Berkeley Lab based on information provided by Evolution Markets and Spectron.

Berkeley Lab used a variety of public and some private sources of data to compile capital cost data for a large number of U.S. wind power projects. Data sources range from pre-installation corporate press releases to verified post-construction cost data. Specific sources of data include: EIA Form 412, FERC Form 1, various Securities and Exchange Commission filings, various filings with state public utilities commissions, Windpower Monthly magazine, AWEA's Wind Energy Weekly, DOE/EPRI's Turbine Verification Program, Project Finance magazine, various analytic case studies, and general web searches for news stories, presentations, or information from project developers. For 2009 and 2010 projects, data from the Section 1603 Treasury Grant program were used extensively. Some data points are suppressed in the figures to protect data confidentiality. Because the data sources are not equally credible, little emphasis should be placed on individual project-level data; instead, it is the trends in those underlying data that offer insight. Only wind power cost data from the contiguous lower-48 states are included.

Wind turbine transaction prices were compiled by Berkeley Lab. Sources of transaction price data vary, but most derive from press releases, press reports, and Securities and Exchange Commission filings. In part because wind turbine transactions vary in the services offered, a good deal of intra-year variability in the cost data is apparent. Additionally, the data do not 
adequately capture the recent softening of the wind turbine market since late 2008, as relatively few publicly reported wind turbine sales transactions exist since that time.

Wind power project performance data are compiled overwhelmingly from two main sources: FERC's Electronic Quarterly Reports and EIA Form 923. Additional data come from FERC Form 1 filings and, in several instances, other sources. Where discrepancies exist among the data sources, those discrepancies are handled based on the judgment of Berkeley Lab staff. Data on curtailment are from ERCOT (for Texas), MISO (for the Midwest), Xcel Energy (for its Northern States Power, Public Service Company of Colorado, and Southwestern Public Service Company subsidiaries), and from BPA (for the Northwest).

Wind project operations and maintenance costs come primarily from two sources: EIA Form 412 data from 2001-2003 for private power projects and projects owned by POUs, and FERC Form 1 data for IOU-owned projects. Some data points are suppressed in the figures to protect data confidentiality.

\section{Policy and Market Drivers}

The wind energy integration, transmission, and policy sections were written by staff at Berkeley Lab and Exeter Associates, based on publicly available information.

\section{Future Outlook}

This section was written by staff at Berkeley Lab, based largely on publicly available information. 


\section{References}

Acker, T. 2007. Arizona Public Service Wind Integration Cost Impact Study. Prepared for Arizona Public Service Company. Flagstaff, Arizona: Northern Arizona University.

Almon, B. 2011. Personal communication with Brian Almon, Public Utility Commission of Texas. January 31, 2011.

American Wind Energy Association (AWEA). 2011a. U.S. Wind Industry Annual Market Report: Year Ending 2010. Washington, D.C.: American Wind Energy Association.

American Wind Energy Association (AWEA). 2011b. U.S. Wind Industry First Quarter 2011 Market Report. Washington, D.C.: American Wind Energy Association.

American Wind Energy Association (AWEA). 2010. AWEA Small Wind Turbine Global Market Survey, Year Ending 2009. Washington, D.C.: American Wind Energy Association.

AWS Truepower. 2011. windTrends Bulletin: 2010 Q4. Released March 1, 2011.

Bloomberg New Energy Finance (Bloomberg NEF). 2011. North America Wind Market Outlook: Q1 2011. February 23, 2011.

Bloomberg New Energy Finance (Bloomberg NEF). 2010. Q3 2010 Earnings Review. November 22, 2010.

Bonneville Power Administration (BPA). 2011a. McNary-John Day 500-kilovolt Transmission Line. http://www.bpa.gov/corporate/RecoveryAct/mcnary-johnday.cfm.

Bonneville Power Administration (BPA). 2011b. BPA Announces Decision to Build Central Ferry-Lower Monumental Line. March 24, 2011. http://www.bpa.gov/corporate/BPANews/ArticleTemplate.cfm?ArticleId=article20110325-01.

Brooks, D., E. Lo, R. Zavadil, S. Santoso and J. Smith. 2003. Characterizing the Impact of Significant Wind Generation Facilities on Bulk Power System Operations Planning: Xcel Energy - North Case Study. Prepared for the Utility Wind Integration Group. Arlington, Virginia: Electrotek Concepts.

BTM Consult (BTM). 2011. International Wind Energy Development: World Market Update 2010. Ringkobing, Denmark: BTM Consult ApS.

Bureau of Land Management (BLM). 2011. OnLine Transmission Line. March 18, 2011. http://www.blm.gov/nv/st/en/fo/ely_field_office/blm_programs/energy/on_line_transmissi on.html.

Bureau of Ocean Energy Management, Regulation, and Enforcement (BOEMRE). 2010. Commercial Lease of Submerged Lands for Renewable Energy Development on the Outer Continental Shelf. U.S. Department of Interior. Renewable Energy Lease Number OCS-A 0478. Washington, D.C.

California ISO (CAISO). 2010. Integration of Renewable Resources at 20\% RPS. Folsom, California: California Independent System Operator.

California ISO (CAISO). 2007. Integration of Renewable Resources. Folsom, California: California Independent System Operator. 
CapX2020. 2011. Project Update: Brookings County-Hampton 345 kV Transmission Line.

February 23, 2011. http://www.capx2020.com/Projects/pdf/brookings_countyhampton_02.24.2011.pdf.

Central Maine Power (CMP). 2011. Maine Power Reliability Program: Construction Updates. March 18, 2011. http://www.mainepower.com/construction.asp.

Central Maine Power (CMP). 2010. "Maine Utility Regulators Approve \$1.4 Billion

Transmission Line Investment.” May 14, 2010. http://www.mainepower.com/news11.asp.

Chadbourne \& Parke. 2010. "Financing Utility-Scale Solar Projects.” Project Finance Newswire. November 2010. pp. 21-31.

Charles River Associates. 2010. SPP WITF Wind Integration Study. Little Rock, Arkansas: Southwest Power Pool.

Chernova, Y. 2010. "Loss of Renewable Energy Grants Could Threaten Smaller Projects." The Wall Street Journal, December 10, 2010.

David, A. 2009. Wind Turbines: Industry and Trade Summary. ITX-02. Washington, D.C.: U.S. International Trade Commission.

David, A. 2010. Impact of Wind Energy Installations on Domestic Manufacturing and Trade. ID-25. Washington, D.C.: U.S. International Trade Commission.

David, A. 2011. U.S. Wind Turbine Trade in a Changing Environment. WINDPOWER 2011. Poster Presentation. Anaheim, California. May 23-25, 2011.

Department of Energy (DOE). 2011. Department of Energy Finalizes Loan Guarantee for New Transmission Project to Deliver Renewable Energy to Southwest. February 15, 2011. http://www.energy.gov/10068.htm.

Department of Energy (DOE). 2008. 20\% Wind Energy by 2030: Increasing Wind Energy's Contribution to U.S. Electricity Supply. DOE/GO-102008-2567. Washington, D.C.: U.S. Department of Energy.

Eber, J. 2011. Remarks of John Eber ((JPMorgan Capital Corporation) during the "Financing Solar Projects" panel discussion at the PV America conference, Tuesday, April 5, 2011. http://hosted.mediasite.com/mediasite/SilverlightPlayer/Default.aspx?peid=8e3f2ef1f4bb47 $\underline{\text { f69a5581535eee1df81d }}$

Electrotek Concepts, Inc. 2003. Systems Operations Impacts of Wind Generation Integration Study. Prepared for We Energies. Knoxville, Tennessee: Electrotek Concepts.

Energy Information Administration (EIA). 2011. Annual Energy Outlook 2011. DOE/EIA0383(2011). Washington D.C.: Energy Information Administration.

EnerNex Corp. 2010. Eastern Wind Integration and Transmission Study. NREL/SR-550-47078. Golden, Colorado: National Renewable Energy Laboratory.

EnerNex Corp. 2008. Wind Integration Study for Public Service of Colorado, Addendum, Detailed Analysis of 20\% Wind Penetration. Prepared for Xcel Energy. Denver, Colorado: Xcel Energy.

EnerNex Corp. 2007. Final Report Avista Corporation Wind Integration Study. Knoxville, Tennessee: EnerNex Corporation. 
EnerNex Corp. 2006. Wind Integration Study for Public Service Company of Colorado. Prepared for Xcel Energy. Denver, Colorado: Xcel Energy.

EnerNex Corp. and Idaho Power Co. 2007. Operational Impacts of Integrating Wind Generation into Idaho Power's Existing Resource Portfolio: Report Addendum. Boise, Idaho: Idaho Power Company.

EnerNex Corp., Ventyx, and Nebraska Power Association. 2010. Nebraska Statewide Wind Integration Study. NREL/ SR-550-47519. Golden, Colorado: National Renewable Energy Laboratory.

EnerNex Corp. and WindLogics Inc. 2006. Final Report - 2006 Minnesota Wind Integration Study, Volume I. Prepared for the Minnesota Public Utilities Commission. Knoxville, Tennessee: EnerNex Corporation.

EnerNex Corp. and WindLogics Inc. 2004. Wind Integration Study-Final Report. Prepared for Xcel Energy and Minnesota Department of Commerce. Knoxville, Tennessee: EnerNex Corporation.

Eto, J., J. Undrill, P. Mackin, R. Daschmans, B. Williams, B. Haney, R. Hunt, et al. 2010. Use of Frequency Response Metrics to Assess the Planning and Operating Requirements for Reliable Integration of Variable Renewable Generation. LBNL-4142E. Berkeley, California: Lawrence Berkeley National Laboratory.

Federal Energy Regulatory Commission (FERC). 2011. Order Conditionally Accepting in Part and Rejecting in Part Tariff Filing and Requiring Compliance Filings in ER11-1991. 134 FERC I[ 61,141. Washington D.C.: Federal Energy Regulatory Commission.

Federal Energy Regulatory Commission (FERC). 2010a. Transmission Planning and Cost Allocation by Transmission Owning and Operating Public Utilities. 131 FERC II 61,253. Docket No. RM10-23. June 17, 2010. Washington D.C.: Federal Energy Regulatory Commission.

Federal Energy Regulatory Commission (FERC). 2010b. FERC Removes Barriers to Development of Needed Transmission in Midwest Region. 133 FERC II 61,221. Docket No. ER10-1791. December 16, 2010. Washington D.C.: Federal Energy Regulatory Commission.

Federal Energy Regulatory Commission (FERC). 2010c. Order Conditionally Accepting Tariff Revisions and Addressing Petition for Declaratory Order. 133 FERC II 61,224. Dockets No. ER10-1401, ER10-2191 and EL10-76. December 16, 2010. Washington D.C.: Federal Energy Regulatory Commission.

Federal Energy Regulatory Commission (FERC). 2010d. Notice of Proposed Rulemaking on the Integration of Variable Energy Resources under RM10-11. 133 FERC II 61,149.

Washington D.C.: Federal Energy Regulatory Commission.

Federal Energy Regulatory Commission (FERC). 2010e. Order Conditionally Accepting Proposed Tariff Revisions RE Westar Energy, Inc. under ER09-1273. 130FERC II 61,215. Washington D.C.: Federal Energy Regulatory Commission.

Federal Energy Regulatory Commission (FERC). 2007. 2006 State of the Markets Report. Washington, D.C.: Federal Energy Regulatory Commission. 
Federal Energy Regulatory Commission (FERC). 2005. 2004 State of the Markets Report. Washington, D.C.: Federal Energy Regulatory Commission.

First Wind. 2011. First Wind Begins Commercial Operations at Milford II Wind Project. May 9, 2011. http://www.milfordwind.com/milford/news.cfm?ID=2688e8aa-d57f-407d-904b$15582 \mathrm{~d} 055071$.

GE Energy. 2011. Oahu Wind Integration Study Final Report. Honolulu, Hawaii: University of Hawaii.

GE Energy. 2010a. New England Wind Integration Study. Holyoke, Massachusetts: ISO New England Inc.

GE Energy. 2010b. Western Wind and Solar Integration Study. NREL/SR-550-47434. Golden, Colorado: National Renewable Energy Laboratory.

GE Energy. 2008. Analysis of Wind Generation Impact on ERCOT Ancillary Services Requirements. Prepared for the Electricity Reliability Council of Texas. Schenectady, New York: GE Energy.

GE Energy. 2007. Intermittency Analysis Project Appendix B: Impact of Intermittent Generation on Operation of California Power Grid. Sacramento, California: California Energy

Commission, PIER Research Development \& Demonstration Program.

GE Energy. 2005. The Effects of Integrating Wind Power on Transmission System Planning, Reliability, and Operations: Report on Phase 2. Prepared for the New York State Energy Research \& Development Authority. Schenectady, New York: GE Energy.

Huron Daily Tribune. 2011. Thumb Loop Project Approved. February 26, 2011. http://knowwind.org/webdoc/thumb_loop_project_approved.htm.

ICF International. 2011. Firming Renewable Electric Power Generators: Opportunities and Challenges for Natural Gas Pipelines. Washington D.C.: The INGAA Foundation, Inc.

Idaho Public Utilities Commission (IPUC). 2010. In the Matter of the Petition of Pacificorp dba Rocky Mountain Power for an Order Revising the Wind Integration Rate for Wind Powered Small Power Generation Qualifying Facilities. PAC-E-09-07 Order No. 31021. March 12, 2010.

IHS CERA. 2010. Power Plant Construction Costs: Recovery Paused as Costs Go Flat Once More. December 21, 2010.

IHS Emerging Energy Research (IHS EER). 2011. North America Wind Energy Market Forecast: 2011-2025. Cambridge, Massachusetts: IHS Emerging Energy Research.

ITC Transmission Co. (ITC). 2010. Thumb Loop: 345kV Transmission Line. September 2010. http://www.itctransco.com/ITCprofile_ThumbLoop910.pdf

Johnson, D. 2011. Personal communication with Doug Johnson, Bonneville Power Administration. May 11, 2011.

Los Angeles Department of Water and Power (LADWP). 2011. Completion of Wind Power Project Brings More Renewable Energy to LADWP Customers. May 4, 2011. http://www.ladwpneighborhoodnews.com/go/doc/1643/1080779/\&printerfriendly=1. 
Lower Colorado River Authority (LCRA). 2011. PUC Selects Hill Country Route for New Transmission Line Mostly Along IH 10. January 20, 2011.

http://www.lcra.org/newsstory/2011/pucselectshillcountryrouteih10.html.

MAKE Consulting. 2011. U.S. Wind Power 2011. Hǿjberg, Denmark: Make Consulting.

Mintz Levin. 2010. Renewable Energy Project Finance in the U.S.: An Overview and Midterm Outlook. Mintz Levin green paper.

Missouri Public Service Commission (Missouri). 2010. PR-11-86 - PSC Opens Case to Investigate Southwest Power Pool Cost Allocations and Cost Overrun. Case No. EO-20110134. December 1, 2010. http://www.psc.mo.gov/press-releases/electric/pr-11-86- pscopens-case-to-investigate-southwest-power-pool-cost-allocations-and-costoverruns/?searchterm=PR-11-86

North American Electric Reliability Corporation (NERC). 2010. 2010 Long-Term Reliability Assessment. October 2010.

New York Independent System Operator (NYISO). 2010. Growing Wind: Final Report of the NYISO 2010 Wind Generation Study. Rensselaer, New York: New York Independent System Operator.

NV Energy. 2010. NV Energy and Great Basin Transmission Finalize Agreement for the One Nevada Transmission Line. August 20, 2010. http://investors.nvenergy.com/phoenix.zhtml?c=117698\&p=irolnewsArticle\&ID=1462035\&highlight $=$

PacifiCorp. 2011. Energy Gateway: Bringing New Transmission to the West. February 2011. http://www.pacificpower.net/content/dam/pacificorp/doc/Transmission/Transmission_Proje cts/2669-20_EnergyGateway_FactSheet_v5.pdf.

PacifiCorp. 2010. 2010 Wind Integration Study. Portland, Oregon: PacifiCorp.

PacifiCorp. 2007. Technical Appendix for the 2007 Integrated Resource Plan. Portland, Oregon: Pacificorp.

PacifiCorp. 2005. Technical Appendix for the 2004 Integrated Resource Plan. Portland, Oregon: PacifiCorp.

Pfeifenberger, J. 2010. Transmission Planning: Economic vs. Reliability Projects. Presentation to the EUCI Conference, Chicago. October 13, 2010.

Porter, K. and J. Rogers. 2010. Status of Centralized Wind Power Forecasting in North America. NREL/SR-550-47853. Golden, CO: National Renewable Energy Laboratory.

Porter, K., S. Fink, C. Mudd and J. DeCesaro. 2009. Generation Interconnection Policies and Wind Power: A Discussion of Issues, Problems, and Potential Solutions. NREL/SR-55044508. Denver, Colorado: National Renewable Energy Laboratory.

Project Finance. 2011. "North American Power \& Renewables: Wind debt faces a frosty 2011." January 2011 issue of Project Finance magazine.

Puget Sound Energy. 2007. 2007 Integrated Resource Plan, Appendix G-Wind Integration Studies. Bellevue, Washington: Puget Sound Energy.

Rayl, R. 2010. "Next Phase of Edison's Tehachapi Transmission Project to Commence Construction," California Eminent Domain Report, September 30, 2010. 
Sharyland Utilities. 2011. Hereford to Nazareth to Silverton 345 kV CREZ Transmission Line. March 22, 2011. http://www.sharylandutilities.com/hereford_nazareth_silverton.asp.

Shiu, H., M. Milligan, B. Kirby and K. Jackson. 2006. California Renewables Portfolio Standard Renewable Generation Cost Analysis: Multi-Year Analysis Results and Recommendations. Consultant report prepared by the California Wind Energy Collaborative. Sacramento, California: California Energy Commission.

Southern California Edison (SCE). 2010. Southern California Edison Celebrates Milestone for a Major Renewable Transmission Project. May 4, 2010. http://www.edison.com/pressroom/pr.asp?bu=\&year=0\&id=7390.

Southwest Power Pool (SPP). 2010a. Submission of Tariff Revisions to Modify Transmission Cost Allocation Methodology. Docket No. ER10-1069-000.

Southwest Power Pool (SPP). 2010b. SPP Approves Construction of New Electric Transmission Infrastructure To Bring \$3.7 Billion in Regional Benefits. April 27, 2010. http://www.spp.org/publications/Priority_Projects_Approved_4-27-10.pdf.

Tansey, B. 2011. "BPA Delays Network Open Season for New Transmission Requests.” Energy Prospects West, May 10, 2011.

Tempkin, A. 2010. “Citigroup's Wind-Win.” International Financing Review, Thompson Reuters, December 18, 2010, Issue 1864, p. 32.

TransCanada. 2011. Zephyr and Chinook Power Transmission Lines. http://www.transcanada.com/zephyr.html.

UBS Limited. 2010. Global Wind - Outlook 2011. UBS Investment Research. 30 November.

UBS Limited. 2011. European Wind Manufacturers. UBS Investment Research. 18 April.

United States Forest Service. 2010. Record of Decision: Special Use Authorization to Southern California Edison Company for the Tehachapi Renewable Transmission Project. October 4, 2010. http://asset.sce.com/Documents/Environment\%20\%20Transmission\%20Projects/ROD_TRTP.pdf.

U.S. Partnership for Renewable Energy Finance (US PREF). 2010. Prospective 2010-2012 Tax Equity Market Observations. July 2010, v1.2.

Ventyx. 2011. Velocity Suite Data Product. Accessed May 2011.

Welch, K. 2011. "PUC Approves Line Route to Transmit Wind Energy," Amarillo Globe News, March 9, 2011.

Western Electricity Coordinating Council (WECC). 2010. Scope of the Efficient Dispatch Toolkit Cost-Benefit Analysis. Salt Lake City, Utah: Western Electricity Coordinating Council.

Wyden, R. 2010. U.S. Trade in Environmental Goods: Follow-Up Report to 'Major Opportunities and Challenges to U.S. Exports of Environmental Goods.' Washington, D.C.: United States Senate.

Xcel Energy and Great River Energy (Xcel). 2010. Notice of Change in Timing of the Brookings Project and Development Plan. Minnesota PUC Docket No. ET2/TL-08-1474. May 19, 2010. 


\section{Wind Energy Web Sites}

\section{U.S. Department of Energy Wind and}

\section{Water Power Program}

www.windandwater.energy.gov

\section{Wind Powering America}

www.windpoweringamerica.gov

\section{Lawrence Berkeley National Laboratory}

http://eetd.lbl.gov/EA/EMP/re-pubs.html

\section{National Renewable Energy Laboratory \\ www.nrel.gov/wind}

\section{Sandia National Laboratories}

www.sandia.gov/wind

\section{Pacific Northwest National Laboratory}

www.pnl.gov

\section{Lawrence Livermore National Laboratory}

www.llnl.gov

\section{Oak Ridge National Laboratory}

www.ornl.gov

\section{Argonne National Laboratory}

www.anl.gov

\section{Idaho National Laboratory}

www.inl.gov

\section{For more information on this report, contact:}

Ryan Wiser, Lawrence Berkeley National Laboratory

510-486-5474; RHWiser@lbl.gov

Mark Bolinger, Lawrence Berkeley National Laboratory

603-795-4937; MABolinger@lbl.gov

\section{On the Cover}

The U.S. Department of Energy's 1.5-MW wind turbine installed at NREL's National Wind Technology Center, near Boulder, Colorado, for long-term research and testing.

\author{
Ames Laboratory \\ www.ameslab.gov
}

Los Alamos National Laboratory

www.lanl.gov

\section{Savannah River National Laboratory \\ http://srnl.doe.gov}

\section{Brookhaven National Laboratory \\ www.bnl.gov}

\section{American Wind Energy Association \\ www.awea.org}

\section{Database of State Incentives for Renewables \& Efficiency \\ www.dsireusa.org}

International Energy Agency - Wind Agreement www.ieawind.org

\section{National Wind Coordinating Collaborative www.nationalwind.org}

\section{Utility Wind Integration Group}

www.uwig.org us arenturos ENAROY

Energy Efficiency \& Renewable Energy
Prepared by the National Renewable Energy Laboratory (NREL) NREL is a national laboratory of the U.S. Department of Energy

Office of Energy Efficiency and Renewable Energy Operated by the Alliance for Sustainable Energy, LLC
For more information contact: EERE Information Center 